المخصبات الكيماوية للمحاصيل الزراعية في مصر - حالة مصنع دمياط "دراسة في الجغرافية الاقتصادية"

د.أيمن عبد المطلب السعيد*

aymaneltemamy@gmail.com

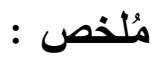

تؤُثر المخصبات الكيماوية للتربة في مصر علي كمية الإنتاج الزراعي وجودته، ووصل عدد مصانعها بr مصنعاً أنتجت اب مليون طن عام 9 1 ـ ب بأنواعها المختلفة، وتتوطن في الوادي والدلتا وإقليم قناة السويس حيث تتوفر عوامل قيامها، وتوفر 9.7 مليون طن للاستهلاك المحلي مع تصدير ع. 1 (مليون طن، لكنها تعاني من أزمات خاصة بالكميات والأنواع التي توزع علي المزارعين. وأسهم مصنع دمياط للمخصبات الآزوتية بنسبة

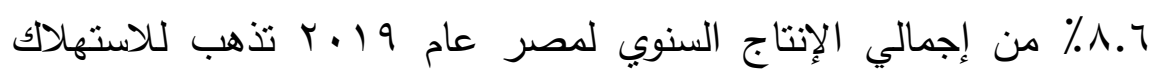
المحلي والتصدير ، وتوجد آثار سلبية على مكونات البيئة في منطقة المصنع لكنها ليست بالقدر الكبير ، كما ينتج عنه آثار اقتصادية منها ما هو ايجابي وآخر سلبي، ويمكن النهوض بهذه الصناعة من خلال الإدارة الجيدة لها

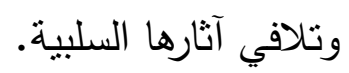

كلمات دالة: المخصبات، دمياط، البيئة

* أستاذ مساعد بقسم الجغر افيا - كلية الآداب - جامعة العريش

(المخصبات الكيماوية للمحاصيل الزراعية في مصر ...) د. أيمن عبد المطلب السعيد. 


\section{$\ddot{d}$}

مـثمب

تُعد المخصبات الكيماوية للتربة من المستلزمات المُهمة للقطاع الزراعي

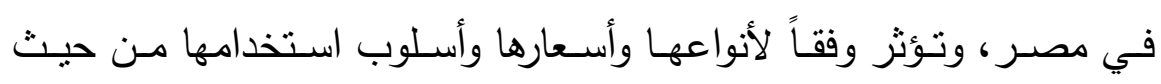
الكمية والتوقيت في كمية الإنتاج الزراعي وجودته، وعليه في التكلفة والعائد، وتُعرف بالأسمدة الكيماوية. أهمية الاراسة ومشكلتها:

وتعود أهمـية صناعة المخصبات الكيماوية في مصر إلى ما يلي: ا - تعتبر صناعة استراتيجية مؤثرة اقتصادياً واجتماعياً وسياسياً. ץ- وصل متوسط التكثيف الزراعي في مصر إلي ^. ا. في العام. ب- تحرير أسـعار المخصبات الكيماويـة ممـا يـؤثز في أسـعار المحاصيل

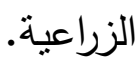

ع - تـوفر خاماتهـا فـي مصـر مـن الفوسـفات والغـاز الطبيعـي والجـبس والكبريت. ه - أهميتها في زيـادة الإنتاج الرأسـي للفدان وبالتـالي توفير الغذاء وعدم ارتفاع أسـعاره، حيث تسهم في زيادة خصوبة التربة بعد حجز السد العالي لطمي النيل وفقر الأراضـي المستصلحة للعناصر المعدنية وأهمها عنصر

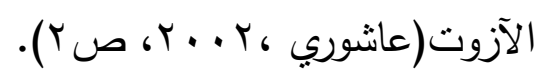
وتتمثل مشكلة الدراسـة في الأزمات المتكررة التي يتعرض لها سوق المخصبات الكيماويـة في مصر من حيث تراجع الكميات المعروضـة منها وارتفاع أسعارها، في الوقت الذي يتم فيه تصديره.

(المخصبات الكيماوية للمحاصيل الزراعية في مصر...) د. أيمن عبد المطلب السعيد. 


\section{أسباب اختيار الموضوع :}

1- أهية صناعة المخصبات الكيماوية في المساهمة في تحقيق الأمن الغذائي. r- زيادة أسعارها عالمياً مما يؤثر علي ميزان المدفوعات مع استيراد كميات منها. ب- تعد استثمار جيد للخامات التي تدخل في صناعتها بدلاً من تصديرها خام. مصادر البيانات : أعتمد علي مصادر منتوعة منها الجهاز المركزي للتعبئة العامة و الإحصاء، والهيئة العامة للتتمية الصناعية، وغرفة الصناعات الكيماوية، وشركة مصر لإنتاج الأسمدة الكيماوية بدمياط، ووزارة التجارة الخارجية، ووزارة الزراعة، والمجلس التصديري للأسمدة ، ومقابلات شخصية مع عدد من العاملين في مجال صناعة المخصبات الكيماوية و وتداولها ، وتم الحصول علي بعض البيانات من خلال تصميم لنموذج استبيان بعـدد

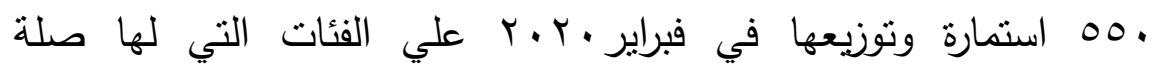
بالمخصبات الكيماوية من مزارعين وعاملين في هذا القطاع بما فيهم العاملون بشركة مصر لإنتاج الأسمدة بدمياط، وبعد جمعها تبين صحة 9 ه 0 استمارة تم الحُصول من خلالها علي بعض البيانات النوعية. أهداف الدراسة : تهدف الدراسة إلي ما يلي :

1- دراسة تطور صناعة المخصبات الكيماوية في مصر، وتوزيعها المكاني، وتطور الإنتاج وتسويقه.

r- إلقاء الضوء علي المقومات الجغرافية لانتشارها خاصة في دمياط . r- إبراز مراحل صناعة المخصبات الكيماوبة في مصنع دمياط ودوره في المسـاهمة في تغطيـة الاستههلاك المحلي والتصدير مـع إبراز الآثار البيئية والاقتصادية المنزتبة عليها ـ

(المخصبات الكيماوية للمحاصيل الزراعية في مصر ...) د. أيمن عبد المطلب السعيد. 
الدراســات السـابقة : وجـد عـدد مـن الدراسـات الجغرافيـة التهي نتاولـت . المخصبات الكيماوبـة للتربـة في ثتاياهـا مثل : دراسـة محمد الديب ، 9 و كيف يختار موقع المشروع الصناعي ، ودراسته أيضاً . 191 تصنيع مصر

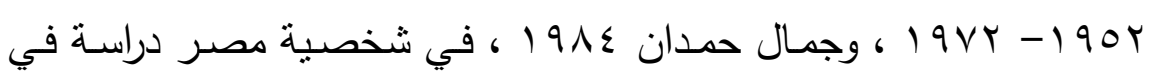
عبقربـة المكان ، ودراسـة شـاملة قام بها سـعيد عبده ، ، 199 1 عن إنتاج واستهلاك الأسمدة الكيماوية في مصر دراسة في الجغرافية الاقتصسادية ، كما توافرت بعض الدراسـات غيـر الجغرافيـة ومنهـا : دراسـة ثثـاء عبـد العزيـز ه99 19، عن اقتصاديات التكلفة والعائد في صناعة الأسمدة في مصر حالة شـركة أبـوقير، ودراسـة الإدارة العامـة للبحـوث بـوزارة الزراعـة ، . . . ب عنـ استراتيجية تصنيع الأسمدة الكيماوية في مصر ، ثم دراسـة قطاع الدراسات والبحـوث بـوزارة التجـارة الخارجيـة، ع . . ب عـن إنتاج الأسـدة واسـتهلاكها وتجارتها الخارجيـة ، ودراسـة الجهاز المركزي للتعبئة العامـة والإحصـاء ، 9 . . . عن اقتصاديات صناعة الأسمدة في مصر ، وتوافرت بعض الأوراق البحثية والتقارير التي تتاولت صناعة المخصبات الكيماوية ومشكلة الغذاء في عدداً من الندوات والمؤتمرات. وتفترض هذه الدراسة : أهمية المخصبات الكيماوية في زيادة الإنتاج الرأسي للفدان في الزراعات غير العضوية وبالتالي توفيرها محلياً مع تصدير فائض الاستهلاك من خلال الإدارة الجيدة لهذه الصناعة واحتواء آنارها السلبية

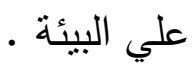

(المخصبات الكيماوية للمحاصيل الزراعية في مصر ...) د. أيمن عبد المطلب السعيد. 
مناهج الاراسة وأساليبها : اعتمدت الدراسة على المنهج التاريخي في تتبع تطور صناعة المخصبات الكيماوية في مصر، والمنهج الموضوعي بدراسة الجوانب الجغرافية المتعددة لهذه الصناعة مع التطبيق علي شركة مصر للأسمدة بدمياط ، مع اتباع عدد من الأساليب الاحصائية و الكارتوجرافية

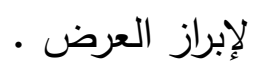

ويتكون البحث من النقاط التالية والتي تسبقها مقدمة وتتتهى بخاتمـة

أولاً: تطور صناعة المخصبات الكيماوية في مصر •

ثانياً: التحليل المكاني لصناعة المخصبات الكيماوية والعوامل المؤثرة فيها . ثالثاً: أنواع المخصبات الكيماوية في مصر . ربعاً: تطور إنتاج المخصبات الكيماوية . خامساً: الاستهلاك المحلي والتجارة الخارجية . سادساً: الإطار النطبيقي ( مصنع دمياط ) ويشمل : أ- مقومات صناعة المخصبات الكيماوية .

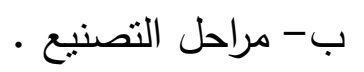

$$
\text { د - الإنتاج - }
$$

هـ - الآثار الناتجة عن صناعة المخصبات الكيماوية . ونعرض فيما يلي لهذه العناصر ...

(المخصبات الكيماوية للمحاصيل الزر اعية في مصر ...) د. أيمن عبد المطلب السعيد. 
أولا : تطور صناعة المخصبات الكيماوية في مصر. يسعي الإنسان منذ القدم إلي تحسين نمو النبات بإضـافة بعض المعادن والمواد العضوية(Travis P., 1985, P.7)، وتستخدم مصر المخصبات الكيماوية منذ فترة طويلة حينما بدأت في استيراد مخصبات النترات من شيلي عام r ب (1، وبعدها استمرت في استيراد ما يدخل في تخصيب التربـة لمدة هب عاماً حتي تم بناء أول مصنع لصناعة المخصبات الكيماوية في مصر ، ومرت هذه الصناعة في مصر بثناث مراحل، وهي كالتالي: أ- المرحلة الأولي وتتتهي عام ، 9 أ(النشأة) : واتسمت هذه المرحلة ببناء دصنعين فقط لإنتاج المخصبات الكيماوية، حيث تم الاعتماد فيها علي القطاع الخاص الذي كان نشيطاً في تلك الفترة ، حيـث بـدأت الثـركة الماليـة والصـناعية بالغربيـة في إنشـاء أول مصـنع لهـا بكفر الزيات عام 9 و 9 لإنتاج الأسمدة الفوسفاتية بطاقة م ا ألف طن وبدأ الإنتاج عام هبو ا، كما بدأ في إنتاج المخصبات الآزوتية "النيتروجينية" في مصر مـع إنشاء مصنع عبده باشـا بالسويس عام • 190 لينتج نترات الجير بطاقـة rم ألف طن، ونشـط إنتاج المصنع الأول في كفر الزيـات خـلال الحرب العالمية الثانيـة لتوقف الاستيراد ، كذللك إنتاج مصنع السويس كونه الوحيد المنتج للنترات .

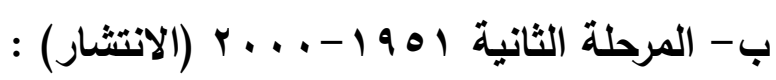
تُعد المرحلـة الرئيسية لتطور صـناعة المخصبات الكيماويـة في مصر بسبب إنشـاء العديد من المصـانع في جهات متقرقة بعدد ب ا مصنعاً، ففي 
عـام 1907 تـم إنتـاء مصـنع كيمـا لإنتاج المـواد الكيماويـة والمخصـبات الآزوتيـة برأس مـال 1 مليون جنيـه علي مسـاحة 9 و فدان جنوب شـرق أسوان بحوالي ء كم تشـمل مدينـة سكنية للعـاملين، وتم إنشـاء هذا المصنع لاستتثمار الكهربـاء المولدة مـن محطـة كهربـاء أسـوان والتي يصـل فائضــها

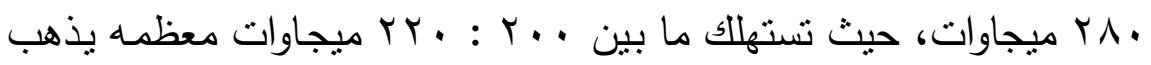
في التحليل الكهربائي للمياه .

وتـم إنشـاء شـركة النصـر لصـناعة المخصبات الكيماويـة عـام . 197 وبدأ مصنعها الأول في الإنتاج عام \&7 9 ابطاقة رrr ألف طن سنوياً من الكوك والكيماويات، وأنشئ مصنعها الثاني عام ع 19 أنفس طاقة الإنتاج لتقطيـر القطـران، وأنشــئ المصـنع الثالـث بطاقـة ـ به ألـف طـن لإنتـاج النترات، كما تم تجديد المصنع الأول عام .... . . .

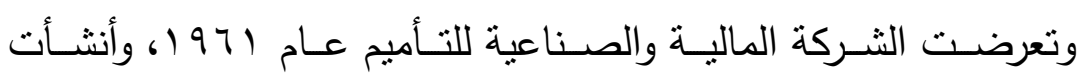
مصنعها الثاني في أسيوط عام الو9، وفي عام (991 انضمت الثركة الماليـة إلـي الثـركة القابضـة للحراريـات والتعدين والتي طرحت 7 \% ٪ مـن

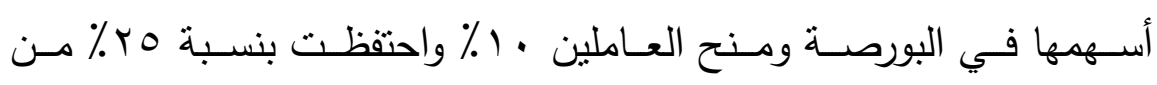
أسهمها، ونم زيادة رأس مال الثركة عام 991 1، كما نم دمج الثركة العربية للمخصبات في الشركة المالية عام 999 1. وأنشـئ في طلخـا بالدقهليـة مصنـع الدلتا لإنتاج المخصبات الآزوتيـة بتركيزات مختلفة عام 9 ( ، حيث تخصص في تصنيع اليوريا مستفيداً من الغاز الطبيعي المكتشف بالدلتا. وتم تأسيس شركة أبوقير لإنتاج المخصبات (المخصبات الكيماوية للمحاصيل الزراعية في مصر ...) د. أيمن عبد المطلب السعيد. 
عـام 9 197 وأصـبحت شـركة مسـاهمة عـام ، 1911، وتتـتج المخصـبات الآزوتيـة والمركبة "المخلوطة" والسائلة بكميات كبيرة ومنتوعة علي المستوي المحلي والدولي، حيث تم تشغيل المصنع الأول عام 9 و 1 لتصنيع اليوريا المحببة بطاقة ، 100 طن يومياً وتم رفعها إلي . V0. طن يومياً ، وأنشئ

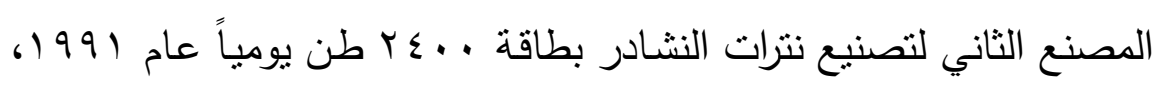
وزادت كفـاءة المصـنع الأول في إنتاج الأمونيـا مـن ألـف طـن يوميـاً إلي

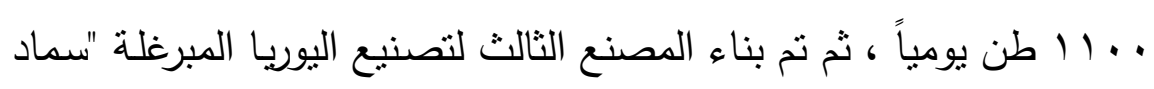

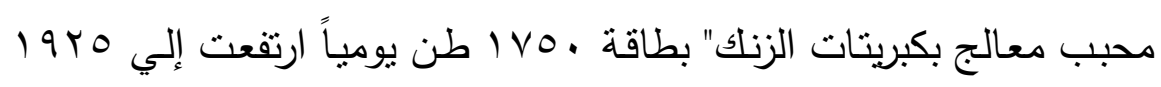
طن يومياً وظهرت شـركة أبـو زعبـل لتصـنيع المخصبات والمـواد الكيماويـة عـام ع 9 ا مثنل السوبر فوسفات والجبس الزراعي وحامض الكبريتيك وحامض الفوسـفوريك. كــا أنثـأت فـي أبـو زعبـل شـركة بــولي ســيرف لتصـنيع المخصبات والكيماويات عام ب99 19 ـ وفي المنطقة الصناعية الحرة بجوار ميناء دمياط تأسست شركة مصر لتصنيع اليوريا عام 1991 ـ ج- المرحلة الثالثة 1 . . ب - حتي الآن (التوسعات) : اتسمت هذه المرحلة بقيام شركات إنتاج المخصبات بالتوسع في تصنيعها من حيث الكمية والنوع مع إنثاء ثمانية مصانع جديدة، فقد قامت الشركة المالية بإنشاء مصنع السويس لتصنيع الأسمدة بتكلفة . . 7 مليون جنيه عام Y . . r، وتم إنتاج اليوريا الناعمة والمحببة عام 0 . . ب، وتصنيع سلفات النشادر وحامض الكبريتيك عام V . . . مع تشغيل خط لتصنيع ثنائي (المخصبات الكيماوية للمحاصيل الزراعية في مصر ...) د. أيمن عبد المطلب السعيد. 
فوسفات الكالسيوم بمصنع السويس عام ^ ...r، ونُقل خط إنتاج من مصنع الثركة المالية بالعين السخنة إلي مصنعها في أسيوط، مع الإعداد لإنشاء مصنع لإنتاج سلفات البوتاسيوم.

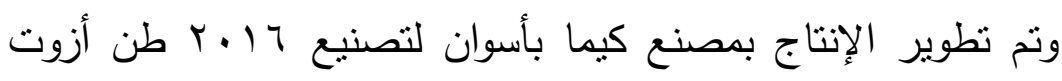

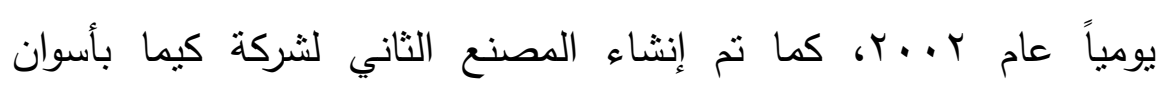

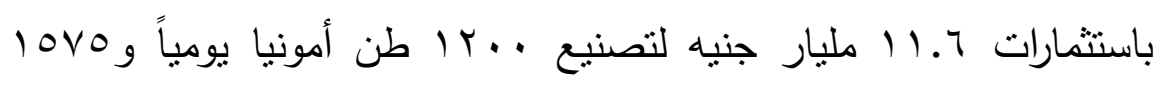

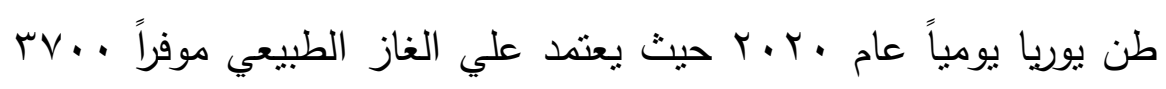

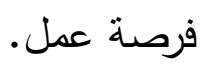
وأُنتجت اليوريا ماغنسيوم واليوريا سلفات من المصنع الثالث بأبو قير

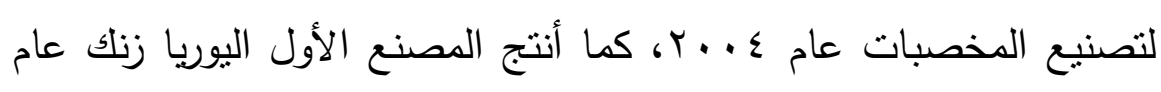

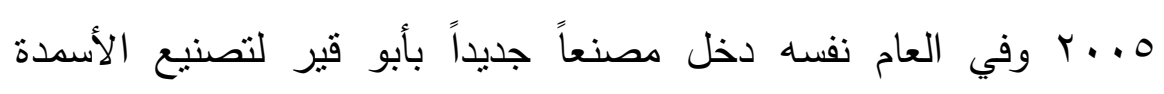

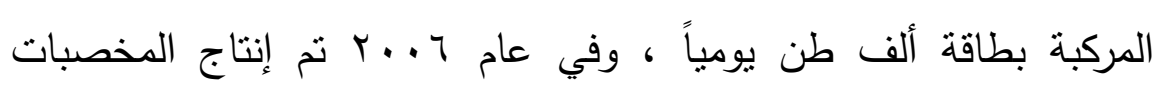

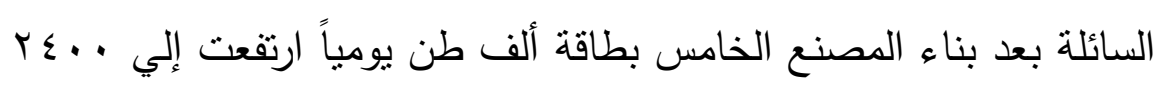

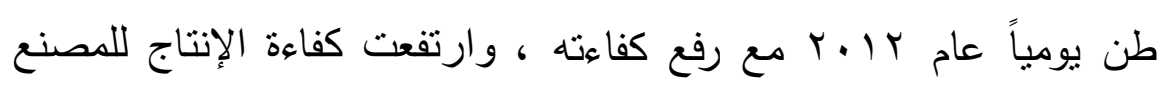

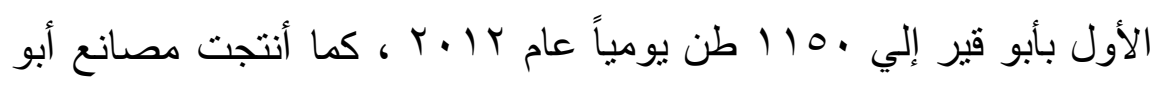
قير مخصبات اليوروفرت والنيتروفيت عام ع ا ـ ب ، وزادت كفاءة المصنع

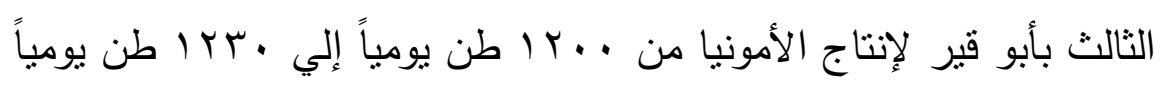

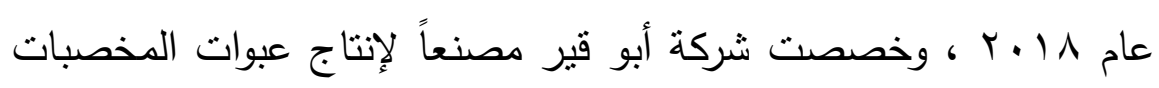

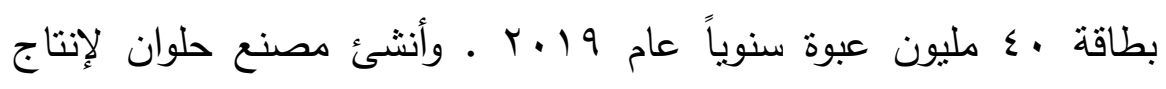

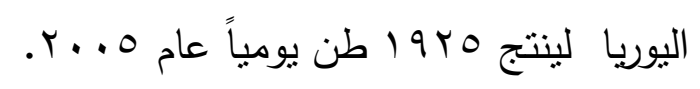

(المخصبات الكيماوية للمحاصيل الزراعية في مصر ...) د. أيمن عبد المطلب السعيد. 
وقامت شركة النصر لتصنيع المخصبات بزيادة إنتاجها بإنشاء مصنعها

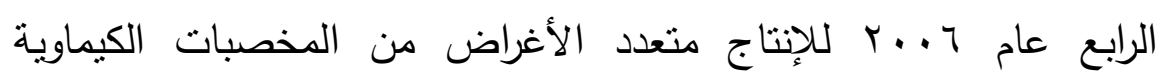
والخامس عام ^ 1 ـ r، وأنشئت الثركة المصرية لإنتاج المخصبات " أورسكم " في عام • 1. ب وقامت ببناء مصنعاً في العين السخنة لتصنيع الأمونيا واليوريا بطاقة او (Y طن يومياً، كما أحدثت شركة مصر للمخصبات توسعات بمصنعها في دمياط عام 17 ـ. ويوضح الثكل (1) مراحل تطور صناعة المخصبات الكيماوية للمحاصيل الزراعية في مصر، ويتبين منها أن المرحلة الأولي بلغت نسبة

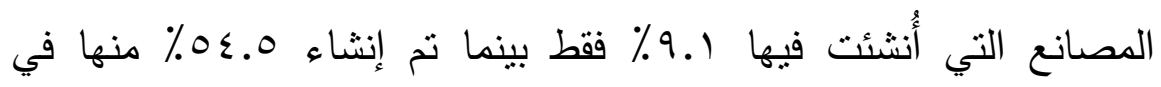
المرحلة الثانية، وإنشاء ع.ب؟\% في المرحلة الثالثة.

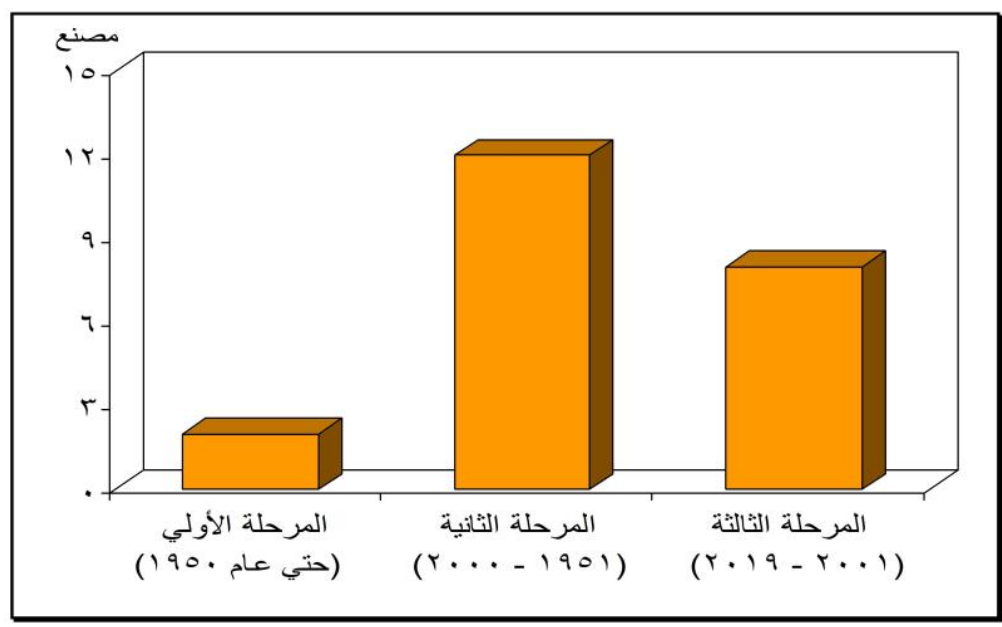

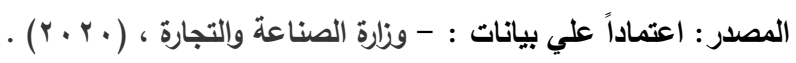

- شركات تصنيع المخصبات الكيماوية في مصر ، سنوات متعددة .

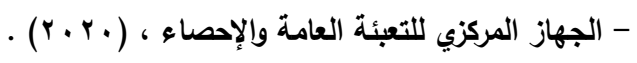

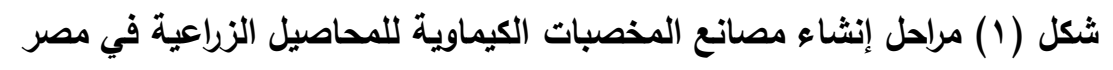

(المخصبات الكيماوية للمحاصيل الزراعية في مصر ...) د. أيمن عبد المطلب السعيد. 
ثانياً: التحليل المكاني لصناعة المخصبات الكيماوية والعوامل المؤثرة فيها: تتركز صناعة المخصبات الكيماوية في المواقع التي تتوفر بها مقوماتها، حيث تتتشر في مواقع تتناسب ومواصفاتها كي تحقق العائد الاستثماري الجيد، مع توفيرها للمستهكين داخلياً وخارجياً بيسر، كما تتتاسب هذه المواقع مع أي تغيرات قد تحدث مع عوامل التوطين بعد ذلك (الديب، 9V9 19، صل • (1).

ويتبـين مـن الجـدول(1) والثـكل(ب) التوزيـع الجغرافي لمصـانع المخصـبات الكيماوية في المحافظات عام 19 ـ ب، حيث يوجد في مصر بr مصنعاً تتوزع في أقاليم متقرقة علي عشر محافظات في المعدور المصري بـالوادي والالتا وإقليم قناة السويس وجميعها منـاطق قربيـة مـن المواد الخـام والسوق الداخلي والموانئ البحريـة حيث السوق الخارجي.

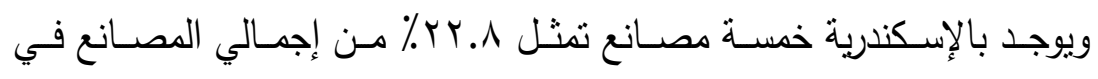

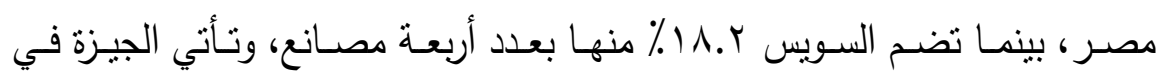

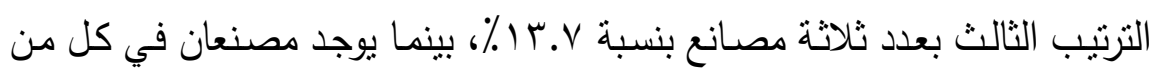

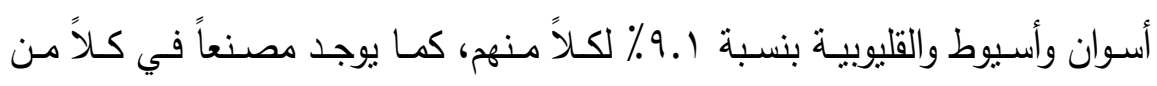
القاهرة والقليوبية والدقهلية ودمياط بنسبة ه.ء ٪ لكل محافظة من الإجمالي.

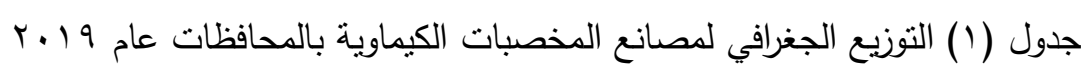

\begin{tabular}{|c|c|c|c|c|c|c|c|c|c|c|c|c|}
\hline جملة & دمياط & الغربية & الدقهلية & القاهرة & القليوبية & أسيوط & أسوان & الجيزة & السويس & الاسكندرية & \multicolumn{2}{|c|}{ بـيــان - محافظة } \\
\hline 9 & 1 & & & & 1 & & & & $r$ & 0 & استثماري & \multirow{2}{*}{ قطاع } \\
\hline Ir & & 1 & 1 & 1 & 1 & $r$ & $r$ & $r$ & $r$ & & عام & \\
\hline Yr & 1 & 1 & 1 & 1 & $r$ & $r$ & $r$ & $r$ & $\varepsilon$ & 0 & \multicolumn{2}{|c|}{ إجمالي } \\
\hline $1 \cdots$ & $\varepsilon .0$ & $\varepsilon .0$ & $\varepsilon .0$ & $\varepsilon .0$ & 9.1 & 9.1 & 9.1 & Ir.V & $1 \wedge . r$ & $r Y . \Lambda$ & \multicolumn{2}{|l|}{$\%$} \\
\hline
\end{tabular}

المصدر: اعتمادا علي بيانات : اتحاد الصناعات المصرية ، غرفة الصناعات الكيماوية ، . • ب ، بيانات غير منشورة عن صناعة المخصبات الكيماوية .

(المخصبات الكيماوية للمحاصيل الزراعية في مصر...) د. أيمن عبد المطلب السعيد. 


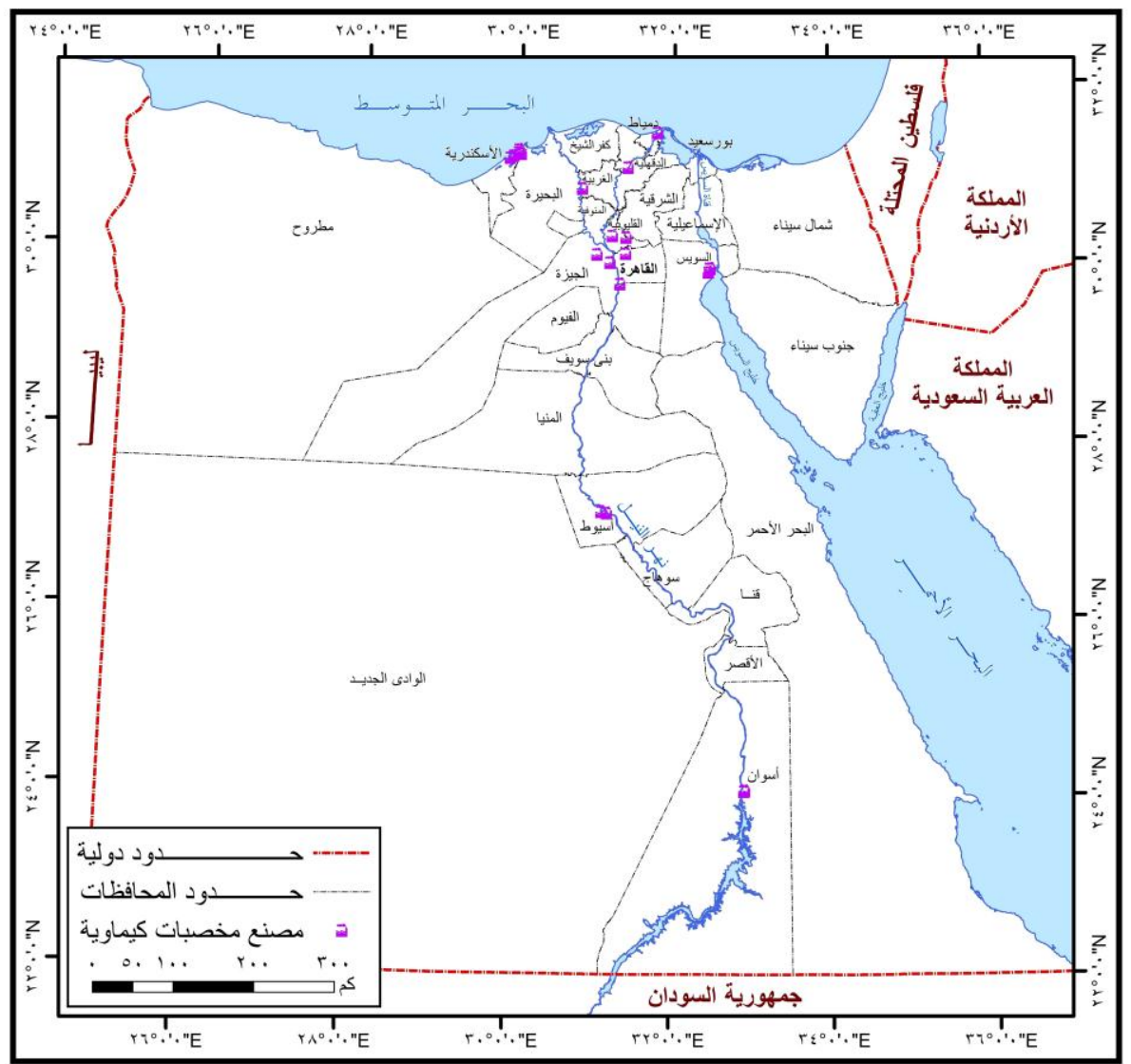

المصدر : مـن إعداد الباحث اعتمـادا علـي جدول (1) - الهيئة المصرية العامـة للمسـاحة، الخرائط

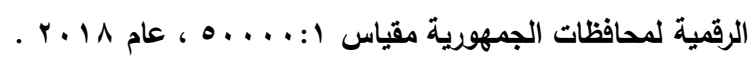

شكل (Y) التوزيع الجغرافي لمصانع المخصبات الكيماوية في مصر عام 9 أ ب وبتضح من الجدول (1) والثكل (ب) التوزيع الجغرافي لمصانع المخصبات الكيماوية بالمحافظات حسب قطاع الإنتاج عام 9 1 • r، حيث يتبين أن القطاع العام يستحوذ علي ا ـهـ٪ من إجمالي المصانع بعدد سا مصنعاً تتوزع في السويس والجيزة وأسوان وأسيوط والقليوبية والقاهرة والدقهلية

(المخصبات الكيماوية للمحاصيل الزراعية في مصر ...) د. أيمن عبد المطلب السعيد. 
والغربية، ويدخل القطاع الاستثماري في الإنتاج بثمانية مصانع بنسبة ا ـ . ـ ٪ في الاسكندرية والسوبس والقليوبية ودمياط.

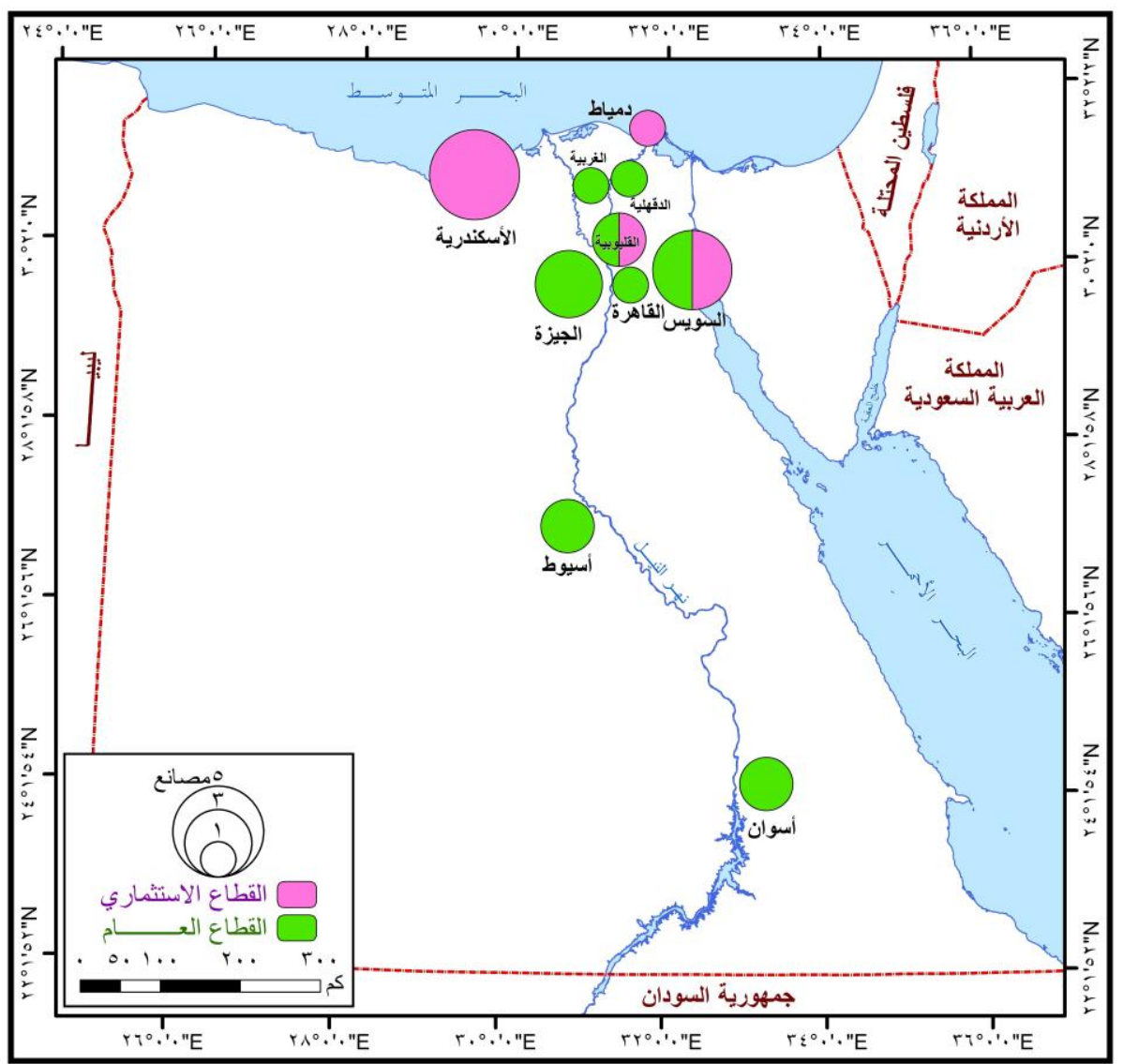

المصدر : مـن إعداد الباحث اعتمـادا علي جدول (1) - الهيئة المصرية العامـة للمسـاحة، الخرائط

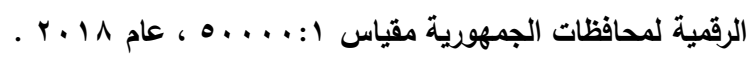
شكل (r) التوزيع الجغرافي لمصانع المخصبات الكيماوية بمحافظات الجمهورية حسب

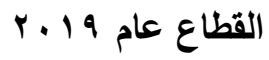

ويتبين من الثكل (ع) المركز المتوسط والمسافة المعيارية واتجاه توزيع مصانع المخصبات الكيماوية بالمحافظات كما يلي:

(المخصبات الكيماوية للمحاصيل الزراعية في مصر ...) د. أيمن عبد المطلب السعيد. 
- يقع المركز الجغرافي المتوسط لتوزيع مصانع المخصبات الكيماوية في محافظة الجيزة في أقصى شمال صعيد مصر ، وعلى الحدود الجنوبية

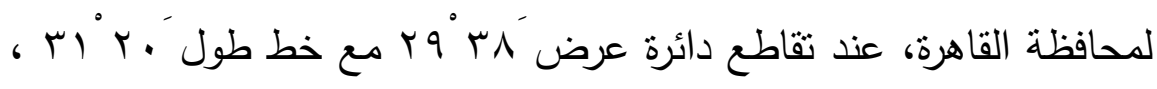
حيث تتركز غالبية المصانع في محافظات "الجيزة والقليوبية والقاهرة" ، بسبب توسطها لمناطق الاستهلاك الرئيسي في الوادي والدلتا ، حيث يحدد المركز المتوسط الموقع الذي يعد منتوسًا جغرافيًا لمواقع مفردات الظاهرة

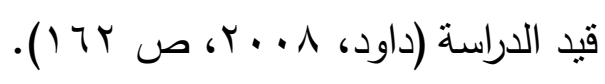
- تمنت المسافة المعيارية انحرافًا معياريًّا واحدًا عن الموقع الوسط لكل مواقع مصانع المخصبات الكيماوية في مصر، حيث يبلغ نصف قطر الدائرة

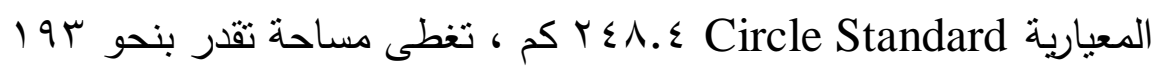
ألف كمץ بنسبة ع.9 ( ٪ من جملة مساحة مصر لتحتوي على ^1 1 مصنع

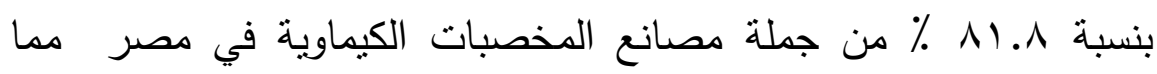
يشير إلى أن نمط التوزيع الجغرافي للمصانع هو نمط التوزيع المنتظم هن هئه

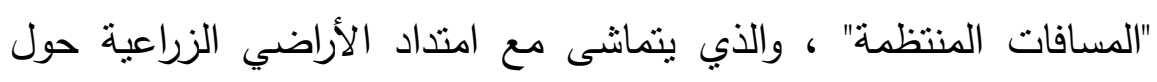

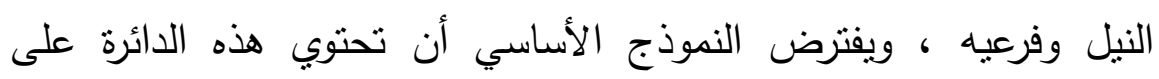

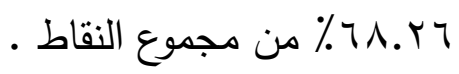

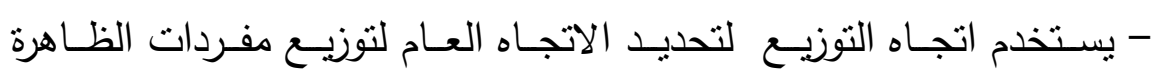
المكانيـة ، وجاء مركز الشكل البيضـاوي منطبقاً على نقطة المركز المتوسط ، ويقيس محوره الأكبر قيمـة الاتجـاه الذى تأخذه معظم مفردات الظـاهرة ، حيث بلغ طول محوره الأكبر r.بس كم أما طول محوره الأصغر فقد بلغ

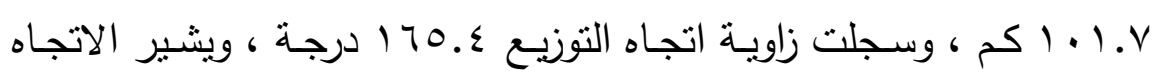

(المخصبات الكيماوية للمحاصيل الزراعية في مصر ...) د. أيمن عبد المطلب السعيد. 
العام لتوزيع مصانع المخصبات الكيماوية في مصر من الجنوب الشرقي إلى الثمال الغربي في وسط الجمهورية حيث المعمور المصري ، وبلغت مساحة

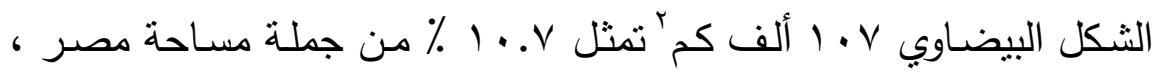

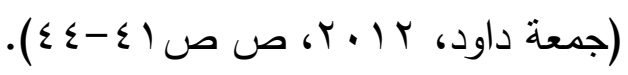

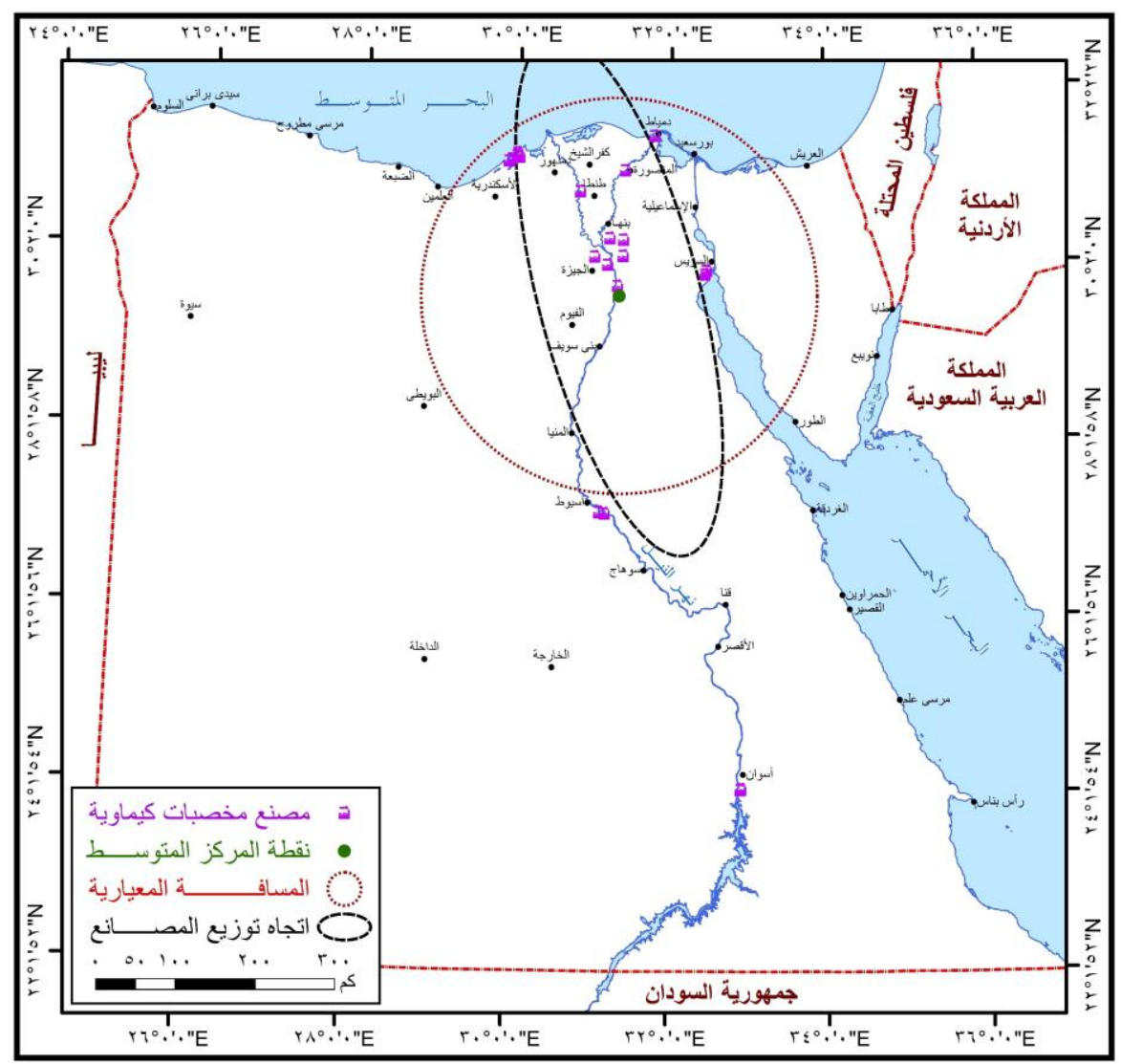

المصدر : من إعداد الباحث باستخذام الحاسب الآلى ، برنـامج (Arc map10.7.1) - الهيئة المصرية

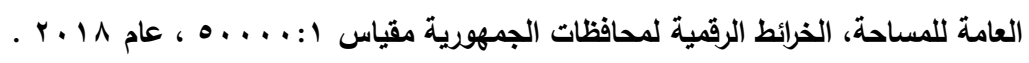

شكل(ء ) المركز المتوسط والمسافة المعيارية واتجاه توزيع مصانع المخصبات

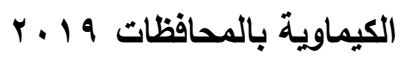

(المخصبات الكيماوية للمحاصيل الزر اعية في مصر ...) د. أيمن عبد المطلب السعيد. 
وباستخدام معامل الجار الأقرب في تحليل متوسط المسافة لأقرب جار

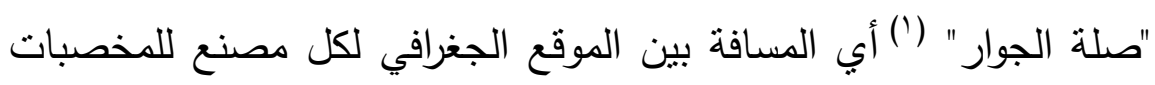
الكيماوية والموقع الجغرافي لمصانع المخصبات الكيماوية الأقرب منها، تنين سيادة النمط العنقودي Clustered في التوزيع الجغرافي لمصانع المخصبات الكيماوية بمحافظات الجمهورية ، حيث سجلت قيمة الجار

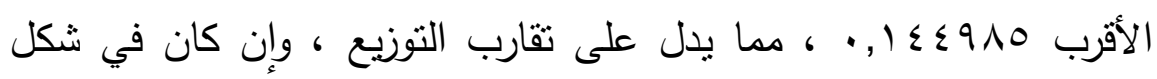

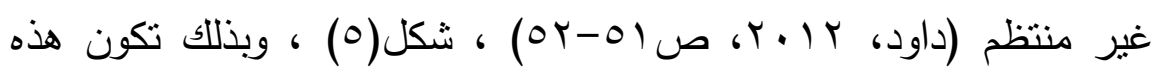
المصانع قريبة من الأراضي الزراعية القديمة والمستصلحة بالإضافة لقرب

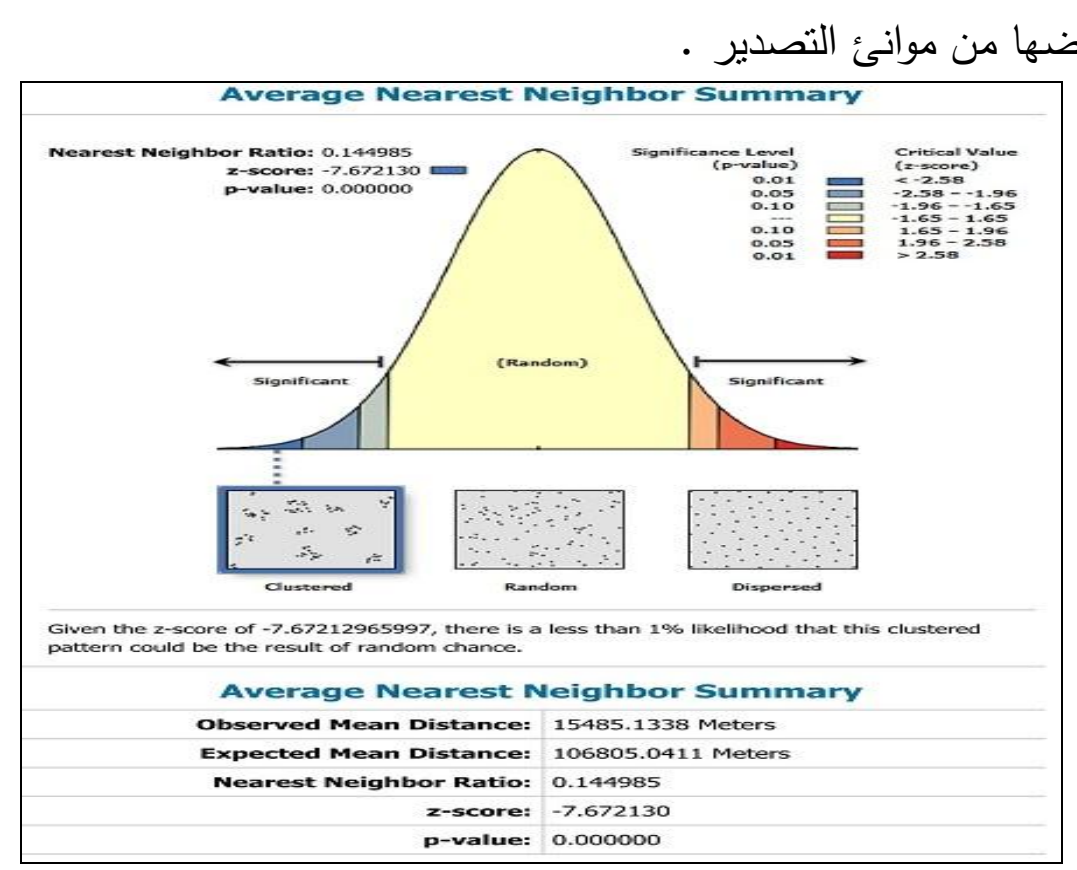

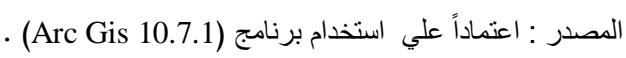

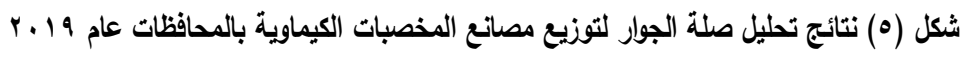

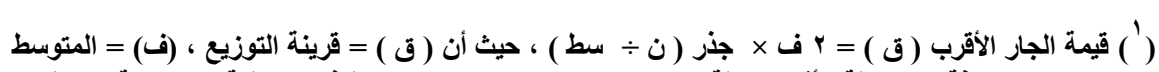

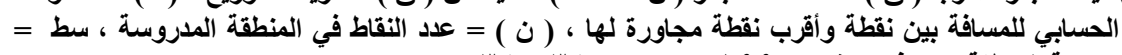

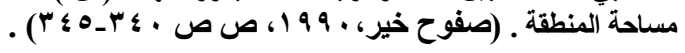

(المخصبات الكيماوية للمحاصيل الزراعية في مصر ...) د. أيمن عبد المطلب السعيد. 
وتقوم صناعة المخصبات الكيماوية وفقاً لتوافر العديد من العوامل حيث

تشجع علي إنشـاء المصـانع في الإقليم المناسب لها حسب نوع وخصـائص تلك المخصبات وطبيعة الإقليم الذي تتوطن فيه، وفيما يلي عرض للعوامل المؤثرة علي توطن صناعتها في مصر : أ - المواد الخــام : يتم الحصول علي العناصر الغذائية التي تستخدم في صـناعة المخصبات الكيماويـة مـن مصسادر متعـدة ومعظمهـا مسن خـلال قطاع التعدين ، حيث تمر بعدها بعمليات فصل لعناصرها الغذائية لتتحول (How Fertilizer is Made? , بعدها إلي أنتكال مناسبة للاستخدام (2020 وتهنم كثير من الصناعات ومنها صناعة المخصبات الكيماويـة باختيار مناطق توطنها خاصة موقعها بالنسبة للخامات مراعاة لتكلفة النقل ، خاصـة أنها لا تتوزع بالتساوي في جميع المناطق نظراً لتبعثرها ، ويتحدد تأثيرها في التوطين علي نسبة ما تفقده تلك الخامات من وزنها الأصلي بعد تصنيعها (الديب، 910 (،ص (1)0) • وتعتمد هذه الصـناعة علي كميـات كبيرة الحجم وثقيلة الوزن من المواد الخام وأهمها في مصر ما يلي:

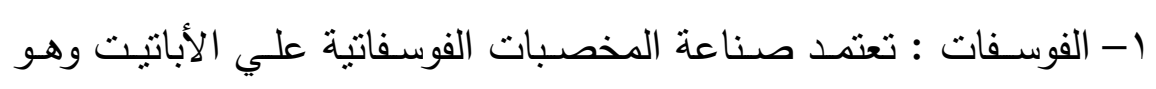
أحد أنواع الفوسفات ، والتي تمثل نحو VV\% من استخداماته، حيث بصنع السوبر فوسفات والأسمدة المركبة وفوسفات النيتروجين من تفاعل الفوسفات مع حض الفوسفوريك وحمض الكبريتيك ، وقد تطحن صخوره لتضاف إلي التربــة الحامضـية مباشـرة ، ويتركـز خـامس أكسـيد الفسـفور فـي صــور الفوسفات بنسبة تتراوح بين · rو • ٪ كحد أدني ، ولذلك يتم التخلص من (المخصبات الكيماوية للمحاصيل الزر اعية في مصر ...) د. أيمن عبد المطلب السعيد. 
كميات كبيرة من الثوائب ، وبالتالي تتركز مصانعه قرب مناجمه أو بجوار شبكات النقل كونه مادة أساسية في صناعته ولها وزن وحجم كبيران .

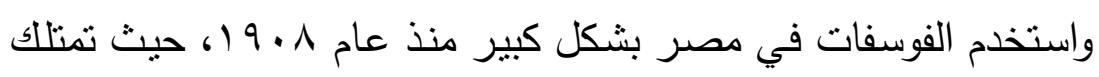

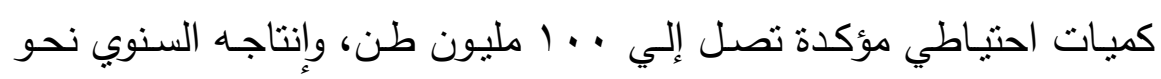

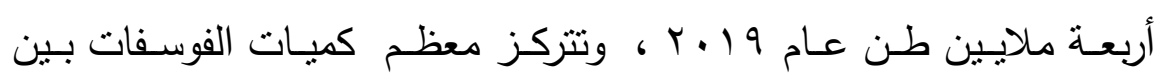
صخور الكريتاسي الأعلى في ثناث مناطق رئيسية ، و هي: منطقة البحر

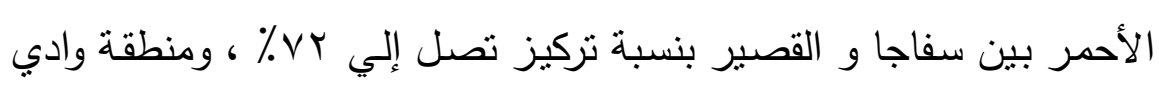

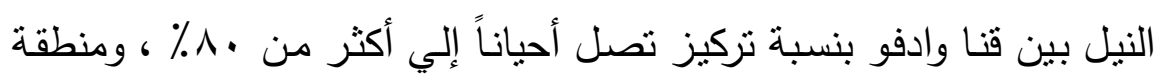

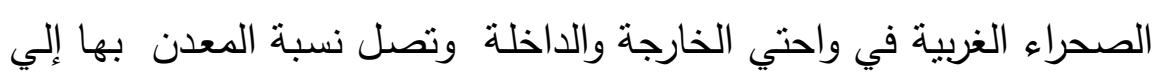

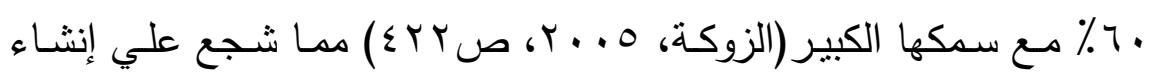
مصنع لإنتاج سماد الفوسفات بها.

r- الغاز الطبيعي: تعتمد صناعة المخصبات الآزوتية علي الغاز الطبيعي

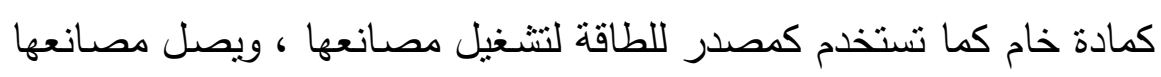

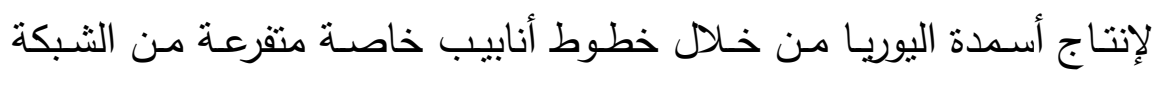

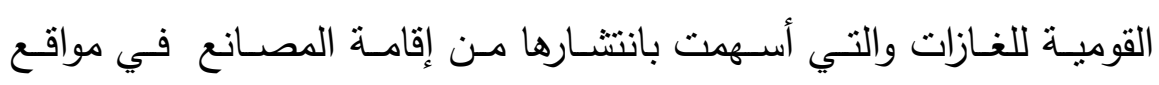
مختلفة ، ويستخرج الغاز الطبيعي من أحواض: الدلتا وخليج السويس وأبو لغاني

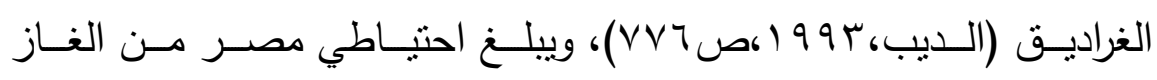

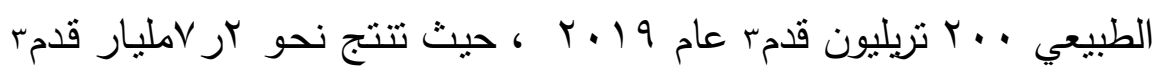

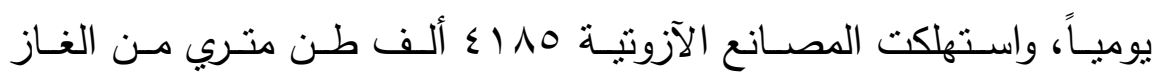

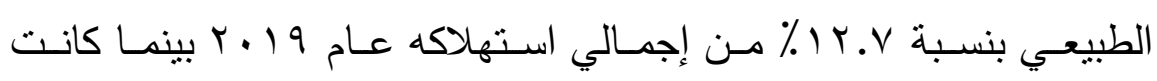

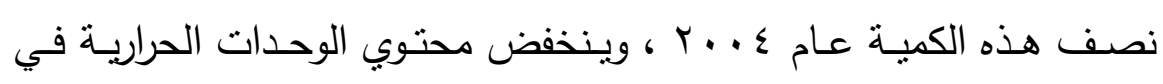

(المخصبات الكيماوية للمحاصيل الزراعية في مصر ...) د. أيمن عبد المطلب السعيد. 
الغاز الطبيعي المستخرج بسبب ارتفاع نسب الغازات الخاملة مهـا يتطلب

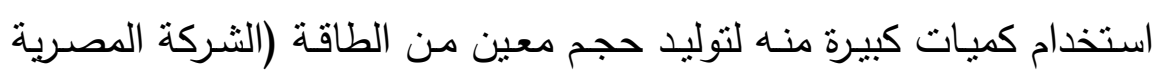

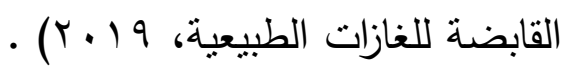
r-المتبخرات "البوتاسيوم والجبس": نوجد في خليج السويس ومدخل البحر

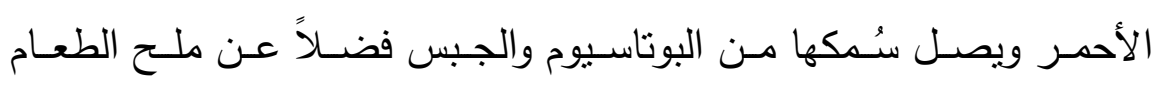

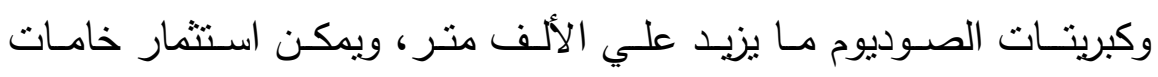

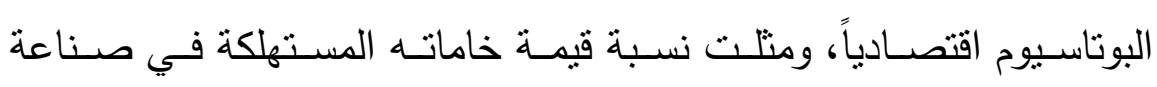

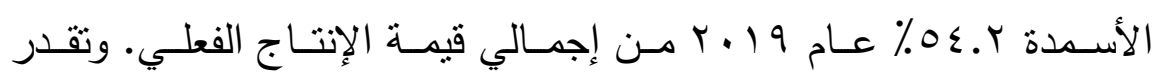
احتياطيات الجبس في مصر بنحو · •r مليون طن على جانبي خليج السويس وساحل البحرين المتوسط والأحمر وفي سيناء والفيوم، ويستخدم في هي هي

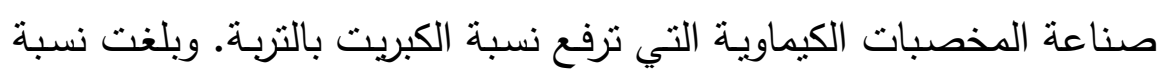

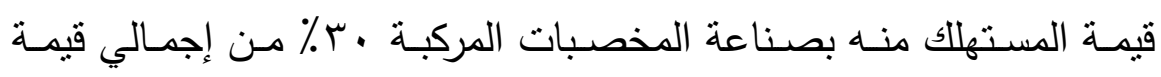

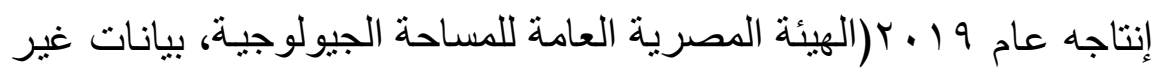
منشورة عن الثروة المعدنية، 9 (ب)، ويوضح شكل (T) التوزيع الجغرافي

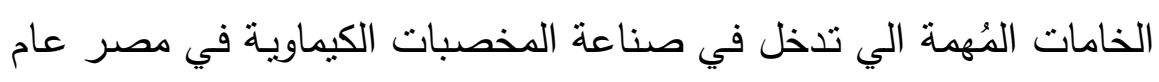
.$r .19$

(المخصبات الكيماوية للمحاصيل الزراعية في مصر ...) د. أيمن عبد المطلب السعيد. 


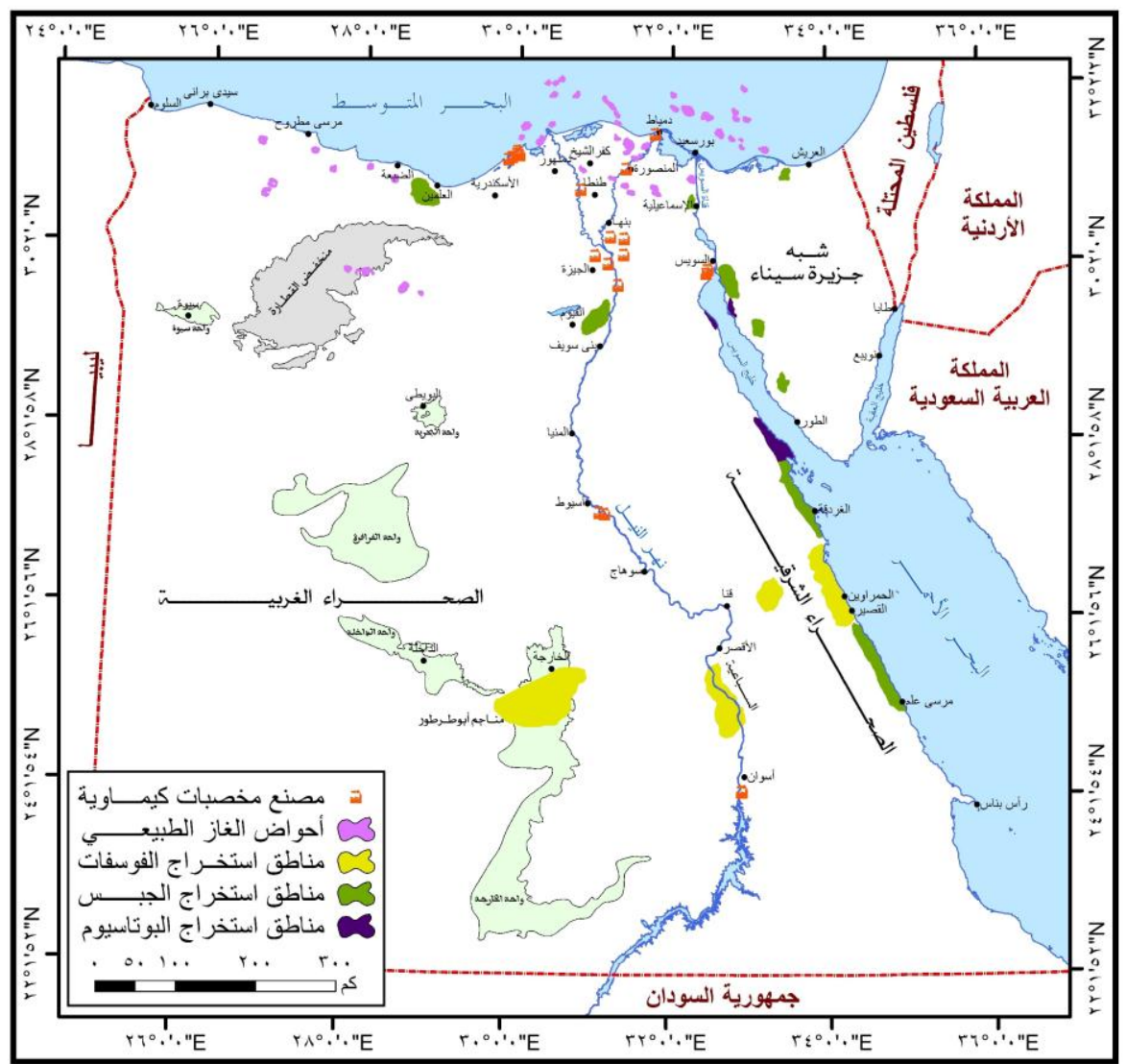

المصدار: اعتمـاداً علـي: هيئة الثروة المعدنية، خرائط توزيـع الثروة المعدنيـة في مصر، مقيـاس ا: r.19، ro...

شكل( ا) التوزيع الجغرافي لأهم الخامات الي تلخل في صناعة المخصبات الكيماوية

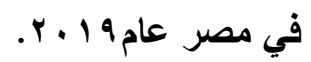

ب- الطاقة ـــة : تُعـد صــناعة المخصـبات الكيماويــة مــن الصــناعات المستهلكة للطاقة بشكل كبير سواء كمادة خام أم كمصدر للتشغيل ، ولذلك هناك اهتمام للحصول عليها بتكلفة اقتصـادية مسع قرب توطن المصـانع من مصدرها قدر الإمكان (الديب، 9 (1، ص (سم))، وبتضح ذلك في صناعة

(المخصبات الكيماوية للمحاصيل الزراعية في مصر ...) د. أيمن عبد المطلب السعيد. 
المخصبات الآزونيـة مثل مصـانع أبو قير التي ترتبط بالحقول المتتاثرة في خليج أبو قير بطول عكم ، ومصانع السويس التي يصلها الغاز الطبيعي من حقل أبو الغراديق بخط أنابيب بطول • ماكم ، ومصنع طلخا الذي يصله الغـاز الطبيعي من حقل أبو ماضـي من خـلال خط أنابيب بطول 0 ـ كم (عبده ، 910 (، ص1/1 (1) ، ويرتبط مصنع دمياط بحقل الوسطاني بخط أنابيب طولـه س سكم ، ويعتمد مصنع كيما لإنتاج الأسمدة في أسوان علي

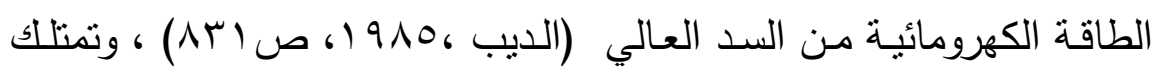
المصـانع محطات لتوليد الكهربـاء تعدل بـالقوي الحراريـة في أوقات انقطاع الكهرباء من الثبكة القومية للكهرباء ـ وبلغت نسبة الطاقة المستخدمة في صناعة المخصبات الكيماوية ؟.^ץ ٪ من إجمالي قيمة الإنتاج للكهرباء عام

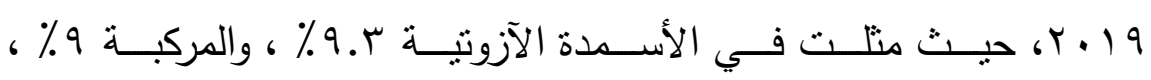
والفوسفاتية ^٪ ، والبوتاسية ؟ ٪ (الجهاز لمركزي للتعبئة العامـة والإحصـاء $\cdot(r \cdot r \cdot \sigma$

ج- النقــلـ : تتأثز صناعة المخصبات الكيماوية بالعديد من العوامل كونها مـن الصـناعات الكبيـرة الحجـم وأهمهـا النقـل حيــث يُراعي تـوافر الطـرق ووسائل الحركة ، بل يتم إنشاؤها في حالة عدم توافرها بمجرد إقامة مصانعها ، ويرجع تأثير النقل في توطن هذه الصناعة إلي تكلفته حيث تضاف علي سعر المنتج لتضم نقل الخامات والعمال إلي المصنع ثم نقل المنتج إلي الأسواق المحلية أو الخارجيـة ، وتراعي التكلفة بالنسبة لكل كيلومتر طولي حيث تقل في المسافات الطويلة عن القصيرة ( بكير،A . . . Y،ص (N). (المخصبات الكيماوية للمحاصيل الزراعية في مصر ...) د. أيمن عبد المطلب السعيد. 
وتتوفر في مصـر شـبكة جيـدة مـن الطـرق البريـة في الـوادي والـدلتا ومنطقة القناة كما تتناثز الموانئ علي ساحل البحرين المتوسط والأحمر في بورسعيد ودمياط والإسكندرية والسويس والعين السخنة وسفاجا، وهي مواقع صناعية جاذبة لصناعة المخصبات الكيماوية، بسبب موقعها بالنسبة للداخل والخارج ووفرة وسائل النقل (سيف، • 99 (، ص V VTr)، وتستثر الموانئ في تصـدير المخصبات الكيماوية إلي دول العالم لقربها من مصانع: دمياط وأبو قير وطلخـا وكفر الزبـات وحلـوان كمـا تسـتخدم في استيراد كميـات أخري. وتسـتخدم سيارات النقل الثقيـل في نقل المخصبات الكيماويـة بشـكل واسـع حيـث تصـل بمرونـة وسـرعة إلـي جهـات التوزيـع بالـداخل أو إلـي مـوانئ

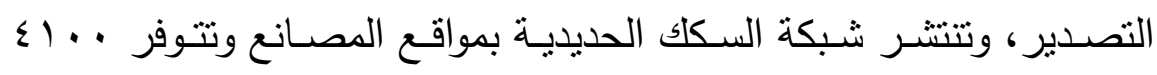
عربة مغلقة بحمولة V ا ألف طن لنقل المخصبات، ويقتصر النقل النهري لها علي منتجات مصانع كيما إلي محافظات الصعيد لتبدأ من أسوان حتي

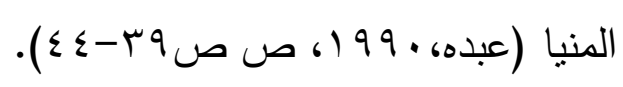

د- العمـالة : تتطلب صناعة المخصبات الصناعية لعدد متوسط من العمالة بسبب اعتمادها علي التقنية الحديثة ، ويعمل في مصر بهذا القطاع INV.

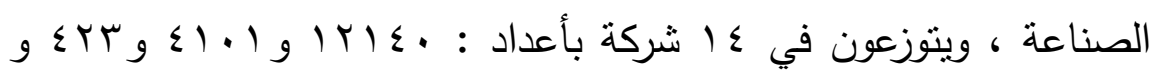
Vr.1 عاملاً في مصانع إنتاج المخصبات الآزوتية والفوسفاتية والبوتاسية والمركبة علي الترتيب ، بإجمالي أجور ^.؟1 مليون جنيه

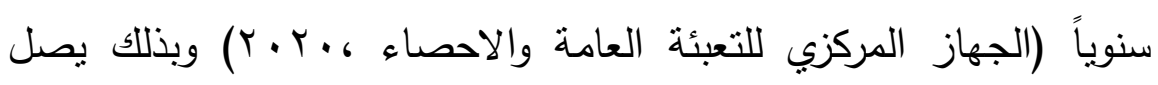
(المخصبات الكيماوية للمحاصيل الزراعية في مصر ...) د. أيمن عبد المطلب السعيد. 
منوسط دخل العامل بها حوالي ^^ء ألف جنيه سنوياً. وتعمل مستويات مختلفة من العمالة بهذه الصناعة من إداريين وفنيين وعمال، وتجذبها حيث دوليث

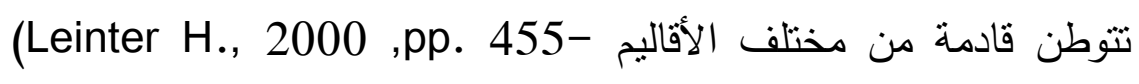
(465 ، وتعد تكاليف العمالة ونقل الخامات والمنتج من العوامل المؤثرة

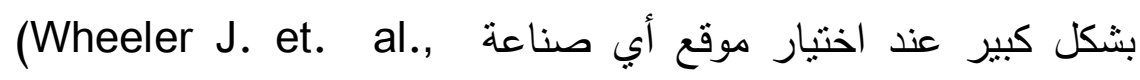

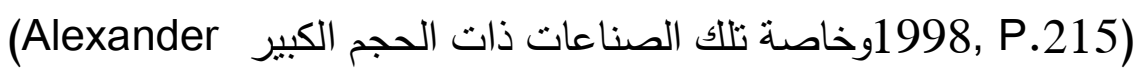

\section{.J. Gibson L., 1979, P. 445)}

هـ رأس المسال : تحتاج صناعة المخصبات الكيماوية إلي استثمارات كبيرة أثناء الإنشاء في توفير الأراضي والمباني ووحدات الإنتاج ووسائل النقل

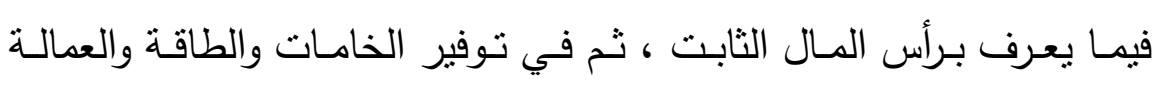

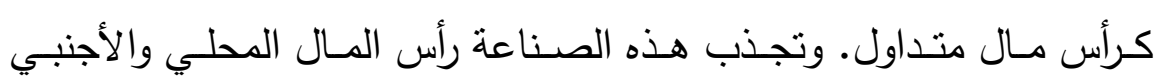
لتوافر عوامل قيامها في مصر وارتباطها بأحد أهم قطاعات الاقتصاد والأمن وأن

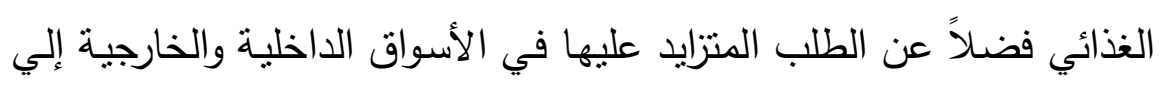

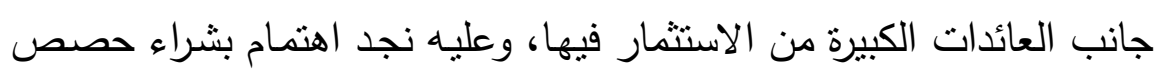

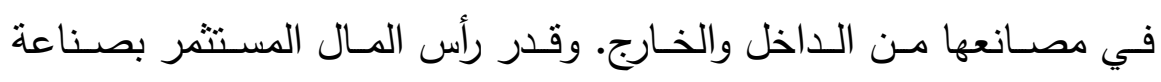

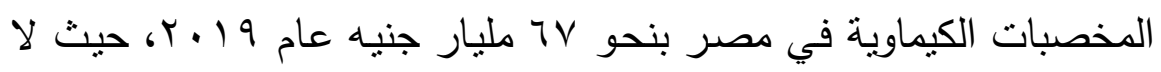

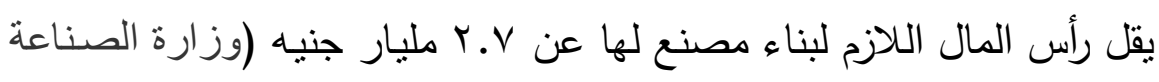

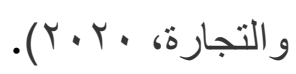

و- الميـاه: تُعد أحد العوامل المؤثرة في صناعة المخصبات الكيماوية حيث

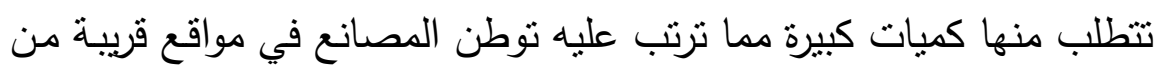
(المخصبات الكيماوية للمحاصيل الزراعية في مصر ...) د. أيمن عبد المطلب السعيد. 
مصادرها وتوصل لها من خلال خطوط أنابيب مستقلة، حيث يحتاج إنتاج طناً مـن حامض الكبريتيك إلي كمية ميـاه تتراوح بين · r و ب ألف لتر ، بينما إنتاج الطن من سلفات الأمونيوم يتطلب . بم ألف لتر (شركة مصر

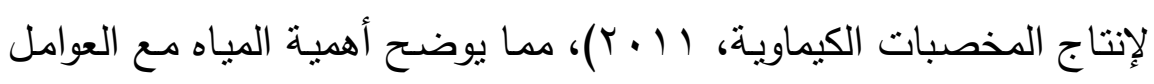
الأخرى عند التخطيط لاختيار موضع المصانع. ي- الســـوق : يؤثر السـوق بشكل واضـح في نوطن صناعة المخصبات الكيماويـة ، ويعتبـره البعض أهـم العوامـل المـؤثرة فـي تـوطين مصـانعها

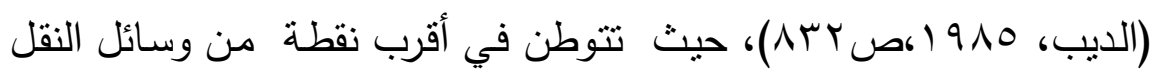
المختلفـة بالنسـبة للأسـواق المحليـة أو الخارجيـة ، وتختلــ طبيعـة تـوطن مصانع المخصبات الكيماوية وفقاً لهدف التصنيع ، حيث نجد المصانع التي تم إنشاؤها مسبقاً بهدف توفيرها للسوق المحلي تركزت في قلب الوادي والدلتا ومنها مصـانع كفر الزيـات وطلخـا وكيما ، بينمـا توطنت المصـانع التي تم إنشـاؤها بعد ذلك بـالقرب من الموانئ البحريـة والتي كانت تستهدف السوق

الخارجي منذ البداية ومنها مصانع أبوقير والسويس ودمياط والعين السخنة .

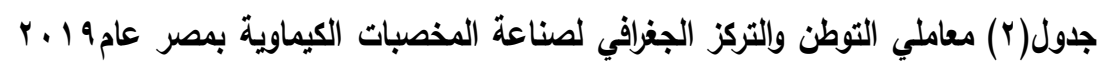

\begin{tabular}{|c|c|c|c|c|c|c|c|c|c|c|}
\hline أسيوط & الغربية & |القليويية & القاهرة & | أسوان & مياط & لدقهلية & الجيزة & سكندرية | & |السويس & معامل - محافظة \\
\hline$\cdots r$ & $\ldots r$ & $\ldots$. & - & $\cdots \varepsilon$ & $\cdots 9$ & .1 . & .10 & $.1 \mathrm{~V}$ & .rY & التوطن ( **) \\
\hline r.qT & .91 & .94 & $\because V V$ & 1.01 & r.7V & $1 . .1$ &.$\wedge 9$ & $.9 r$ & $1 \leq . \times 9$ & التركز (***) \\
\hline
\end{tabular}

المصدر : اعتمادا علي بيانات الجهاز المركزي للتعبئة العامة و الإحصاء ،9 19 . . . (*) معامل التوطن : إنتاج المخصبات الكيماويـة بالمحافظة / إجمالي إنتاجها في مصر - عدد سكان المحافظة / إجمالي عدد سكان مصر. (") معامل التركز : النسبة المئوية للعاملين بصناعة المخصبات بالمحافظة إلي إجمالي العاملون بالصناعة في مصر / النسبة

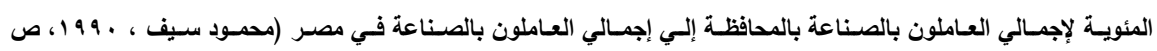
• ص (1) (1)

(المخصبات الكيماوية للمحاصيل الزر اعية في مصر ...) د. أيمن عبد المطلب السعيد. 
وتتفـاوت هـذه العوامـل الجغرافيـة في تأثيرهــا علـي تـوطن صـناعة المخصـبات الكيماويـة بأنواعهـا في مصـر ، ويوضـح الجدول (r) معامـل تـوطن صــاعة المخصـبات الكيماويـة في مصـر والـذي يقـل في جميع محافظات تركزها عن الواحد الصحيح ، كما يتبين من الجدول درجة التركز لهذه الصناعة في كل محافظة ، حيث بلـغ تركزهـا في السويس (9 ب.؛ ()

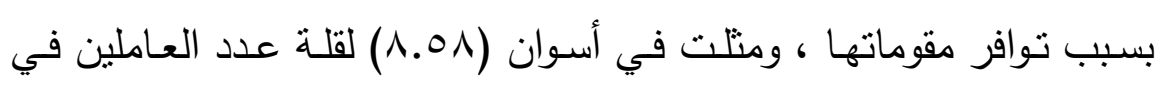
قطاع الصناعة فيها ، كما بلغت في دمياط (V.T.T) لتوفر عوامل قيامها

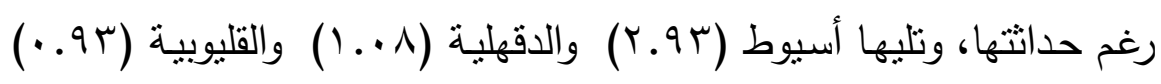
حيـث تتوفر بعض مقومـات الصـناعة ، ورغـم أهميـة هـذه الصــاعة في الاسكندرية إلا أن نسبة تركزهـا (r 9 . ·) فقط لمنافسـة الصناعات الأخرى ، ثم تأتي الغربيـة (19. • ) رغم قدم الصـاعة بها لكنها وجدت منافسـة من إن

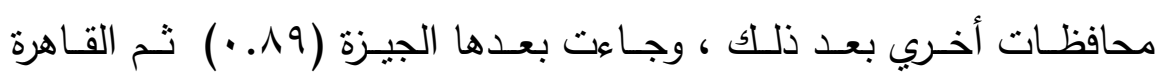
حيث تثتوع الصناعات فيهما .VV)

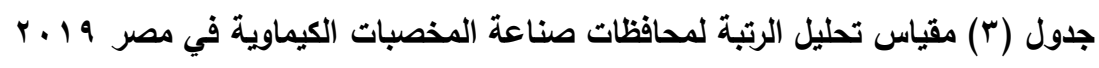

\begin{tabular}{|c|c|c|c|c|c|c|c|c|c|c|}
\hline السويس & دمياط & أسوان & أسيوط & الغزبية & إسكندرية & القليويية & الدقهلية & الجيزة & القاهرة & محافظة \\
\hline 1 & $\wedge$ & 0 & 1. & 9 & ؛ & 7 & $V$ & $r$ & $r$ & الرتبة \\
\hline
\end{tabular}

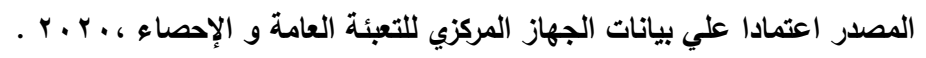
ويتضــح مـن الجـدول (ب) مقيـاس تحليـل الرتبــة لمحافظـات صــاعة المخصبات الكيماويـة في مصر عام 9 1 ـ حيث يربط بين حجم العمالة

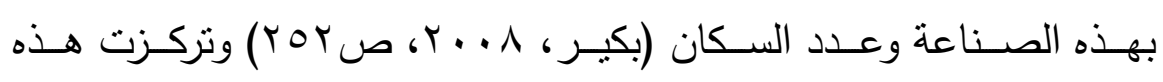
الصـناعة في المحافظـات بالترتيــب التـالي: السـويس، والقـاهرة، والجيـزة، (المخصبات الكيماوية للمحاصيل الزر اعية في مصر ...) د. أيمن عبد المطلب السعيد. 
والإسـكندرية، وأسـوان، والقليوبيـة، والدقهليـة، ودميـاط، والغربيـة، وأسـيوط، ويتبـين مـن هـا الترتيب التجـاذب بـين تأثير عـاملي المـواد الخـام والسـوق لانتشار هذه الصناعة ولا ترتبط بعدد السكان فقط.

ثالثاً : أنواع المخصبات الكيماوية :

توجد العديد من أنواع المخصبات الكيماوية حيث تنقسم وفقاً لتركيبها إلي: البسيطة أو الأحادية وبها عنصر فقط، والمُركبة وتحتوي مكوناتها علي أكثر من عنصر ، ويتم تصنيعها بسبب احتوائها علي عناصر غذائية مفيدة للنبات لاستمرار نموه بشكل جيد، حيث تسمح بزيادة إنتاج المحاصيل

- (The Importance of Using Chemical Fertilizers, 2019) أ- المخصبات البسيطة : تشمل أسمدة الآزوت ، والفوسفات ، والبوتاسيوم ، والكالسيوم ، والماغنسيوم • ب- المخصبات المركبة المخلوطة .

وتتمنل أنواع المخصبات الكيماوية في مصر من مركبات تحوي سا عنصراً إلا أن "الآزوت، والفوسفات، والبوتاسيوم" أساس هذه الصناعة وفيما يلي الأنواع المُهمة منها: ا- المخصبات الآزوتية : تتكون من عنصر الآزوت وهو الأكثر استخداماً لدوره الأساسي في زيادة النمو الخضري ، ويغني عن الأسدة العضوية للنبات ، ويدخل عنصر النشادر في تركيبها ، ومن أثكالها : اليوريا وبها البيوريت بنسبة \٪ والنيتروجين الذائب بنسبة جـ ٪ ، ونترات الكالسيوم ، وأسمدة السُلفات ، ونترات الأمونيوم بنسبة ـ ٪ نيتروجين. (المخصبات الكيماوية للمحاصيل الزراعية في مصر ...) د. أيمن عبد المطلب السعيد. 
r - المخصبات الفوسفاتية : تصنع من الأباتيت وهو أحد أنواع الفوسفات، والفسفور عنصر مُهم لتخصيب التربة مما يغذي جذور النبات ويساعد في تزهيره ، وأنواعها : فوسفات ثثائي الأمونيوم ، وسوبر فوسفات الكالسيوم الأحادي والثتاثي "المُركز"، والسوبر فوسفات السائل الذي يتكون بمعالجة معدن الأباتيت بحمض الفوسفوريك أو الكبريتيك ، ويتطلب استفادة النبات من الفوسفات تحويله إلي مركبات تذوب في الماء . r - مخصبات البوثاسيوم : يستخدم البوتاسيوم في صناعتها، حيث يساهم في زيادة سمك ساق النبات مع تكبير حجم الثمار ومن منتجاته : نترات البوتاسيوم وسلفات البوتاسيوم • ع - - مخصبات الماغنيسيوم: يعتمد على الماغنسيوم، منل سلفات الماغنيسيوم الذي يساعد في نمو جذور النباتات وكذللك الساق والأوراق مع زيادة حجم الثمار ، حيث يحسن من عملية التمثيل الضوئي وتكوين الخلايا. 0 - مخصبات الكالسيوم : يصنع من أكسيد الكالسيوم ، حيث يكون مسئول عن استقرار الحالة البنائية والفسيولوجية لنسيج النبات لذا فهو فُهم في نمو الثمار وأثناء التذاول والتخزين . 7 - المخصبات المركبة والمخلوطة: وتكون محببة أو سائلة منل نترات البوتاسيوم وسلفات البوتاسيوم. V - مخصبات العناصر الصغرى "الصورة المخلبية": قد تكون أحادية أو مركبة في شكل صلب أو سائل وتتكون من عناصر الحديد والنحاس والمنجنيز والزنك وغيرها ولا يقل تركيزها عن 1\%.

(المخصبات الكيماوية للمحاصيل الزراعية في مصر...) د. أيمن عبد المطلب السعيد. 


$$
\text { ^ - مخصبات أخرى : منل الجبس والكبريت . }
$$

وتتوزع مصانع إنتاج اليوريا في أبوقير بالإسكندرية، وأسوان، وطلخا بالدقهلية، وحلوان بالقاهرة، والعين السخنة بالسويس، والمنطقة الحرة بدمياط، والقليوبية. وتتنج المخصبات الفوسفاتية من مصانع كفر الزيات بالغربية، وانهات

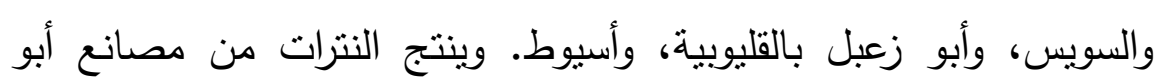
رواش بالجيزة، وأبو قير بالإسكندرية، والسويس، أما سلفات البوتاسيوم

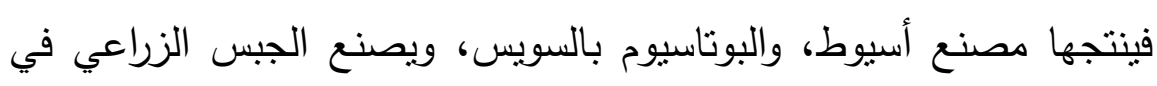

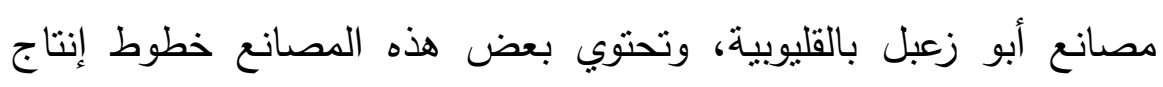

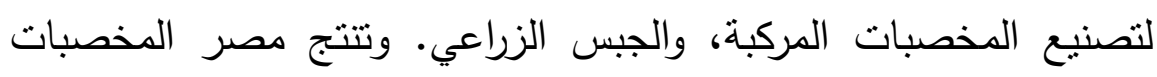
البوتاسية بمفردها بكمبات محدودة، لكن يتم خلطها مع مخصبات الفسفور

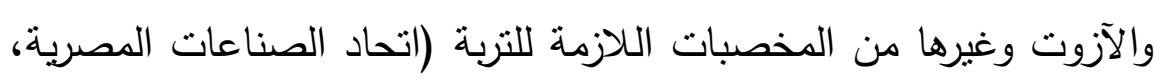

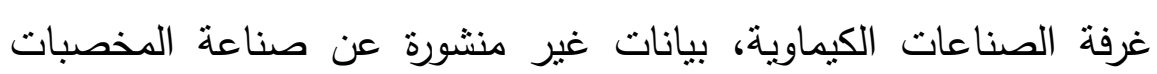

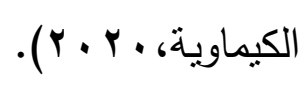

رابعاً : تطور إنتاج المخصبات الكيماوية : تعد صناعة المخصبات الكيماوية أحد الصناعات الاستراتيجية المُههـة التي تُسهم في التتمية الاقتصادية من خلال النهوض بزيادة الإنتاج الزراعي

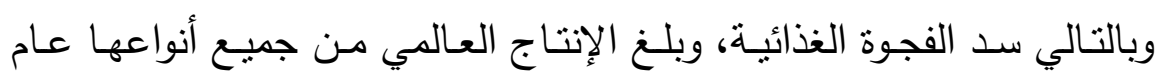

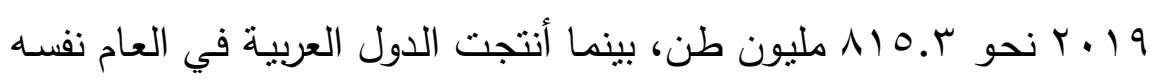

(المخصبات الكيماوية للمحاصبل الزراعية في مصر ...) د. أيمن عبد المطلب السعيد. 


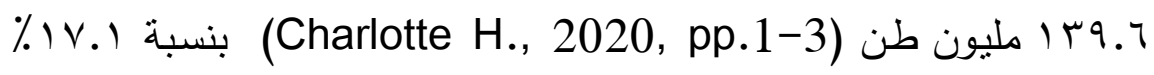

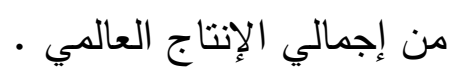

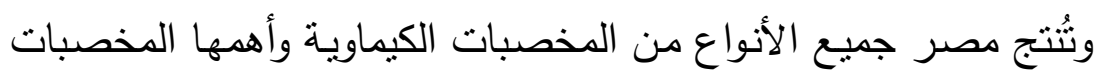

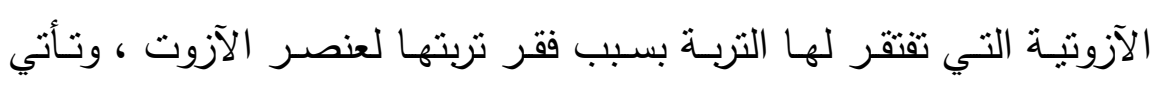

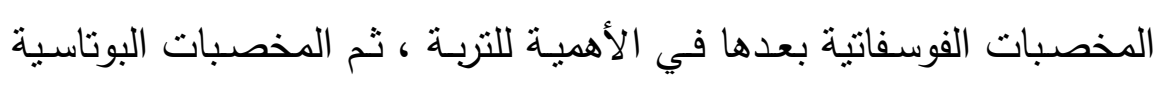

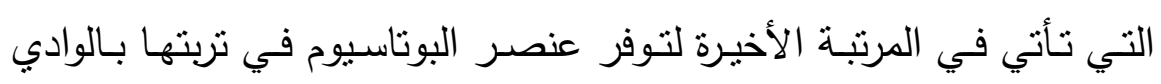

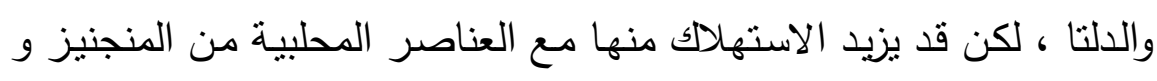

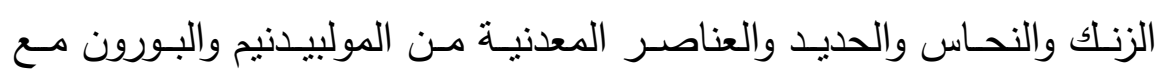
التوسع الأفقي في الأراضي الصحراوية الجيرية والرملية.

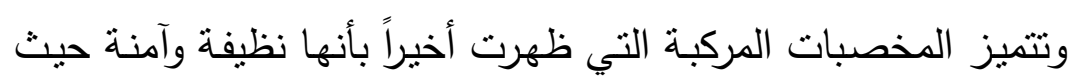

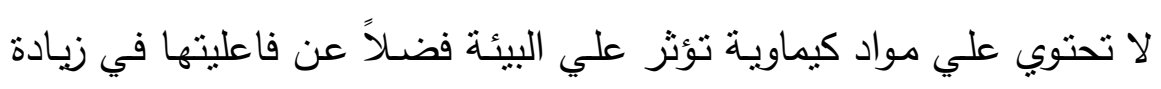

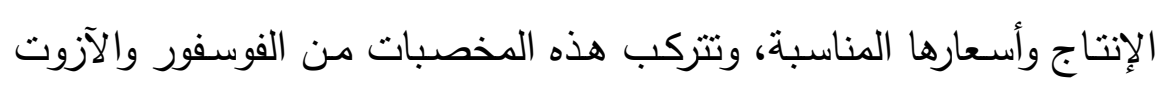

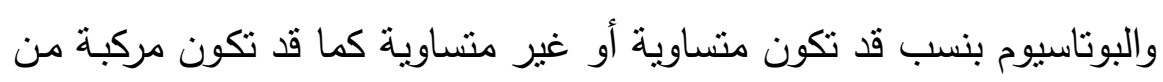
عنصرين فقط مـع إضـافة عناصر مخلبية صغري وأخري معدنية (الجهاز

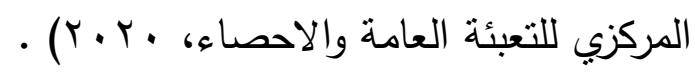
وتستخدم المخصبات الآزوتية بأنواعها للمحاصيل بنسب تتوقف علي لواهي

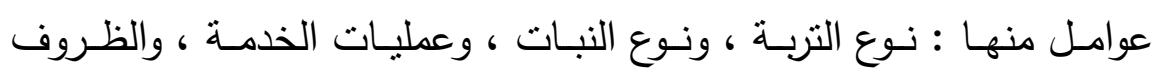

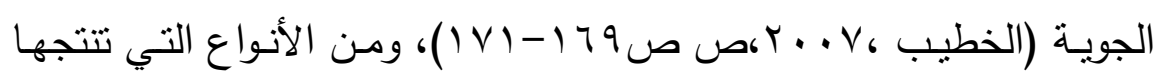

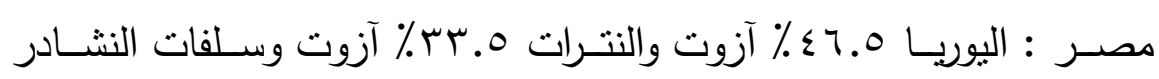

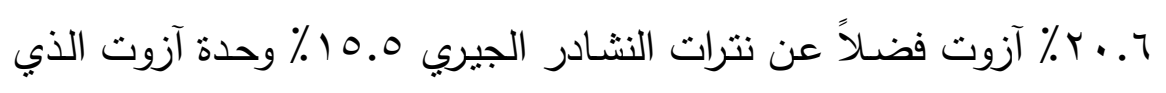
(المخصبات الكيماوية للمحاصيل الزراعية في مصر ...) د. أيمن عبد المطلب السعيد. 
توقف إنتاجه عام 990 ، ، ويصنع من المخصبات الفوسفاتية أنواع متعددة بنسب مختلفة من عنصر الفوسفور الذي يُعد مهماً لكل النباتات حيث بنتج

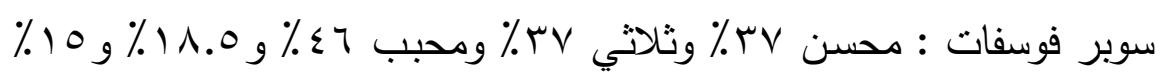
• وأنتجت مصر من النوعين الآزوتية والفوسفاتية V V ألف طن مسع بدايـة

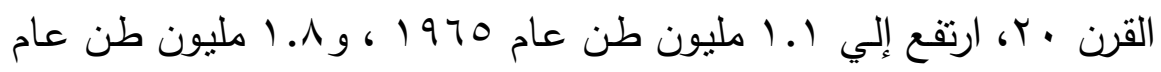

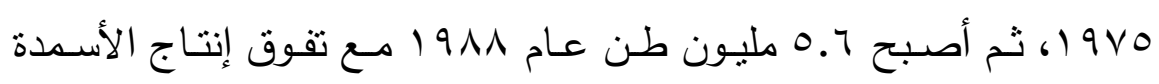

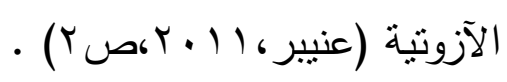

ويتضح من الجدول (ع) والشكل (V) تطور إنتاج المخصبات الكيماويـة

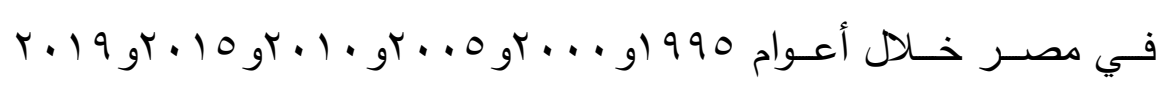

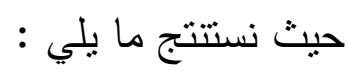

- بلـغ إنتاج المخصبات الكيماويسة في مصر 1990 19. مليون طن عام 19

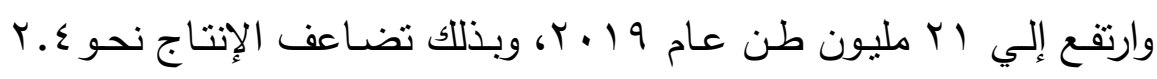
مرة خلال هب عامـاً، بسبب اتجاه الاستشمارات المحلية والأجنبية نحو هذه

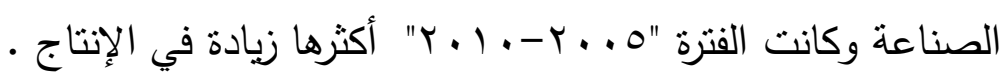
- اتسم القطاع الخـاص بزيادة إنتاجهـ دون تراجع خـلال هذه الأعوام والتي

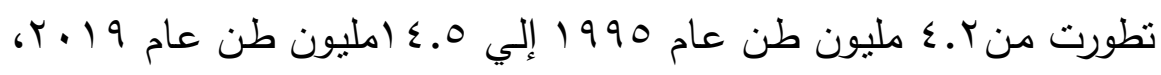
أما القطاع العام فقد اتسم إنتاجه بالتذبذب خـلا تلك الأعوام بسبب توقف عدداً من خطوط الإنتاج في بعض مصـانعه لكثرة عمليات الصيانة نتيجـة تقادم آلاتها مع زيادة العمالة ونظام التسعير •

(المخصبات الكيماوية للمحاصيل الزراعية في مصر...) د. أيمن عبد المطلب السعيد. 
- كان إنتاج المخصبات الكيماوية مناصفة ثقريباً من خلال طرفي الإنتاج عام ه . . r ، لكن تزايد الإنتاج بعدها أكثر من قبل القطاع الخاص ليتوزع الإنتاج بينهما عام 9 ـ ب بنحو الثُلث للقطاع العام والثُلثين للقطاع الخاص.

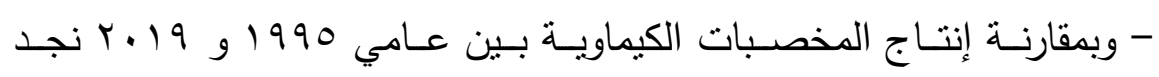

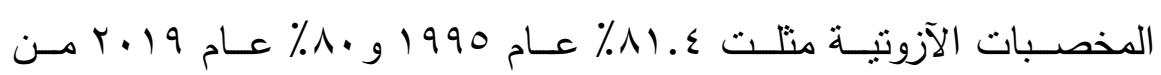
إجمالي إنتاج المخصبات في مصر ، وجاءت المخصبات الفوسفاتية في الترتيب

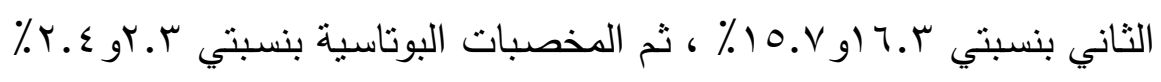
، وبدأ إنتاج المخصبات المركبة منذ عام ^ . . r وبلغت نسبة إنتاجها 9. من إجمالي الإنتاج عام 19 •.r. ويعود تصدر المخصبات الآزوتية الأنواع الأخرى في كمية الإنتاج بمصر إلي أهميتها للتربـة مـع التكلفة غير المرتفعـة في تصنيعها بسبب توافر الغاز

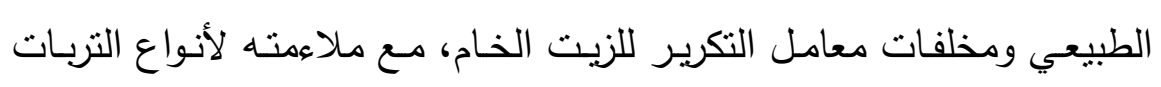
والمحاصيل (السماك ، (9191، صی))، وانتشار التقنية البسيطة لتصنيعها بداية

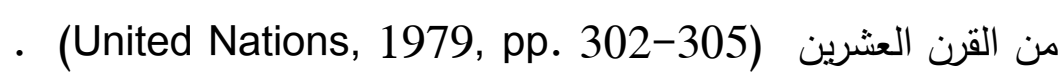

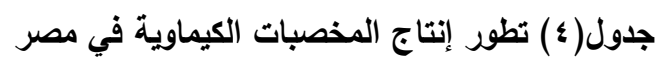

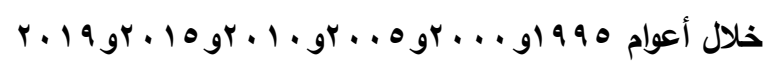

الكمية : بالمليون طن

\begin{tabular}{|c|c|c|c|c|c|c|c|c|c|}
\hline \multirow[b]{2}{*}{ إجمالي } & \multicolumn{4}{|c|}{ الأسمدة } & \multicolumn{2}{|c|}{ قطاع خاص } & \multicolumn{2}{|c|}{ قطاع عام } & \multirow{2}{*}{ عام } \\
\hline & المركبة & البوتاسبية & الفوسفاتية & الآزوتية & $\%$ & الكمية & $\%$ & الكمية & \\
\hline 1.7 & - & $\because Y$ & 1.2 & $\mathrm{~V}$ & $0 . .7$ & $\varepsilon . Y$ & $\varepsilon 9 . \xi$ & $\varepsilon .1$ & 1990 \\
\hline $9 . \varepsilon$ & . & $\because Y$ & $1 . Y$ & $\Lambda$ & 79.1 & 7.0 & $r \cdot .9$ & $r .9$ & $r \ldots$ \\
\hline 11.6 & . & $\cdot r$ & 1.0 & 9.7 & 71 & $\bar{V}$ & $r q$ & $\xi . \xi$ & $r_{\ldots} . .0$ \\
\hline 18.0 & .1 & $\because r$ & 1.8 & 10.5 & $0 V_{.1}$ & 1. & $\varepsilon Y .9$ & $V .0$ & $r .1$. \\
\hline $19 . Y$ & .1 & $\cdot r$ & Y. & 19.8 & 70.1 & $1 Y .0$ & $r \leqslant .9$ & 7.8 & $r .10$ \\
\hline YI &..$\varepsilon$ & .0 & $r . r$ & 17.1 & 79 & $1 \leqslant 0$ & 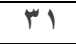 & 7.0 & $r .19$ \\
\hline
\end{tabular}

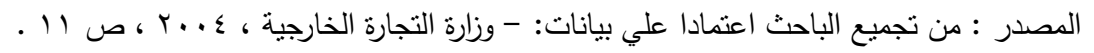

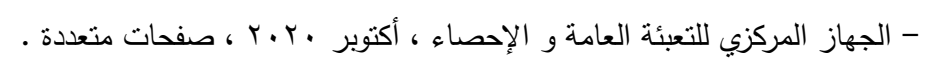

(المخصبات الكيماوية للمحاصيل الزراعية في مصر ...) د. أيمن عبد المطلب السعيد.

$$
\text { VVr }
$$




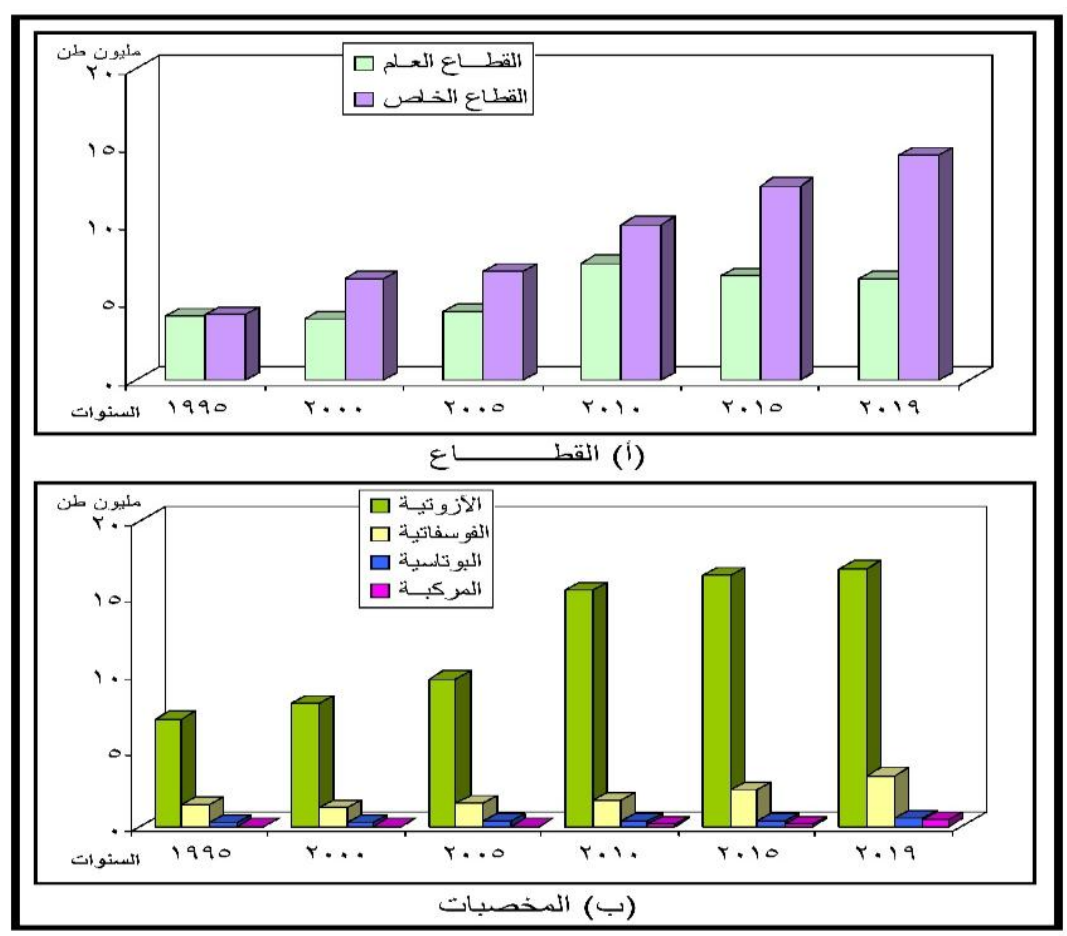

المصدر : اعتماداً علي جدول (ع) .

شكل) تطور إنتاج المخصبات الكيماوية في مصر خلال أعوام

$r+19 g r+10 g r \cdot 1 \cdot g r \cdot 0 g r \cdot . g 1990$

خامساً: الاستهلاك المحلي والتجارة الخارجية :

أ- الاستهلاك المحلي :

بتحليـل العوامـل المـؤثرة في زيـادة الإنتاج الزراعـي وجد أن ـ ٪ منهـا

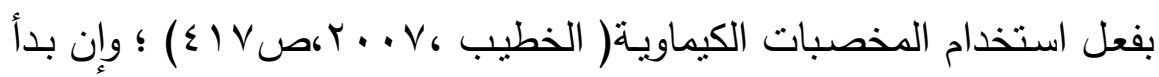
التراجع نسبياً في الكمبات المستخدمة منها في الدول المتقدمة للاتجاه نحو

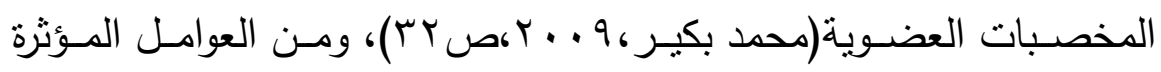
علي استهالاكها: نـوع المحصـول وعناصـر المنـاخ والمسـتوي المـادي للمـزارع

(المخصبات الكيماوية للمحاصيل الزراعية في مصر ...) د. أيمن عبد المطلب السعيد. 
، و 9NV، وحجم الكميات المتوفرة منها بالأسواق والإرشـاد الزراعي(النعيمي

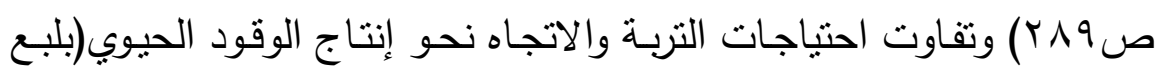

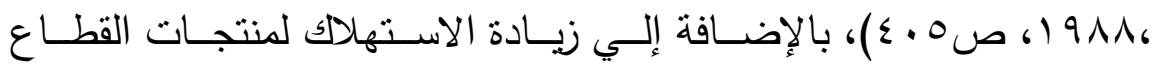
الزراعي مع النمو السكاني وثقافة المُزارع في مجال التسميد وأسعارها. ويوجد ارتبـاط قـوي (ء^ــ •) بـين المخصـبات الكيماويـة المسـتهلكة والمسـاحات المنزرعـة في مصـر بينمـا وجـد ارتبـاط قوي جـداً (79. . ) بـين الكميـات المستهلكة منها والمساحة المحصولية ('). وتزيد باستمرار الكميات المستهلكة من المخصبات الكيماوية في مصر ، حيث كانت 1 مليون طن عام • ج 19 وارتفعت إلي r.7 مليون طن عام • 19 1، وتركز الاستهلاك في المحافظات الرئيسية للإنتاج الزراعي بالوادي والـدلتا في البحيـرة وكفر الثـيخ والثـرقية والدقهليـة والغربيـة والمنوفيـة وقتـا وأســوط والمنيـا وكـان النصـيب الأكبـر فـي الكميـات المسـتهـكة منهــا للمخصبات الآزوتيـة ثم الفوسـاتية وتليها البوتاسبة ، وتُشنتـهلك المخصبات الآزوتية طوال العام ، بينما يزيد استهلاك المخصبات الفوسفاتية شتاءً وأوائل

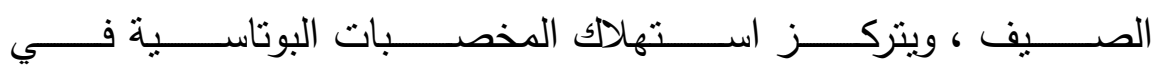
الصبف (عبده، • 99 (مص ص V9-7V) .

ويتضـح مـن الجـدول(0) والثـكل (^) الاســتهلآك المحلـي مـن المخصـبات

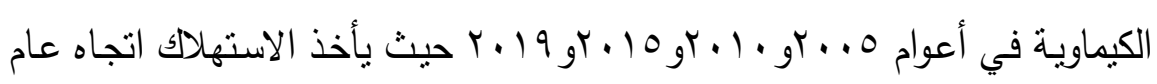

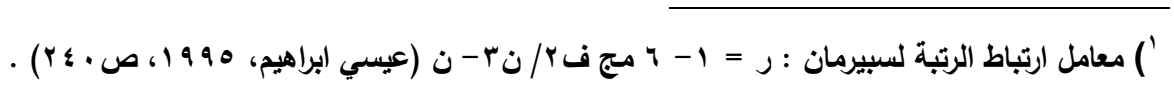

(المخصبات الكيماوية للمحاصيل الزراعية في مصر...) د. أيمن عبد المطلب السعيد. 
نحو الزيادة حيث بلغ V.9مليون طن عام ه ...r وارتفع إلى ع. ا امليون طن عام

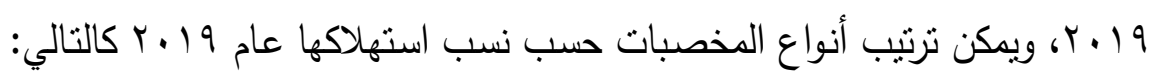

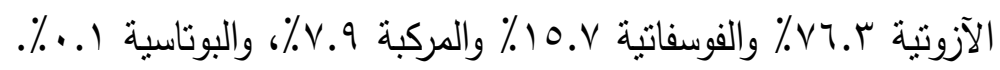
جدول(•) الاستهلاك المحلي من المخصبات الكيماوية في مصر

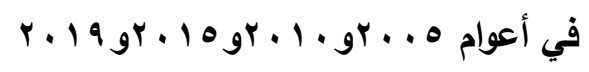

الكمية: مليون طن

\begin{tabular}{|c|c|c|c|c|c|}
\hline الإجمالي & المركبة & البوتاسية & الفوسفاتية & الآزوتية & المخصبات - عـات \\
\hline 9.1 & $\cdot .9$ & $\because \cdots 0$ & 1.9 & 7.9 & $r \ldots o$ \\
\hline$\Lambda . \vee$ & $\cdot .9$ & $\because \cdots 0$ & 1.5 & 7.7 & $r \cdot 1$. \\
\hline $1 . .1$ & $\cdot .9$ & $\because \cdots v$ & 1.0 & $V . V$ & $r+10$ \\
\hline $11 . \varepsilon$ & $\cdot .9$ & $\because \cdots 9$ & 1.1 & A.V & $r+19$ \\
\hline
\end{tabular}

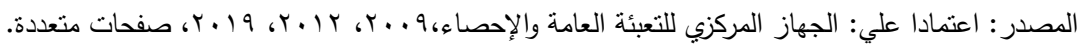

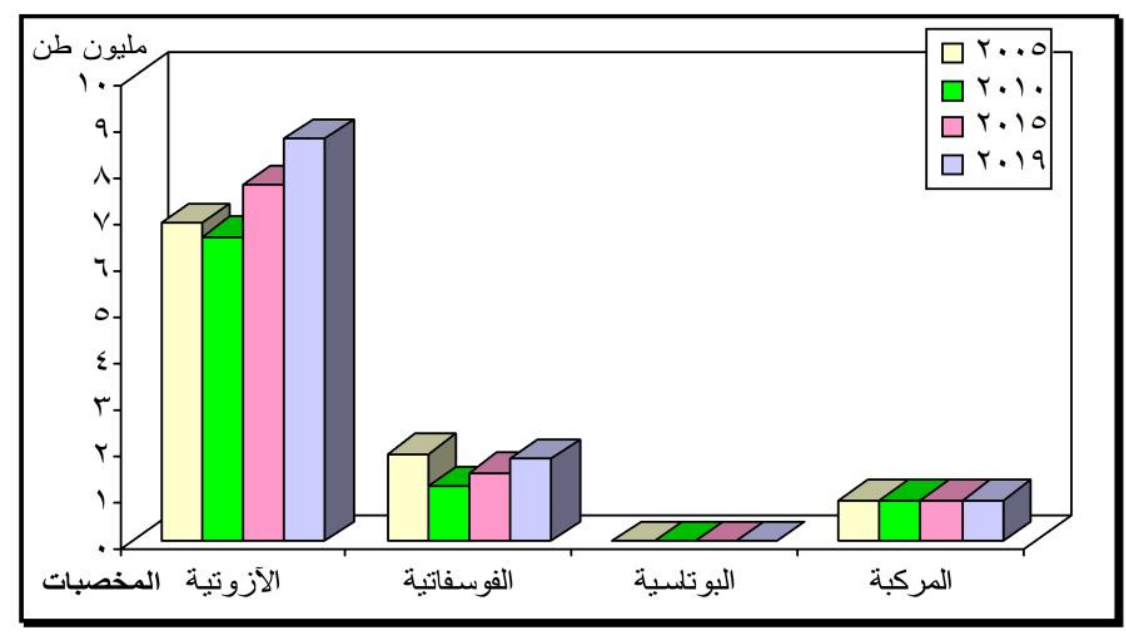

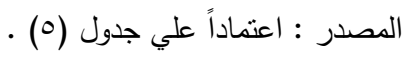

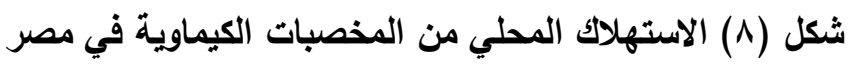

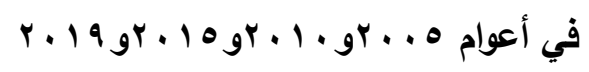

(المخصبات الكيماوية للمحاصيل الزراعية في مصر ...) د. أيمن عبد المطلب السعيد. 
وتتمثل المحاصيل المُهــة التي تُزرع بمصر في الأرز والقـح والقطن

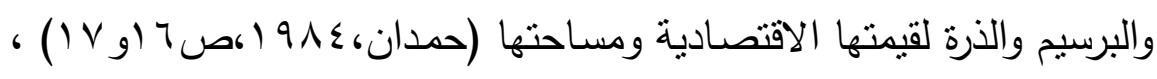

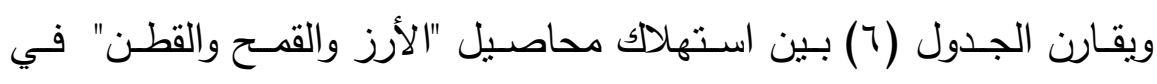

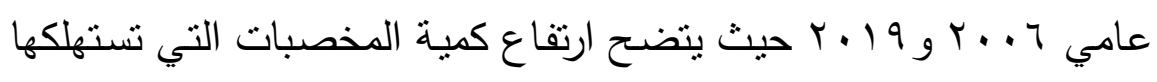

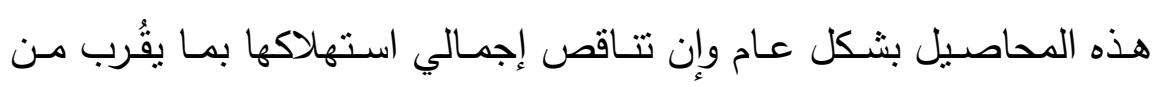

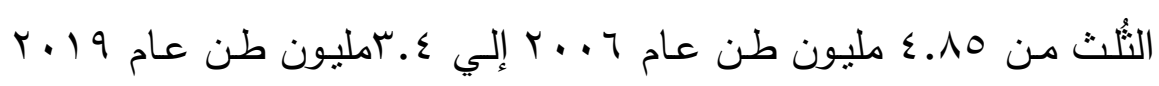
لتتاقص المساحات المنزرعة من الأرز والذي بستهلاك كميات كبيرة من المياه

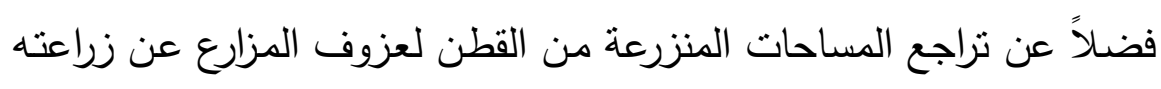

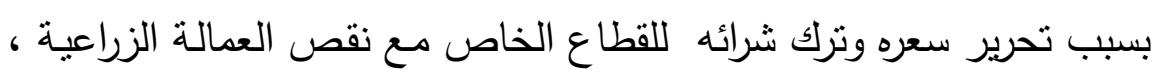

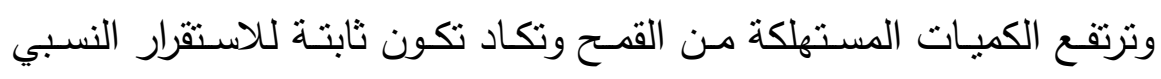

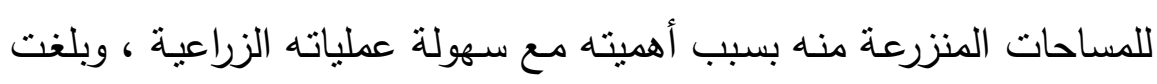

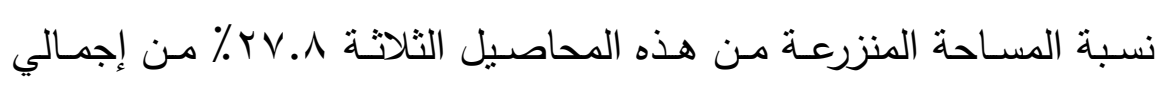

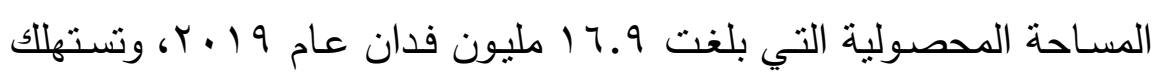

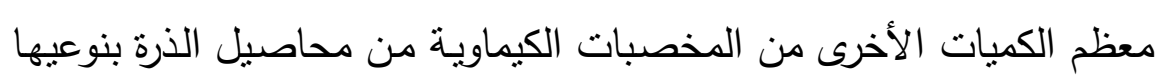

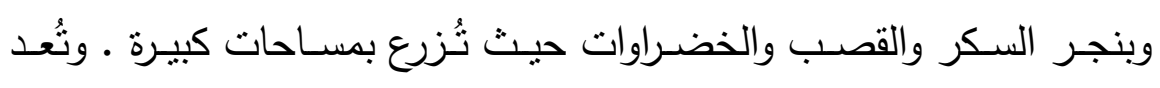

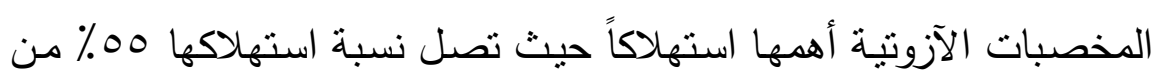

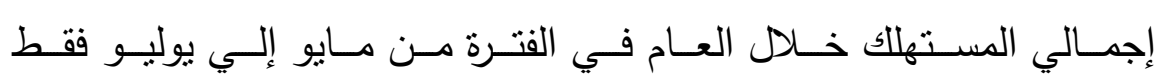

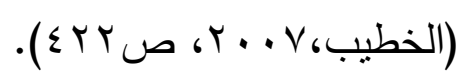

(المخصبات الكيماوية للمحاصيل الزراعية في مصر ...) د. أيمن عبد المطلب السعيد. 
جدول(7) استهلاك القمح والأرز والقطن للمخصبات الآزوتية والفوسفاتية في مصر

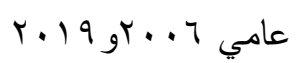

\begin{tabular}{|c|c|c|c|c|c|c|c|c|c|c|c|}
\hline \multirow{2}{*}{$\begin{array}{c}\text { التغييرل } \\
\text { \% }\end{array}$} & \multirow[b]{2}{*}{ إجمالي } & \multicolumn{3}{|c|}{ القطن } & \multicolumn{3}{|c|}{ القمح } & \multicolumn{3}{|c|}{ الأرز } & \multirow{2}{*}{ /لاليحصول/المخصبات } \\
\hline & & |جملة & |الفوسفاتية & |الآزوتية & جملة & |الفوسفاتية & |الآزوتية & جملة & |الفوسفاتية & الآزوتية & \\
\hline- & $\varepsilon . \wedge 0$ &.$\wedge$ &..$^{r}$ & $\because 0$ & r.V & $\because 1$ & $Y .7$ & $1 . r 0$ & $\because 0$ & $1 . r$ & $r \ldots q$ \\
\hline Y9.9- & r.\& & .10 & $\because .0$ & .1 & Y. & .1 & 1.0 & .70 & $\because .0$ &. .7 & $r .19$ \\
\hline
\end{tabular}

المصدر: اعتماداً علي: الجهاز المركزي للتعبئة العامة والإحصاء، المركز القومي للمعلومات، بيانات غير اله

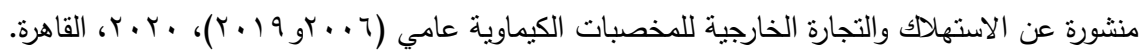

\section{ب - التجارة الخارجية التبنة}

يتأثز السـوق العـالمي للمخصـبات الكيماوبـة بالعديد مـن العوامـل التي

تحدد حجم الطلب عليهـا، ومنهـا الزبـادة السـكانية التي تؤدي إلي الطلب المتتامي علي الغذاء وارتفاع أسـار الحبوب في بعض السنوات لانخفاض الإنتاج نتيجة التغيرات المناخيـة ، وأهمية وجود مخزون مناسب منها بزيـادة

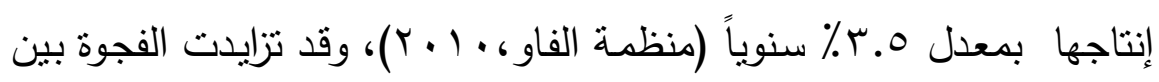
العرض والطلاب عالميـاً نتيجـة فرض الصـين ضـرائب علي صسادراتها مسن

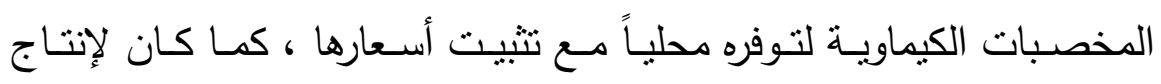
الوقود الحيوي بتخمير الحبوب أثره في نقص كميات الغذاء منها عالمياً مها أدي إلي الاتجـاه أكثر إلـي إنتاج المخصـبات الكيماوبـة ، وللمحافظـة علي البيئة في أوروبـا والولايـات المتحدة تم فرض فيـود علي صـناعتها وتحديــ الكميات المنتجة منها، حيث صنفت هذه الصناعة بأنها من أكثر الصناعات الملوثة للبيئة (السروي، 9 . . r،ص VT) ؛ وترتب علي ذلك زبادة صسادرات الثركات المنتجة لها في الدول النامية ومنها مصر •

(المخصبات الكيماوية للمحاصيل الزراعية في مصر ...) د. أيمن عبد المطلب السعيد. 
1- تطور حجم التجارة الخارجية للمخصبات الكيماوية : دخلت مصر مجـال التجـارة الخارجيـة للمخصبات الكيماويـة منذ أوائل القرن العشرين ، حيث استوردت كميات منها تتاقصت تدريجياً مع الاهتمام بهذه الصناعة وتحول مصر لدولة مصدرة في بداية الثمانينيات خاصـة من

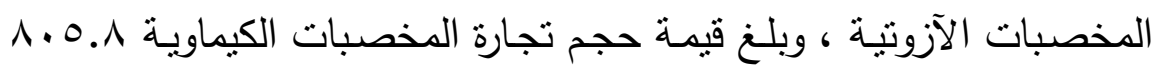

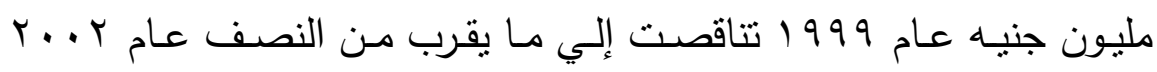
بسبب نراجع كميات الوارد منها ثم زادت أربعة أضعاف لتصل إلي مليون جنيـه عـام ^ . . r مـع زيـادة حجم الصـادرات بعد التوسـع في بنـاء مصـانعها، واتجهـت الصـادرات إلـي : فرنســا والولايـات المتحـدة واسـبانيا

والبرازيل، بينما كانت معظم الواردات من: فنلندا وبلجيكا والنرويج وفرنسا.

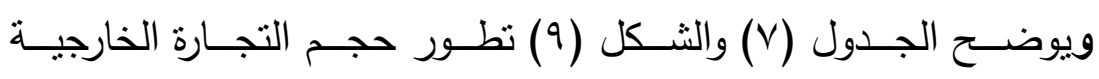
للمخصبات الكيماوية وقيمتها خلال الفترة • 1 ـ -9 1 ـ ب ونستتتج منهما ما بلي - بلغ المتوسط السنوي لصادرات مصر من المخصبات الكيماوية خـل هذه الفترة نحو 7 ـ مليون طن بقيمة ا.. . 1 مليار جنيه تقريباً.

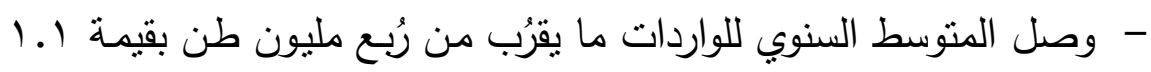
مليار جنيه، وعليه فالميزان التجاري لتجارتها في صالح هذه الصناعة. - تتسـم الكميـات الصـادرة منهـا والمستوردة بالتذبـب لكنها اتخذت اتجاهـاً عامـا نحو الزيـادة، ممـا يشبير إلي الاهنمـام المحلي بزيـادة الإنتاج لمواجهة الطلب المحلي والخارجي. (المخصبات الكيماوية للمحاصيل الزراعية في مصر ...) د. أيمن عبد المطلب السعيد. 


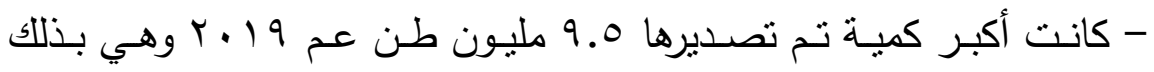
ضعف الكمية التي تم تصديرها من عشرة أعوام ، بينما بلغت أكبر كمية من

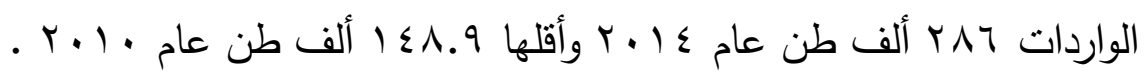

جدول(V) تطور حجم التجارة الخارجية للمخصبات الكيماوية وقيمتها في

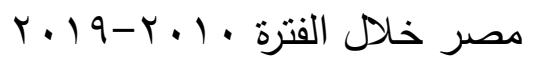

الوحدة : ألف طن ، والقيمة : مليون جنيه

\begin{tabular}{|c|c|c|c|c|c|c|c|c|}
\hline \multicolumn{2}{|c|}{ الميزان التجاري } & \multicolumn{3}{|c|}{ الواردات } & \multicolumn{3}{|c|}{ الصادرات } & \multirow[t]{2}{*}{ / بيان } \\
\hline التغيير \% & قيمة & قيمة & التغيير. & كمية & قيمة & التغيير. & كمية & \\
\hline- & 7111 & $7 \leqslant 1$ & - & $1 \leqslant \wedge .9$ & TVOY & - & $\{790.9$ & $r \cdot 1$. \\
\hline 19.9 & VTYA & $9 \cdot \varepsilon$ & TY.Y & $r \leqslant 1.0$ & AYrr & r.o- & OrI.r & $r+11$ \\
\hline$\varepsilon \theta_{-}$ & $v \ldots 1$ & $\Lambda q \mu$ & $\varepsilon . r_{-}$ & rMI.r & V^१ & $1.9-$ & $\leqslant \leqslant \leqslant 0$ & $r .1 Y$ \\
\hline $9 . \xi$ & จ74 & 901 & Ir & roq & ATIY & 9.5 & \&人ฯY & $r .1 T$ \\
\hline $9 . \mathrm{V}$ & $\Lambda \varepsilon \cdot 7$ & 994 & $1 \cdot . \varepsilon$ & rAT & Qrrर & 9.0 & OrY & $Y \cdot 1 \varepsilon$ \\
\hline$V . r$ & 9.10 & QVY & $10_{0} 0_{-}$ & rrT & q१^V & 19.1 & T & $r .10$ \\
\hline. .1 & $q . Y V$ & $99 \leqslant$ & 1. & r०५.r & $1 \ldots r \mid$ & $1 V_{0} 0$ & $V \leqslant O Y$ & $r .17$ \\
\hline $0 . . Y$ & $1 \leqslant .9 V$ & 1940 & $\cdot .9-$ & Yos & lOVTr & 10 & 1079 & $r . I V$ \\
\hline 1.7 & $1 \leqslant Y Y Y$ & $17 \Lambda$. & 7.0 & $r v \cdot .0$ & $19 \ldots r$ & $\varepsilon . r$ & 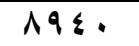 & $r .11$ \\
\hline $1 . r$ & $1 \leqslant 01$. & 10rr &. .9 & rVT & $17 . \leqslant \%$ & $7 . r$ & $90 \ldots$ & $r .19$ \\
\hline & $9 \vee \leqslant V . \wedge$ & 1119.0 & & $r \leqslant 0 . r$ & $1 . \wedge 7 \cdot . r$ & & $7 \leq 74.1$ & المتوسط \\
\hline
\end{tabular}

المصدر : اعتمادا علي بيانات: الجهاز المركزي للتعبئة العامة والإحصاء، بيانات غير منشورة عن التجارة

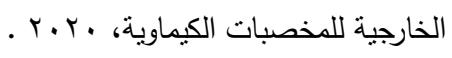

(المخصبات الكيماوية للمحاصيل الزراعية في مصر ...) د. أيمن عبد المطلب السعيد. 


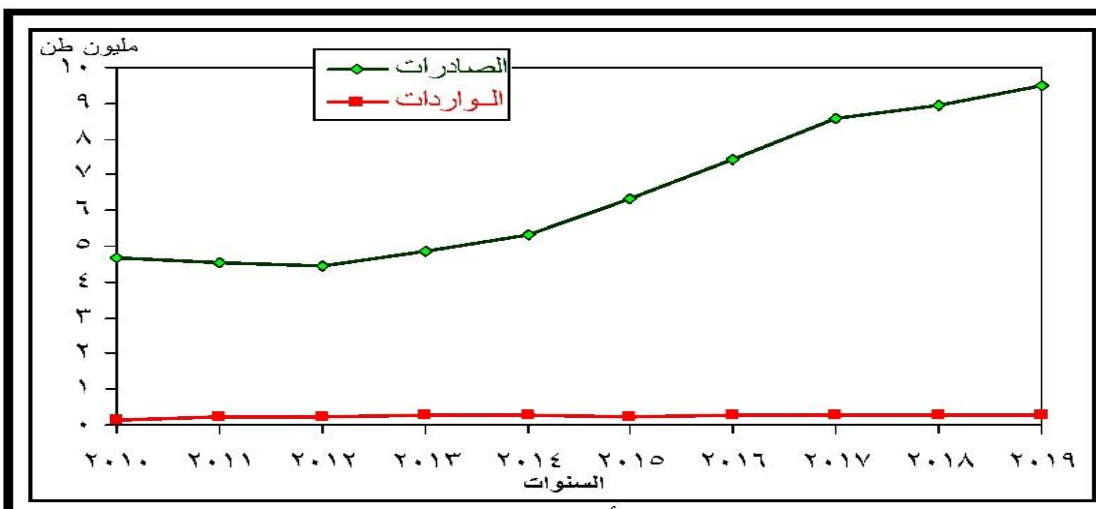
ألكمية (i)
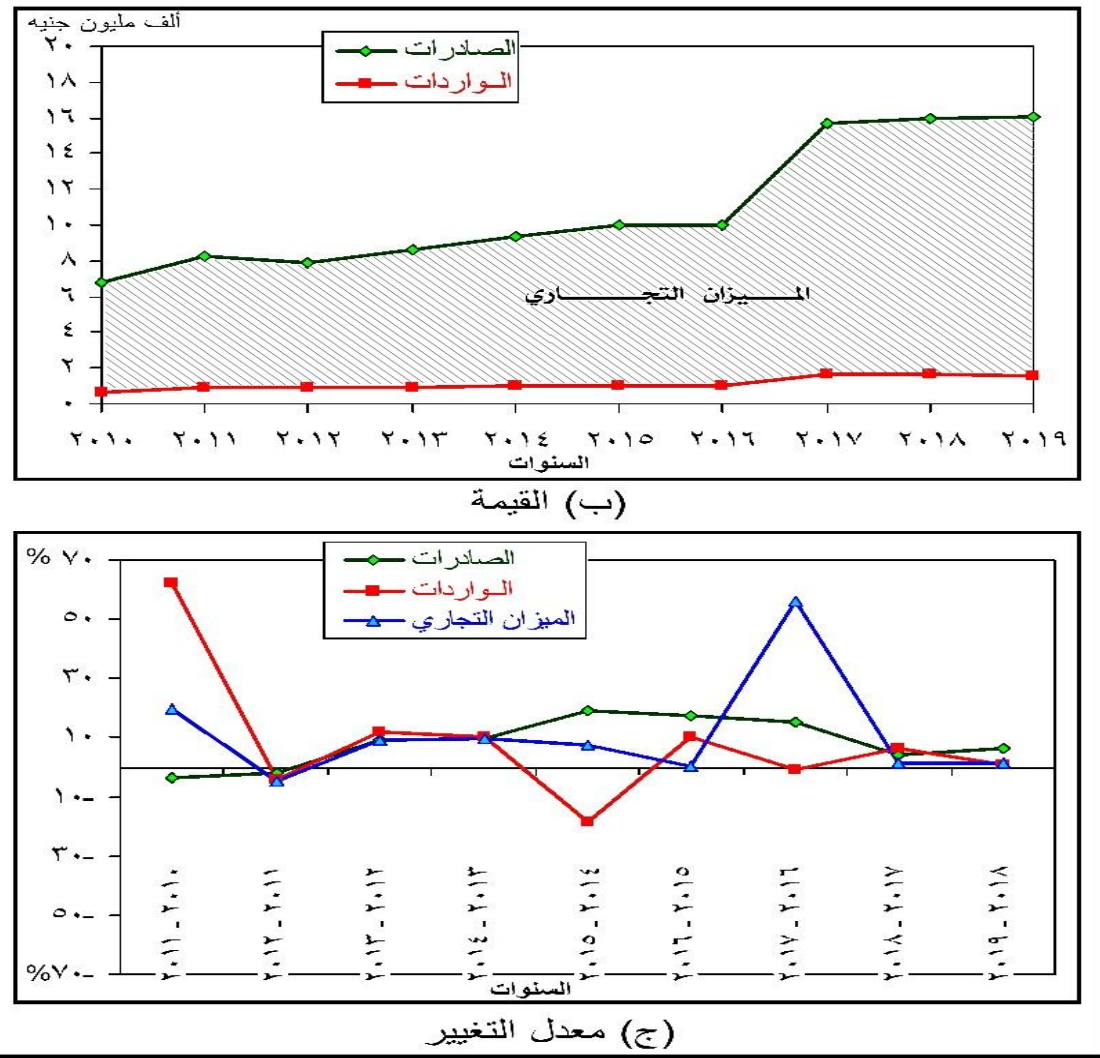

المصدر : اعتمادا علي جدول(V). (اعلم)

شكل(9) تطور حجم التجارة الخارجية للمخصبات الكيماوية وقيمتها في مصر خلال

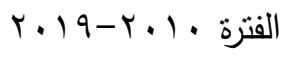

(المخصبات الكيماوية للمحاصيل الزر اعية في مصر ...) د. أيمن عبد المطلب السعيد. 
r- التوزيع الجغرافي لتجارة مصر الخارجية من المخصبات الكيماوية: نستتنج من الجدول (^) والثنكل (• () التوزيع الجغرافي لتجارة مصر الخارجية من المخصبات الكيماوية عام 9 . r، حيث يتبين اتجاهاتها كما يلي:

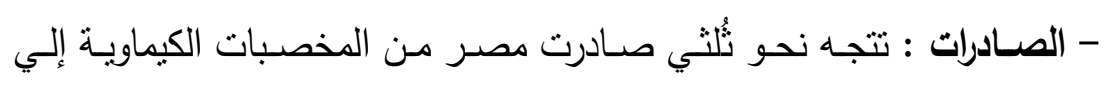

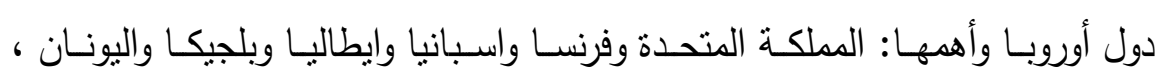
وتليها أمريكا الثـمالية بنسبة س.ب ا ٪ مـن إجمالي الصـادرات إلي الولايـات المتحدة وكندا ، ثم أمريكا اللاتينية بنحو العُشر إلي البرازيل والمكسيك وأورجواي والأرجنتين

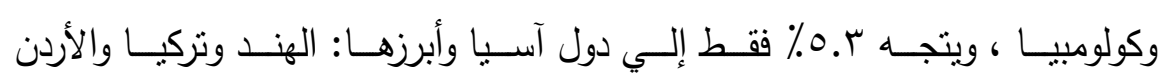

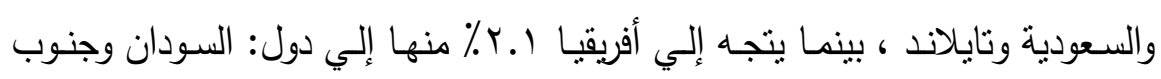
أفريقيا والجزائر وموريشـيوس وكينيا والمغرب وأوغنـدا واريتريـا ، واتجـه إلي استراليا ع. • ٪ فقط من إجمالي الصـادرات . وصدرت مصر المخصبات الكيماويـة "الآزوتية

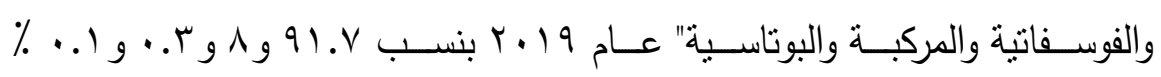
بالترتيب.

- الواردات : اتجهت مصر نحو أوروبـا لشراء r. YV\% من اجمالي وارداتها من المخصبات الكيماويـة من النرويج واسبانيا وفرنسا وألمانيا وأوكرانيا وايطاليا وبلجيكا وروسـيا ، بينمـا اسـتوردت نحـو الخُمس مـن دول آسـيا وهـي نركيـا والأردن وكوريـا الجنوبية وتايوان والصين والإمارات والهند وسنغافورة ، وجاء 1 . • ٪ من وارداتها من

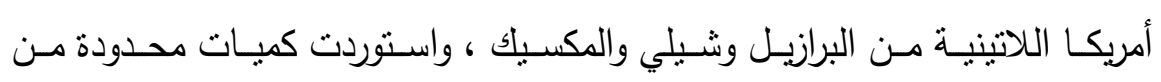
أمريكا الثمالية وأفريقيا واستراليا.

واسـتوردت مصـر الأنـواع المختلفــة مـن المخصـبات الكيماويـة "الآزوتيـة والبوتاسـية

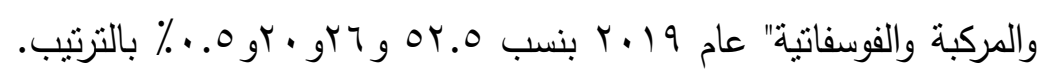

(المخصبات الكيماوية للمحاصيل الزراعية في مصر ...) د. أيمن عبد المطلب السعيد. 
جدول (^) التوزيع الجغرافي لتجارة مصر الخارجية من المخصبات الكيماوية عام 19 ـ ץ الوحدة : ألف طن ، والقيمة : مليون جنيه

\begin{tabular}{|c|c|c|c|c|c|c|}
\hline \multicolumn{3}{|c|}{ الواردات } & \multicolumn{3}{|c|}{ الصادرات } & \\
\hline قيمة & $\%$ & كمية & قيمة & $\%$ & كمية & \\
\hline $11 \wedge \varepsilon$ & $V V . T$ & 411 & $1 . .97$ & 79.1 & $70 \mathrm{VI}$ & أوروبا \\
\hline $1 \cdot .1$ & $\because V$ & 1.1 & 1907.7 & IT.T & $11 \mathrm{VT}$ & أمريكا الشمالية \\
\hline $11 . \mathrm{V}$ &.$\wedge$ & Y. & $179 \leqslant . V$ & $1 \cdot . v$ & 1.17 & أمريكا اللاتنينية \\
\hline TIE.T & $r \cdot .0$ & 07 & $19 . r$ & $0 . r$ & $0 . \varepsilon$ & آسيا \\
\hline 0.9 &.$\varepsilon$ & 1.1 & TY^.T & Y. & $19 V$ & أفريقيا \\
\hline r.o & $\cdot r$ & $\cdot .9$ & 70.1 &.$\varepsilon$ & rq & استر اليا \\
\hline 10Tr & $1 \cdots$ & $r V T$ & $17 \cdot \leq r$ & $1 \cdots$ & $90 \ldots$ & إجمالي \\
\hline
\end{tabular}

المصدر : اعتمادا علي بيانات الجهاز المركزي للتعبئة العامة والإحصاء، بيانات غير منشورة عن اتجاهات

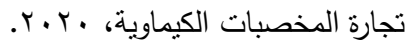

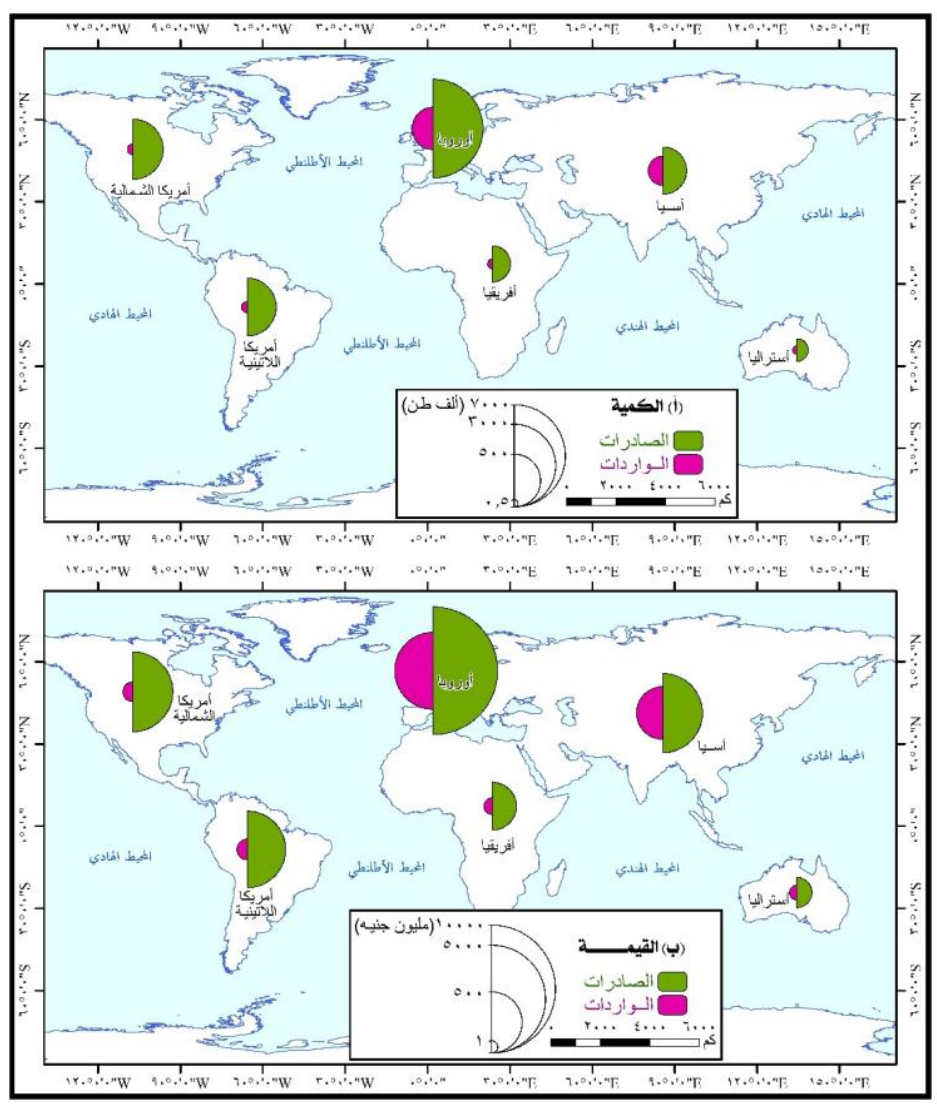

المصدر : اعتمادا على جدول(^).

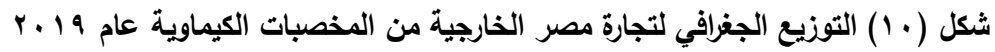

(المخصبات الكيماوية للمحاصيل الزراعية في مصر ...) د. أيمن عبد المطلب السعيد. 
ج- المشكلات التي تواجه المخصبات الكيماوية وكيفية مواجهاتها:

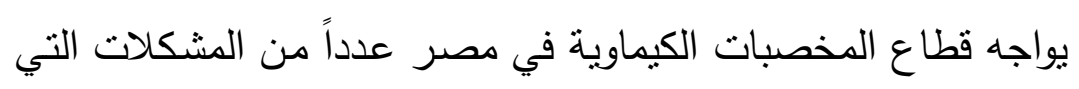

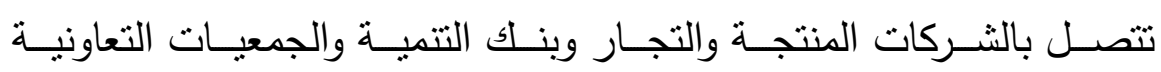
والززارعون، كالتالي : - الثـركات المنتجـة : نواجـه ارتفاع تكلفة الإنتاج بعد زيـادة أسعار الغـاز

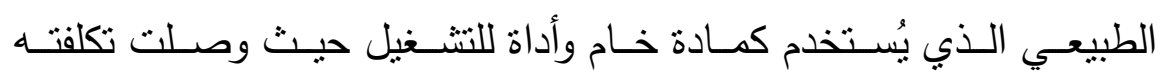

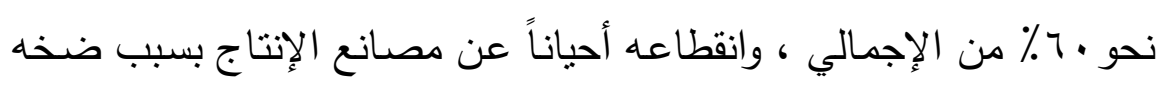

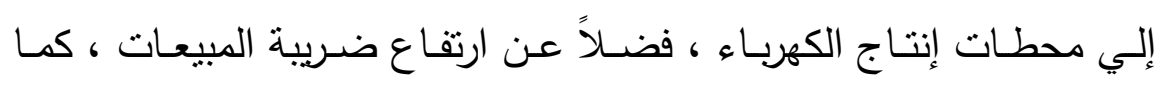
تعاني بعض الثركات من صعوبة تخزين إنتاجها لانخفاض طاقتها التخزينية بسبب ثبات كميـة الإنتاج وموسمية الطلب ، كمـا أن هنـاك شـركات تتنتج بطاقة أقل من طاقتها التصميمية. - التجار : يضطر التجار إلي استلام حصص شـهرية مـن الإنتاج رغم موسمية الطلب وبالثالي يواجهون مشكلة في التخزين •

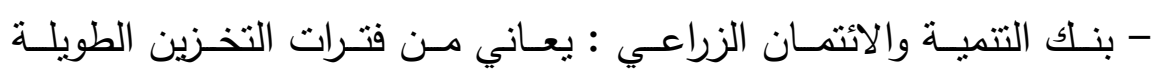

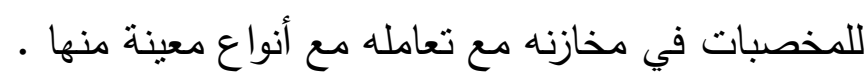

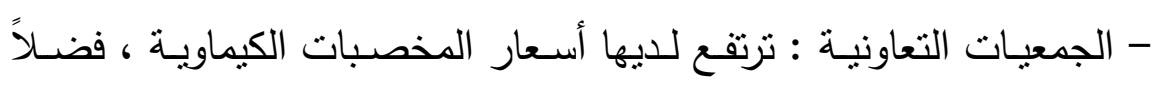
عن نقص في عدد من الأنواع المُهمة لديها ، وقدرتها التمويلية المحدودة

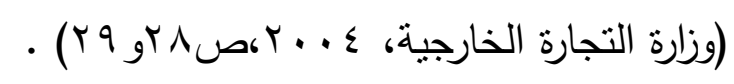

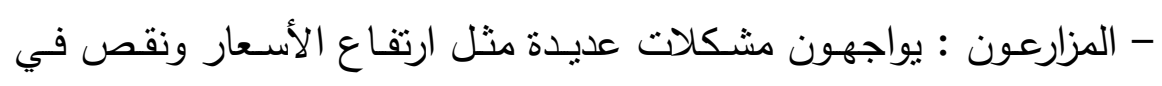
الكميات المتاحسة ، وعدم البيع بالأجل من قبل التعاونيات ، وقلـة الكميات (المخصبات الكيماوية للمحاصيل الزراعبة في مصر ...) د. أيمن عبد المطلب السعيد. 
المخصصة للفدان ، مع وجود السوق السوداء فضلاً عن تراجع دور الإرشاد

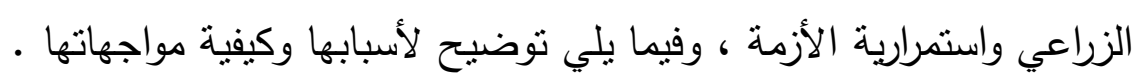

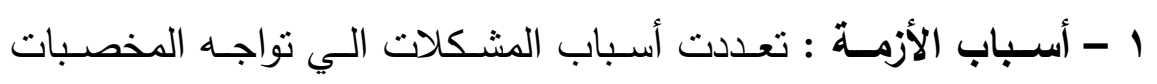
الكيماويـة في مصر وتتبين من الجدول (9) الذي يوضـح أراء أفراد العينة كما يلي : - العجز بين العرض والطلب في السوق المحلي : بصل العجز بين المطروح من المخصبات الكيماوية والمطلوب حوالي ^ــ المليون طن سنوياً أي نحو 0.1 ٪ من إجمالي الاستهلاك رغم أن مصر تحقق فائضاً سنوياً في الإنتاج يصل إلي 9.7 مليون طن ، ويتركز العجز في المخصبات

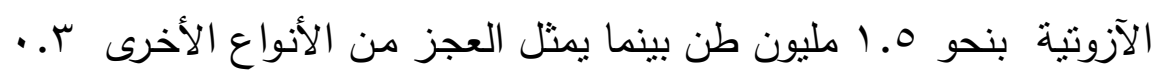

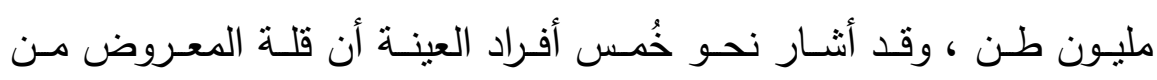

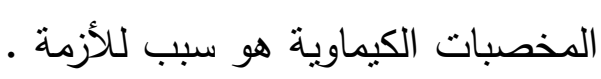

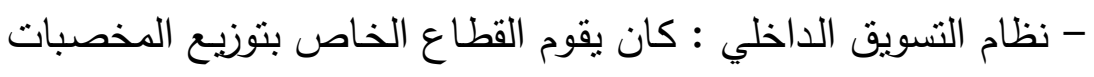

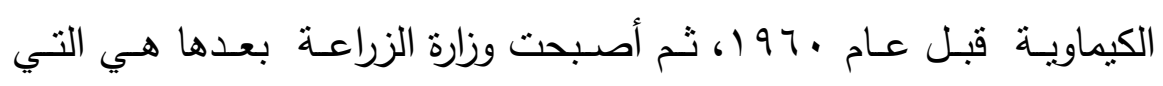
تتشرف علي التوزيع من خـال بنك التتمية والايتمان الزراعي ، والجمعيات

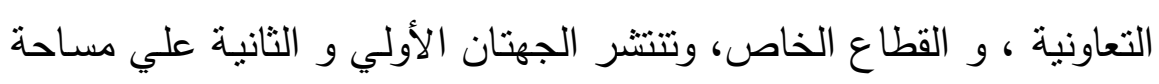

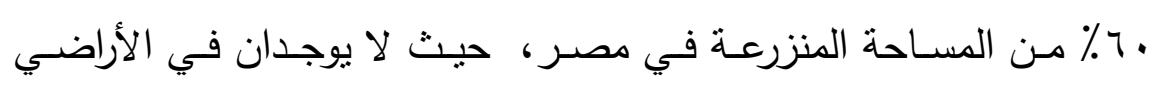

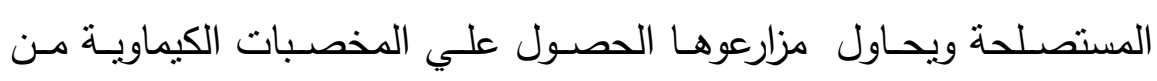

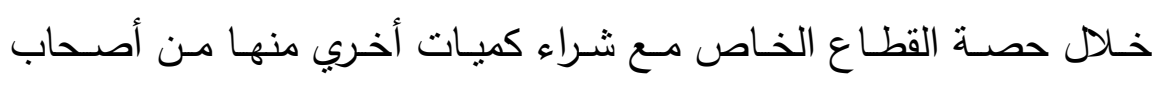
الأراضي المؤجرة ، مع استيعاب الكميات المستوردة ـ وقد كانت التعاونيات (المخصبات الكيماوية للمحاصيل الزراعية في مصر ....) د. أيمن عبد المطلب السعيد. 
بمفردها هي من تقوم بالتوزيع لفترات طويلـة دون أزمات ، لكن مـع نهايـة

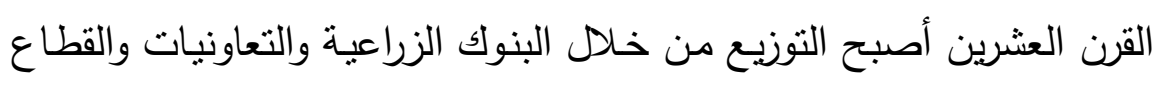

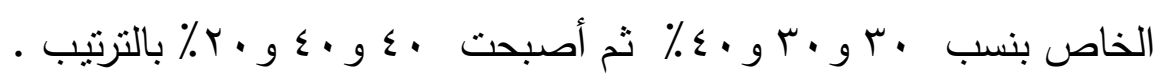

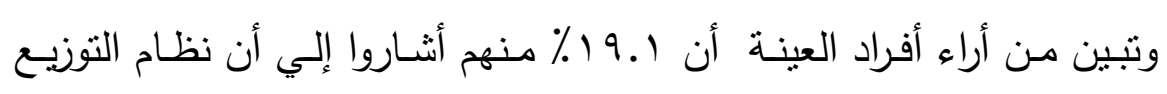

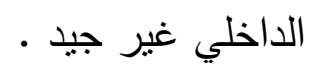
- نظام الحيازات الزراعية : جاء وضيع الحيازات الزراعية في الترتيب

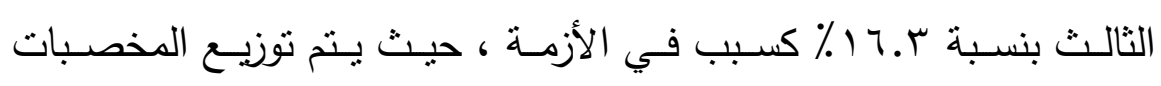

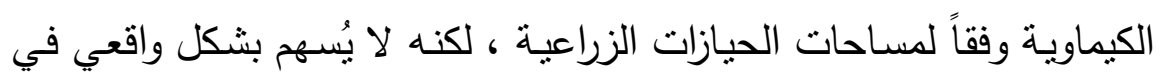

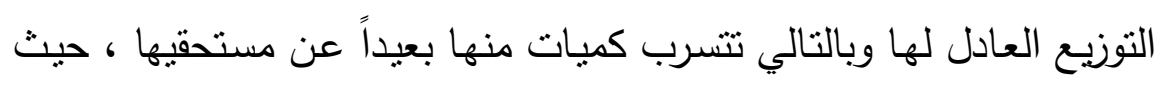

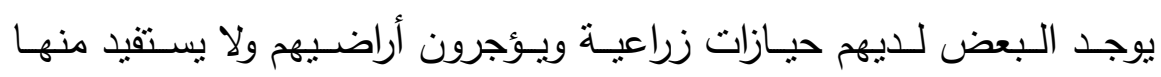

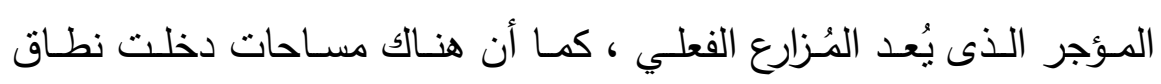
الحيز العمراني ولها حيازات زراعية . - الإرشاد الزراعي : أثـار 0.0 1 من أفراد العينة أنه لم يعُد للإرشـاد

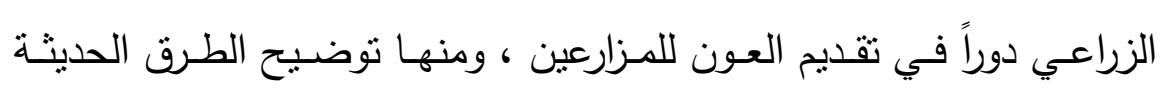

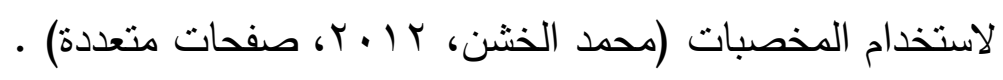

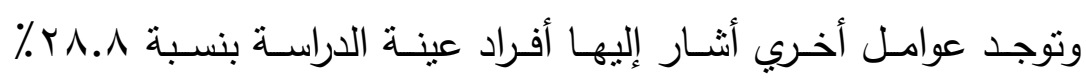

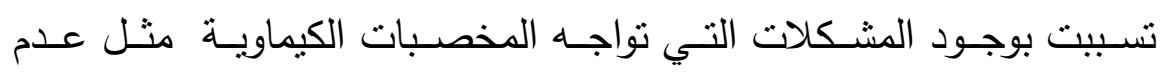

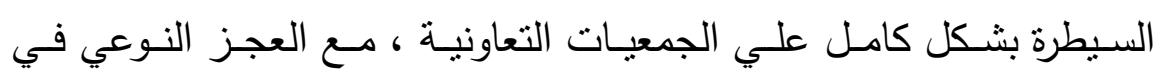
المخصبات الكيماوية نتيجة التقدير الخاطئ في حصر المسـاحات المزروعة

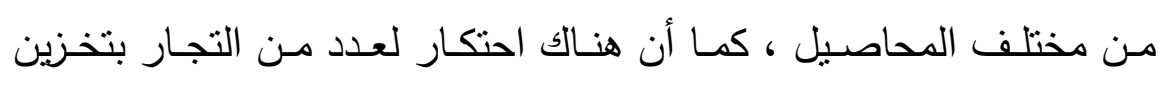
(المخصبات الكيماوية للمحاصيل الزراعية في مصر ...) د. أيمن عبد المطلب السعيد. 
بعض الكميـات ، ولا تلتزم بعض شـركات القطـاع الخـاص بتسليم حصـتها الكاملة المخصصة للسوق المحلي رغم المزايا التي تحصل عليها كالحصول علي الطاقـة والميـاه والكهربـاء والمـواد الخـام بأسـعار مخفضــة فضـلاً علي لـي تخفيض الجمارك علي المدخلات المستوردة لصناعتها، والتعامل ببطء مـع

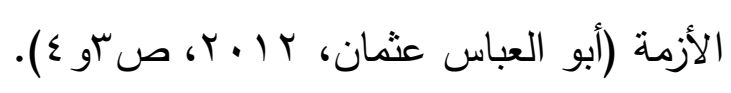

جدول(9) أسباب المشكلات التي نواجه المخصبات الكيماوية لأفراد العينة في مصر

\begin{tabular}{|c|c|c|}
\hline$\%$ & 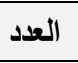 & الأسباب \\
\hline$r \cdot r$ & $1 \cdot r$ & العجز بين العرض والطلب في السوق المحلي \\
\hline 19.1 & $9 v$ & نظام التسويق الاخلي \\
\hline $17 . r$ & $\wedge r$ & نظام الحيازات الزراعية \\
\hline 10.0 & $v 9$ & الإششاد الزراعي \\
\hline$r \wedge . \wedge$ & $1 \leqslant V$ & أخري \\
\hline $1 \cdots$ & 0.9 & الإجمـالي \\
\hline
\end{tabular}

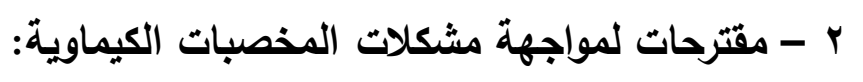

يمكن التعامل مع المشكلات التي تواجه المخصبات الكيماوية في مصر

خاصة مشكلة العجز في الكميات المعروضة منها بالسوق المحلي من خلال أراء أفراد عينة الدراسة كما يوضحها جدول (• ( ) كما يلي: - جاءت أهميـة استمرار حصـول الثـركات علي الخامات اللازمـة لصناعة المخصـبات بسـعر مـنخفض، مــع تخفـيض الجمــارك علـي مسـتلزماتها المستوردة في الترتيب الأول لدي أفراد العينة بحوالي التُلث.

(المخصبات الكيماوية للمحاصيل الزر اعية في مصر ...) د. أيمن عبد المطلب السعيد. 
- وتـأتي تتقيـة الحيـازات الزراعيـة لتشـمل الأراضـي المنزرعـة فعـلاً ، مـع ضمان وصول المخصبات للمزارع الفعلي في الترتيب الثاني بنحو الخُمس • - يُعد حصـول وزارة الزراعـة علي حصـتها كاملـة مـن الإنتاج المحلي مـن المخصبات الزراعية من المقترحات المُهمة لحل الأزمة وجاءت في التزتيب

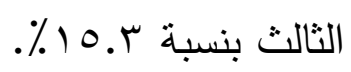
- الاتجــاه نحــو ضــمان وصــول المخصـبات الكيماويـة لمـلاكَ الأراضـي المستصـلحة مـن خـلال الحيـازات الزراعيـة ومتلـت ب. با ٪ مـن أراء أفـراد العينة . ووجدت مقترحات أخري بنسبة 9.0 1\% أشـارت إلي عودة نظام البيع بالأجـل ، وتوفير الأنـواع الرئيسية التي تحتاجهـا التربـة المصـرية ، وزيـادة حصـة الفدان من المخصبات ، والقيام بمحاولات لضبط سوق المخصبات

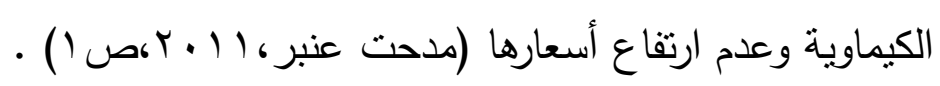

جدول(• (1) مقترحات أفراد العينة لمواجهة مشكلات المخصبات الكيماوية

\begin{tabular}{|c|c|c|}
\hline$\%$ & العدد & المقترحات \\
\hline \multirow[t]{2}{*}{ r..r } & \multirow[t]{2}{*}{109} & حصول الشركات علي الخامات اللازمة لصناعة الدخصبات بسع منخفض، مع تخفيض \\
\hline & & الجمارك علي مستلزماتها المستوردة \\
\hline$r \cdot . \wedge$ & 1.7 & تنقية الحيازات الزراعية لتشمل الأراضي المنزرعة فعلاً، مع ضمان وصوله المخصبات للمزارع \\
\hline & & الفعلي. \\
\hline $10 . r$ & $\vee \wedge$ & حصول وزارة الزراعة علي حصتها كاملة من الإنتاج المحلي من المخصبات الزراعية. \\
\hline Ir.r & iv & ضمان وصول المخصبات الكيماوية لملاك الأراضي المستصلحة من خلال الحيازات الزراعية \\
\hline 19.0 & 99 & أخري \\
\hline $1 \ldots$ & 0.9 & الإجمـالي \\
\hline
\end{tabular}

المصدر : نتائج الاستيان ، فبراير ·r.r.†.

(المخصبات الكيماوية للمحاصيل الزراعية في مصر ...) د. أيمن عبد المطلب السعيد. 
سادساً: الإطار التطبيقي (مصنع دمياط) : يقع مصنع المخصبات الآزوتية بدمياط داخل المنطقة الصناعية الحرة

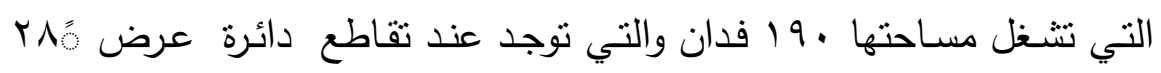

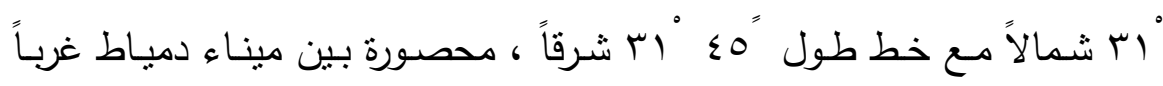

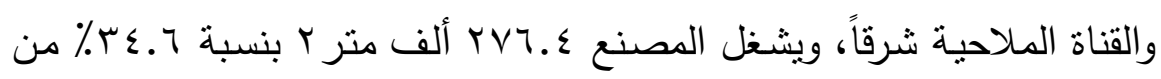
مساحتها بمنتصفها شكل (1) (1)، وترتبط المنطقة الصناعية بالداخل من خلال عدة طرق ومنها الطريق الدولي الساحلي الذي يصلها بمحافظات ساحل البحر

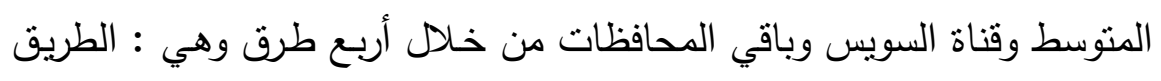

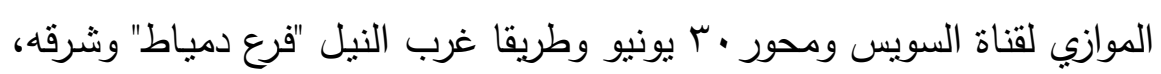

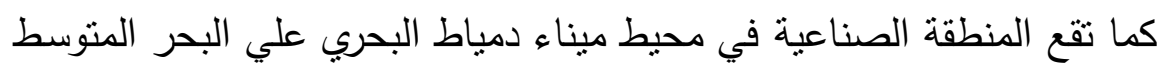

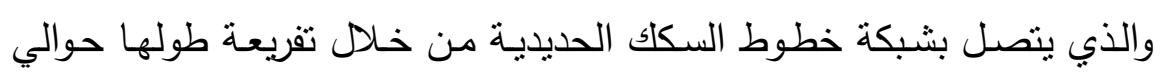
•

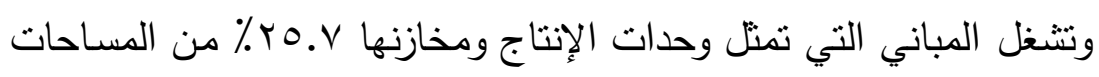

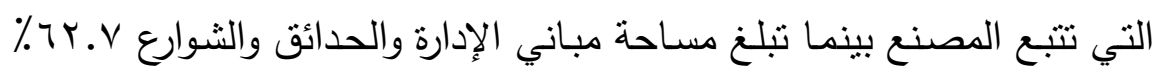

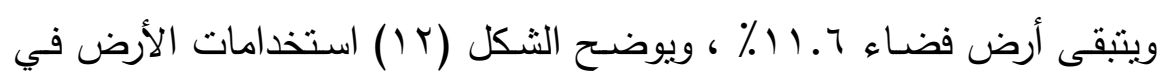

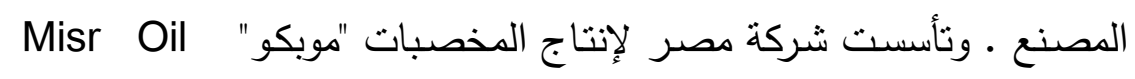
Processing and Fertilizers Company

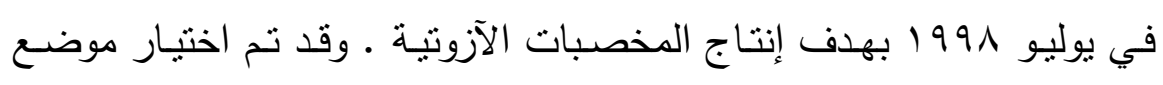

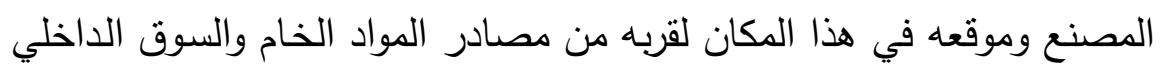

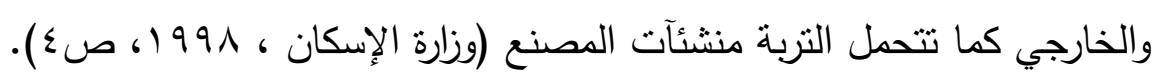

(المخصبات الكيماوية للمحاصيل الزراعية في مصر ...) د. أيمن عبد المطلب السعيد. 


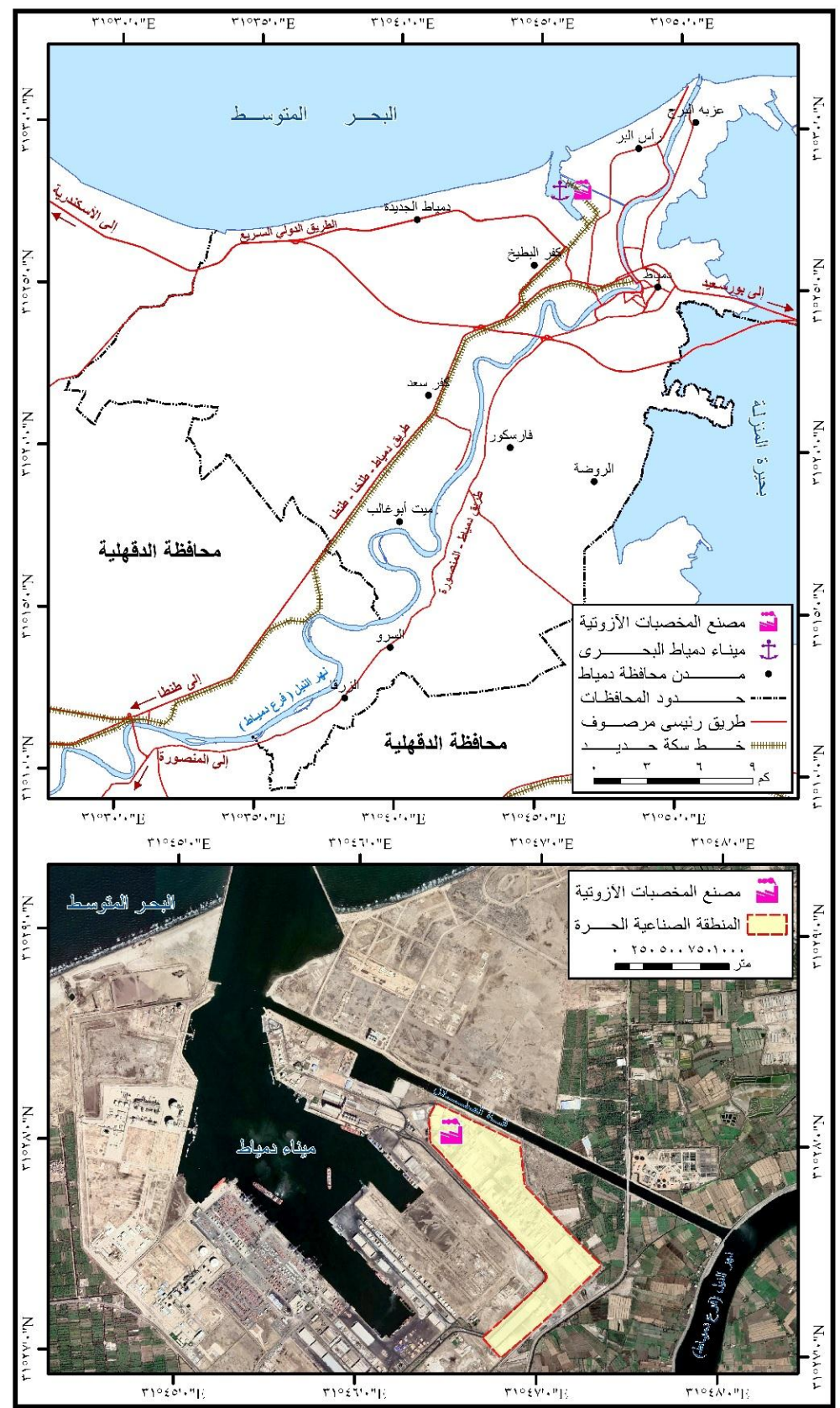

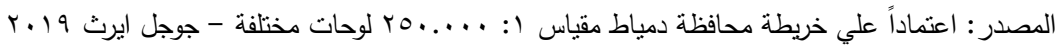
شكل (1) موقع مصنع المخصبات الآزوتية بدمباط

(المخصبات الكيماوية للمحاصيل الزراعية في مصر ...) د. أيمن عبد المطلب السعيد. 


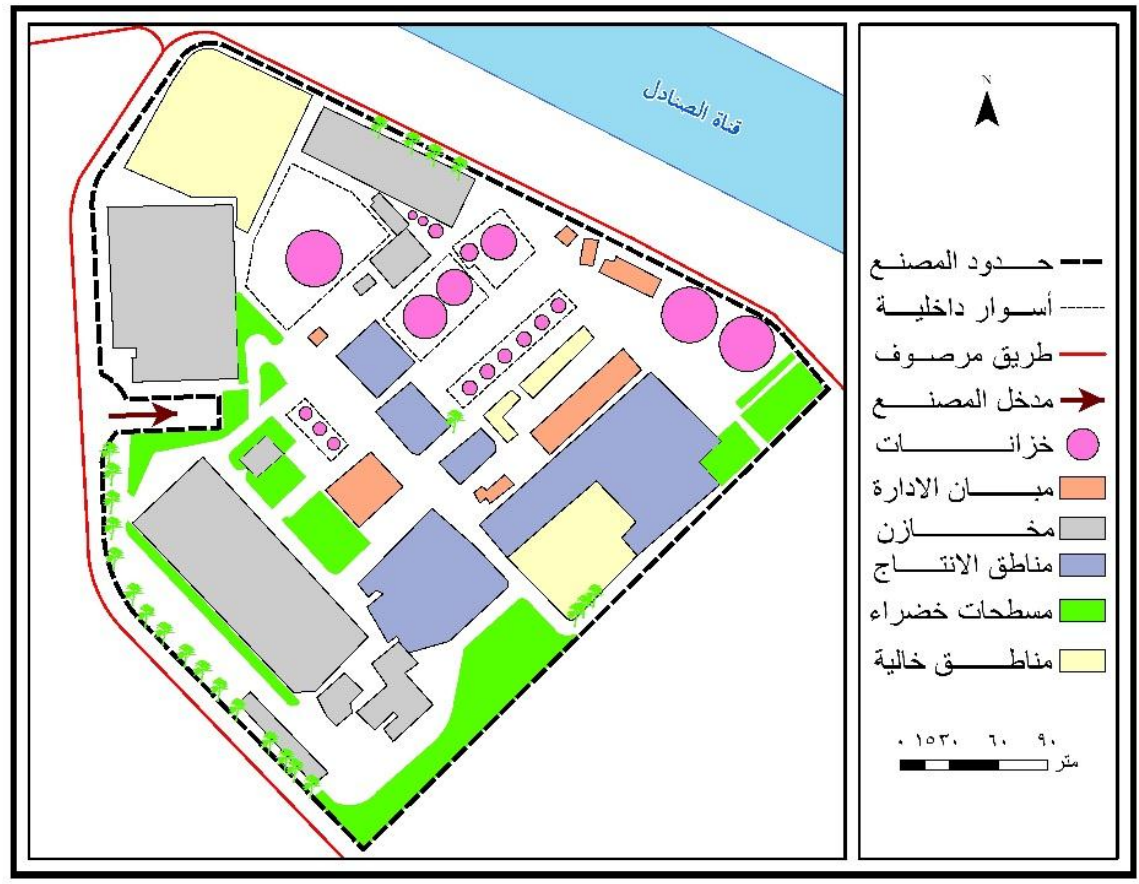

المصدر : اعتماداً علي: شركة مصر لإنتاج الأسمدة الكيماوية، بيانات غير منشورة عن مكونات المصنع،

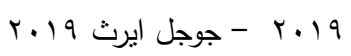

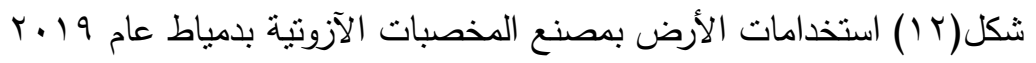

\section{أ - مقومات الصناعة :}

تقوم الصـناعة عندما تتوافر مقوماتها بشكل كلي أو شبه كلي، وبتسم كل إقليم بعوامـل جذب خاصـة بـه لتحدد نـوع وحجم ومسـتوي وخصـائص الصـناعة (الصـقار ، ، 91 (، ص 07) ، وبتطبيـق ذلك علي مصـنع دميـاط لصناعة المخصبات الآزوتبـة نجد أن مقومات إنشـائه متوفرة في موقعه أو بالقرب منه ، وهو ما بتضح من خلال عرضها كما يلي:

(المخصبات الكيماوية للمحاصيل الزر اعية في مصر ...) د. أيمن عبد المطلب السعيد. 
1- المـواد الخـام : تؤئز الخامـات في قيام صـناعة المخصبات الكيماويـة، وعليه من الأهمية دراسـة أنواعها وكمياتها المتوفرة وتوطنها بالنسبة لموقع

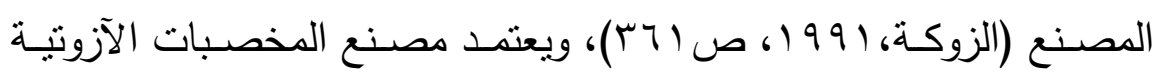
بدمياط على عدداً من المواد الخام في مقدمتها الغاز الطبيعي الذي يستخدم لاستخلاص الهيدروجين منه والذي يُعد أحد الخامات المُهمة التي تدخل في صناعة الآزوت ، ويحصل المصنع عليه من خلال خط أنابيب يمتد من حقول الوسطاني بشـمال الدلتا إلي الغرب منـه ، وبـدأ ضـخ الغـاز الطبيعي للمصنـع بحوالي مب ألف طن متري فقط في بدايـة التشـغيل عام 1991 ليتضاعف في العام الذي تلاه ثم أصبح يضنخ إليه حالياً حوالي 9 هـ مليون

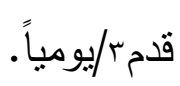

ويوضـح الجدول (1) كميات الغـاز الطبيعي التي يستهلكها المصنع سنوياً من خلال الفترة . . r-9 1 ـ r، وتبين أن استهلاكه أخذ في الارتفاع تدريجياً مع زيادة الخطوط الإنتاجية الجديدة إلي أن بلـغ خلال الخمسة أعوام الأخيرة وq ألف طن متري، وقد توقف إمداد المصنع بالغـاز خـلال فترة

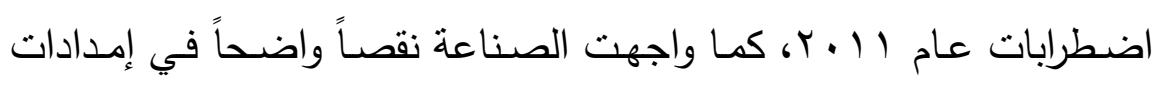
الغـاز الطبيعـي منـذ عـام r| ب بــبـ تراجـع إنتاجـه بشـكل كبيـر قبـل الاكتشافات الجديدة مما أثر علي حصة المصنع منه . ووفقاً لتعاقـدات المصـنع مـع الثـركة المصـرية القابضــة للغــازات فـإن المصنع تصل إليه المليون وحدة حرارية بسعر أقل بين شركات المخصبات الأخرى حيث تمثنل ^.ب دولاز ، وقد يتغير الأمـر في حالة إصـدار قانون (المخصبات الكيماوية للمحاصيل الزراعية في مصر ...) د. أيمن عبد المطلب السعيد. 
تسعير الغاز الذي يعتمد علي قوي العرض والطلب بدلاً من السعر الثابت

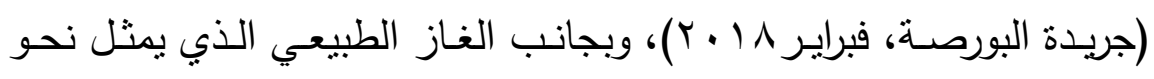
• . . من الخامات التي تعتمد عليها صناعة الآزوت ، يتم الحصول أيضـاً علي الهواء الجوي لإنتاج النيتروجين الذي يـخل في صـناعة الأمونيـا ، بالإضافة إلي المياه ، والنفتا ، والفيول ، والفحم كخامات مساعدة ، ولذلك يتم تأمين الحصول علي هذه المواد الأولية من خـلال تتسيق عقود طويلة

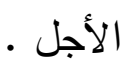
جدول (1) منوسط كميات الغاز الطبيعي المُستهلكة بمصنع دمياط لصناعة المخصبات

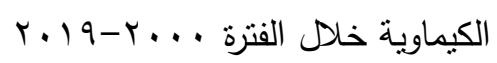

\begin{tabular}{|c|c|c|}
\hline معدل التغيير \% & الكمية & عام \\
\hline - & 100 & $r \ldots \varepsilon_{-} T_{\ldots}$ \\
\hline $0 . Y$ & $17 \pi$ & $r_{\ldots} . q_{-} r_{\ldots o}$ \\
\hline 17. 0 & $r \cdot \varepsilon$ & $T_{0}\left|\varepsilon_{-} r_{0}\right|$. \\
\hline$r \cdot .7$ & rqv & $r .19-r .10$ \\
\hline
\end{tabular}

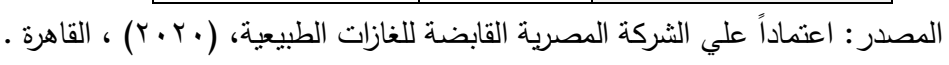

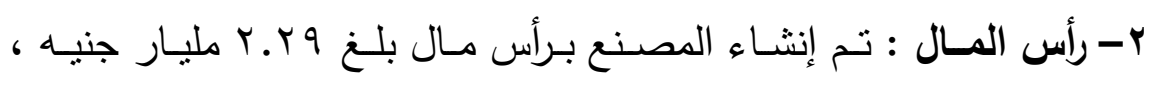
وسـاهم في توفيره جهات مختلفة يوضـحها الجدول (Y I) وتتمثل في هيئة البترول وشركات التأمين والبنوك المصرية وعدداً من المستثمرين المصريين

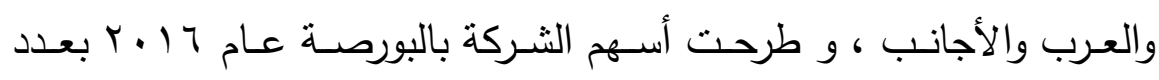
q و مليون سهم وتوزعت نسبتها بالترتيب علي : الثركة المصرية القابضـة

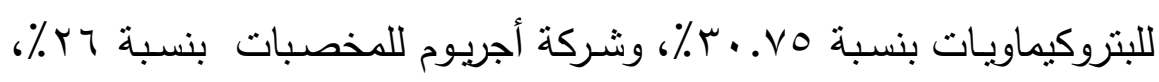

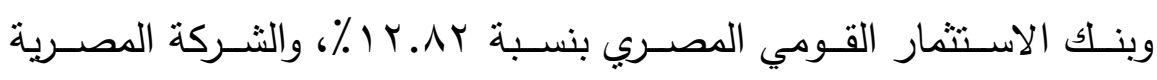

(المخصبات الكيماوية للمحاصيل الزراعية في مصر ...) د. أيمن عبد المطلب السعيد. 


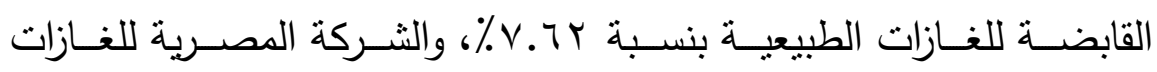

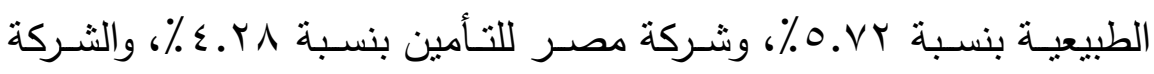
العربية للاستثمارات البترولية بنسبة ץ. .؟٪، وبنك ناصر الاجتماعي بنسبة

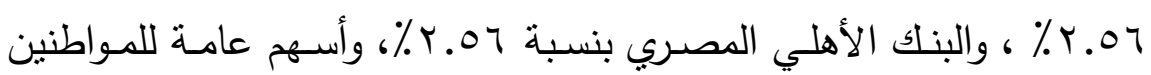

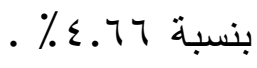

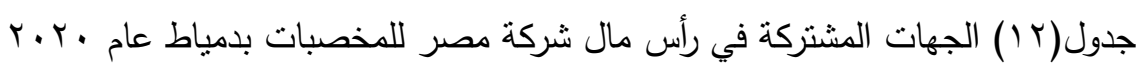

\begin{tabular}{|c|c|}
\hline$\%$ & الجهة \\
\hline$r . v_{0}$ & الثركة المصرية القابضة للبتروكيماويات \\
\hline rq & شركة أجريوم للأسمدة \\
\hline Ir.Ar & بنك الاستثمار القومي المصري \\
\hline V.Tr & الشركة المصرية القابضة للغازات الطبيعية \\
\hline $0 . V r$ & الثركة المصرية للغازات الطبيعية \\
\hline$\varepsilon . Y \wedge$ & شركة مصر للتأمين \\
\hline$r . \cdot r$ & الثركة العربية للاستثمارات البترولية \\
\hline r.07 & بنك ناصر الاجتماعي \\
\hline r.07 & البنك الأهلي المصري \\
\hline$\leq .74$ & أسهم عامة للمواطنين \\
\hline $1 \ldots$ & الإجمالي \\
\hline
\end{tabular}

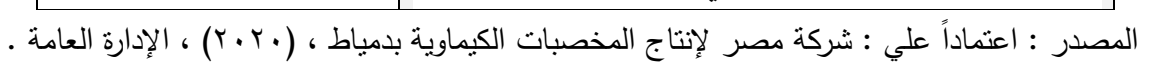

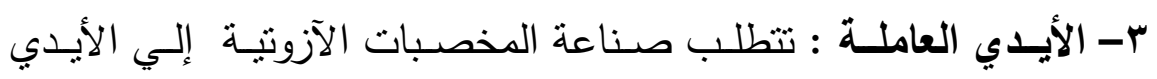
العاملة رغم اعتمادها علي تقنية عالية في التصنيع وذلك من أجل تشغيلها

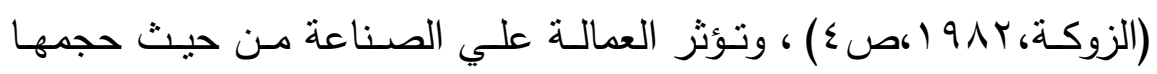

(المخصبات الكيماوية للمحاصيل الزراعية في مصر ...) د. أيمن عبد المطلب السعيد. 
وإنتاجيتها ونسبة أجورها من إجمالي المصروفات ، كما تُعد عاملاً مُهماً في

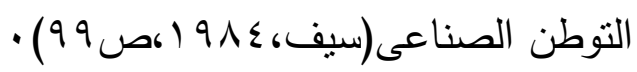

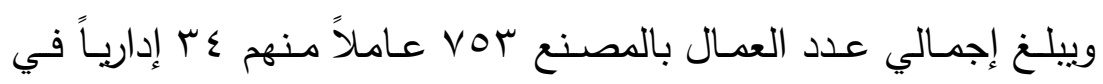

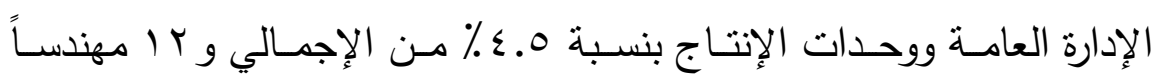

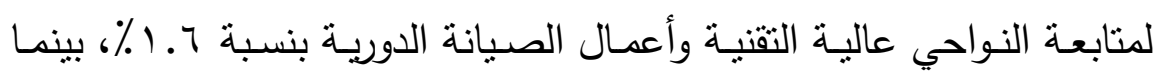

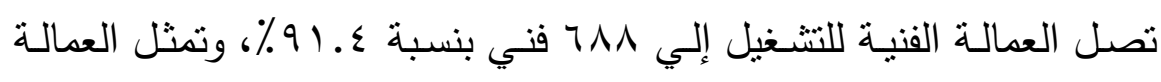

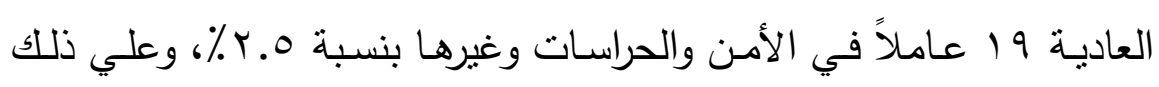
وصلت الكثافة الإجمالية للعاملين بمصنع دمياط لإنتاج المخصبات الآزوتية

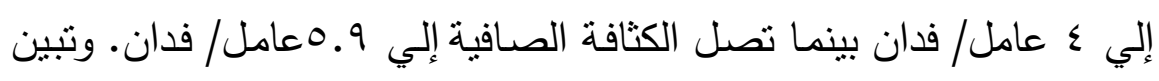

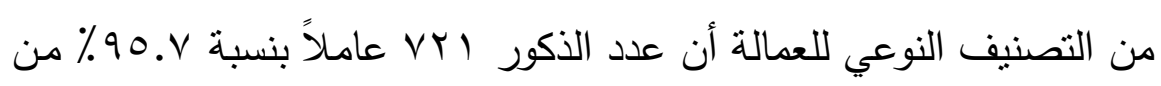

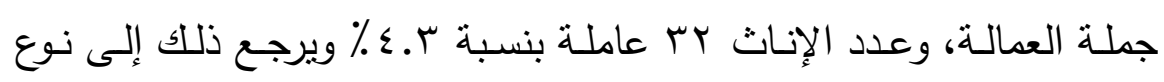

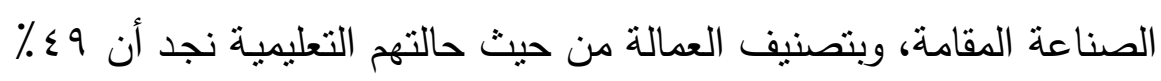

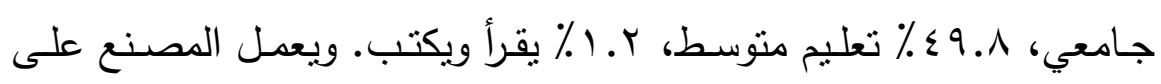

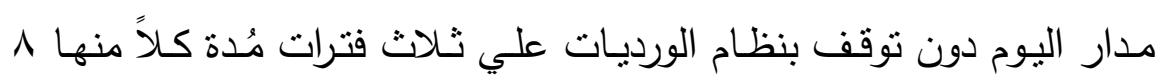
ساعات كالنالي : - الفترة الأولي: تبـدأ مـن السـاعة السـابعة صباحاً إلـي الثالثة بعد الظهر وتضم vr\% من العاملين لوجود الإداريين والعمالة العادية فيها.

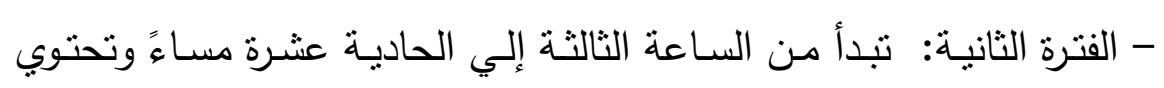

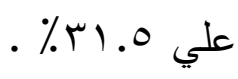

(المخصبات الكيماوية للمحاصيل الزراعية في مصر ...) د. أيمن عبد المطلب السعيد. 
- الفتزة الثالثة: وتبدأ من الحادية عشرة مساء إلي السابعة صباحاً وتحتوي

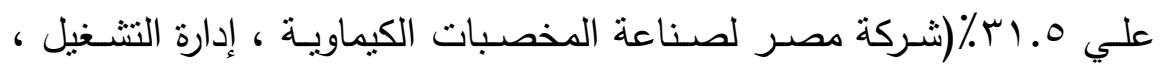
$\cdot(r \cdot 19$ وبلغت جملة أجور العاملين بالمصنع حوالي ع. ـ. 9 مليون جنيها خلا عام

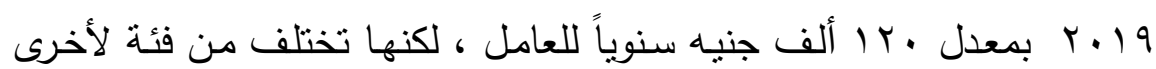
من العمال وفقاً لطبيعة الوظيفة (مقابلات شخصية مع المسئول عن الأجور

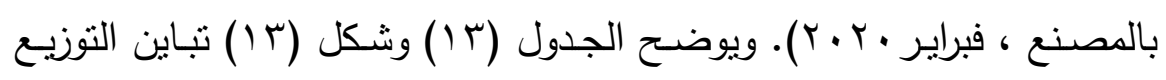
الجغرافي للعاملين بمصنع دمياط لصناعة المخصبات الآزوتيـة حسب محل

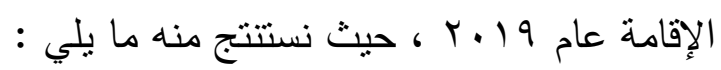

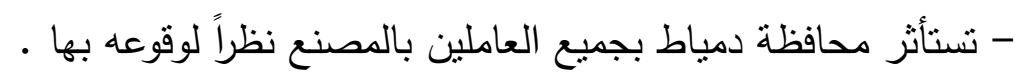

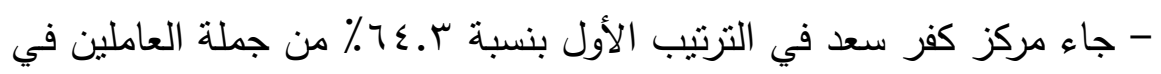
المصنع بسبب قرب المسافة مع مدينة دمياط الجديدة التي ثقع إلي الغرب منه بحوالي وكم ويقيم بها عدد كبير مـن العـاملين فيـه بمـا فيهم معظم العدـال

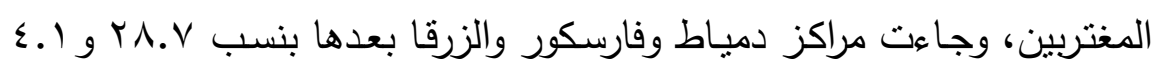
و و.ب\% بالترتيب من جملة العاملين. - تتناسب أعداد العاملين بالمصنع عكسياً مع المسافة منه مما يقلل من زمن رحلة العمل يومياً وهي أحد صور التفاعل المكاني بين المنطقة الصناعية الحرة بدمياط ومراكز العمران بالمحافظة ، وتتحصر وسيلة النقل بين الجماعي بنسبة

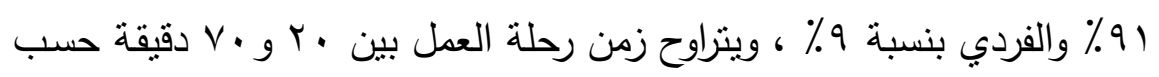

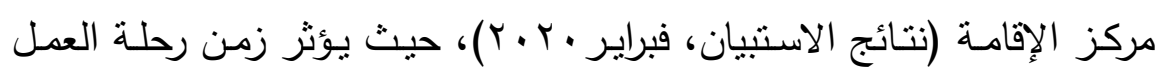

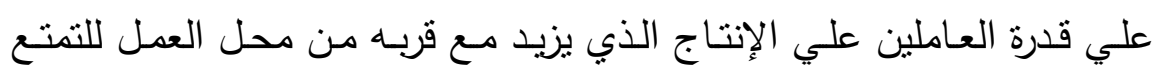

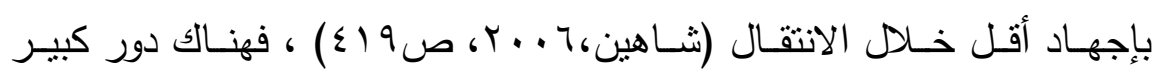
لسهولة الوصـول إلى موقع العدل في جذب العـاملين لـه من مراكز العهـران

(المخصبات الكيماوية للمحاصيل الزراعية في مصر...) د. أيمن عبد المطلب السعيد. 
(Robinson, R. Jocksin, I. 1984, PP. 88, بالإقليم المحيط بـ

جدول(r () التوزيع الجغرافي للعاملين بمصنع دمياط لصناعة المخصبات الآزوتية

حسب محل الإقامة عام 19 .

\begin{tabular}{|c|c|c|}
\hline$\%$ & العدد & المركز \\
\hline $7 \varepsilon . \mu$ & $\varepsilon \wedge Y$ & كفر سعد \\
\hline rA.V & YIA & دمباط \\
\hline$\varepsilon .1$ & M & فارسكور \\
\hline r. 9 & YY & الزرقا \\
\hline $1 \ldots$ & Vor & الإجمالي \\
\hline
\end{tabular}

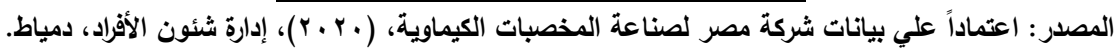

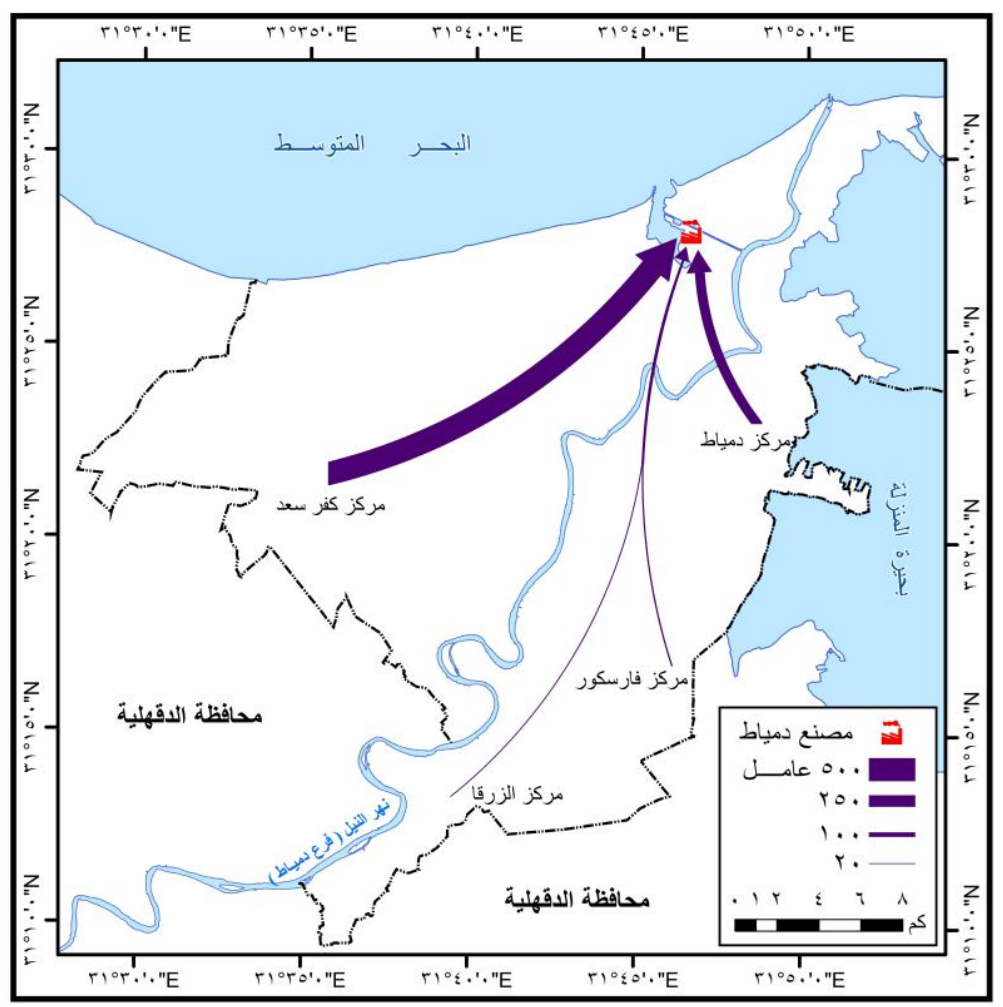

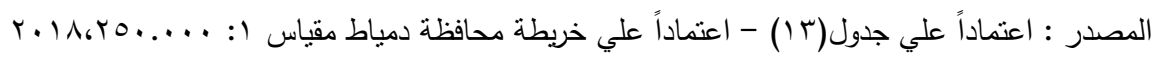

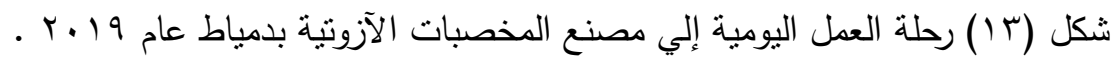

(المخصبات الكيماوية للمحاصبل الزراعية في مصر ...) د. أيمن عبد المطلب السعيد. 
عـ الطاقـة : تُعـد الطاقـة ركيزة مُهـــة لقيام الصـناعة خاصـة تلك التي تتطلب كميـات كبيـرة منهـا، وتختلـف كميـة ونـوع الطاقـة التـي تُستهلك حسـب نوعهـا، ويُفضـل أن يُنــأ المصنـع بجـوار مصدرها أو بـالقرب منها ، حيث تُحدد الطاقـة

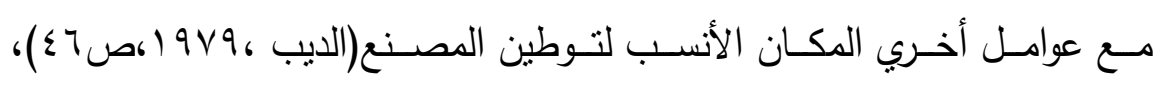
ويراعي وجود أكثر من مصدر للطاقة التي يعتمد عليها المصنع حتي لا تتوقف عمليـات الإنتاج فتحـدث خسـائر أو كوارث نتيجـة توقف توريـدها مـن المصـدر الرئيسـي الـذي تعتمــ عليـه ، ولـذلك يعتمــ مصـنع دميـاط لصـناعة المخصـبات الكيماويـة منـذ إنشـائه علـي الكهربـاء بصــورة رئيسية والمـازوت "الـديزل" بصـفة احتياطية إن وتم توصيل الكهرباء للمصنع من خـل خط خاص من محطة كفر البطيخ المُركبة التي تعمل بالغاز الطبيعي منذ عام 1919 والمـازوت منذ عام بـ99 19 وتقع علي مسـافة ب اكم إلي الجنـوب الثـرقي مـن المصنع علي النيـل بمسـاحة ع ب فدان وطاقة . . r ا ميجاوات ، ويوجد بالمصنع محطة توليد كهربـاء حراريـة تعدل في أوقات انقطساع الكهربـاء فقط ـ وتتــوع استخدامات الكهربـاء بالمصـنع حيث تستخدم في العمليات الإنتاجية بخطوط الإنتاج والتعبئة والإنارة . واستتهلك المصنع نحو TV ألـف ميجاوات/سـاعة عـام 1991 حيث بلغت فترة التشغيل ستة أثـهر فقط بداية من شـهر يوليو ، ويتضـح من الجدول (ع () متوسط كميات الكهرباء المستهلكة بالمصنع خـلال الفترة . . . r-9 1 ـ و ويتبين منـهـ أن الاسـتهلاكك لـم بتعـدي متوسـطه ـ10 ألـف ميجاوات/سـاعة حتي عـام

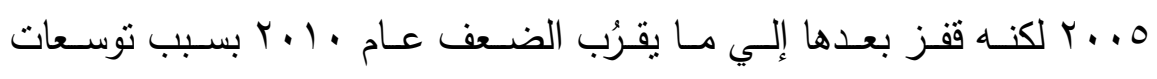
(المخصبات الكيماوية للمحاصيل الزراعية في مصر ...) د. أيمن عبد المطلب السعيد. 
المصنع وإضـافة الخط الثناني للإنتاج ، وانخفض استهلاك المصنع من الكهرباء خلال عام II ألتوقف خـلال أحداث ذلك العام ، كما ارتفع معدل استهلاكه للكهربـاء مـع إنشـاء الخط الثالث عام 1 ا ـ ب ليبلنغ 9. . بـ ألف ميجاوات/سـاعة حتي عام 19 . 19 . جدول(ع ( ) منوسط كميات الكهرباء المستهلكة في مصنع دمياط لصناعة المخصبات

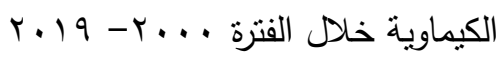

\begin{tabular}{|c|c|c|}
\hline معدل التغيير \% & ميجاوة & عام \\
\hline - & $|T \leqslant Y V|$ & $r \ldots \varepsilon_{-}{ }^{\prime} \ldots$ \\
\hline $1 \cdot . r$ & $1 \leq 1.9 Y$ & $r \ldots q_{-} r_{\ldots}$ \\
\hline 19.0 & YA.TYA & $\left.r_{\cdot} \mid \varepsilon_{-} r_{+}\right)$. \\
\hline 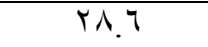 & rч.9Y. & $r \cdot 19-r \cdot 10$ \\
\hline
\end{tabular}

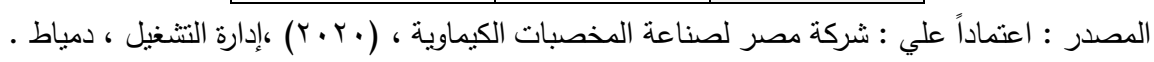
هـ النقـل : يـؤثر النقل بشكل واضـح في قيـام الصـناعات بأنواعها وأحجامها المختلفة ، وتتميز محافظة دمياط بوجود أنماط مختلفة من وسائل النقل منمنلة في النقل المائي "ميناء دمياط ونهر النيل" ، والنقل البرى بنوعيه ، والنقل الجوي من خلال ميناء بورسعيد الجوي الأقرب لدمياط علي مسافة 00 كم شرقاً . ويقع المصنع في وسط هذه الثبكة المتتوعة مـن وسـئل النقل، حيث يطل علي قناة الصنادل مباشرة من جهة الشرق وهي قناة تم حفرها لتربط بين حوض ميناء دمياط بنهر النيل وتتكون من جزئين : يصل طول الأول منها . هب امتراً

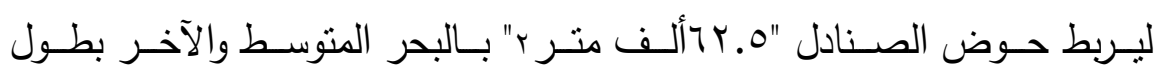
• مVامتراً لتصل الحوض بالنيـل وبذللك يـرتبط المينـاء بـاخل الوادي والدلتا من

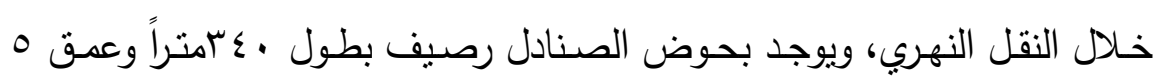

(المخصبات الكيماوية للمحاصيل الزراعية في مصر...) د. أيمن عبد المطلب السعيد. 
أمتار، كما توجد أرصفة ميناء دمياط إلي الغرب مباشرة من المصنع مما يسهل نقل منتجاته المخصصـة للتصدير إليها مما يخفض من تكلفة النقل بشكل كبير، ويمر خط سكة حديد الميناء إلي الغرب منـه مباشرة ، وتحيط بالميناء شبكة من الطرق البريـة المرصـوفة التي تسـل نقل منتجاتـه للـاخل مثنل : طريـق دميـاط القاهرة الغربـي ( •9 اكم) ، وطريـق دميـاط القـاهرة الثـرقي (•9 اكم) ، والطريـق السـاحلي دميـاط اسـكندرية (·ـ آكم) مـروراً بمحافظـات الدقهليـة وكفر الثـيخ والبحيـرة ، وطريـق دميـاط بورسـعيد (00كم) الذي يربطها بطريـق قنـاة السـويس ومحور ·r بوليو ، شكل (ع ا) .

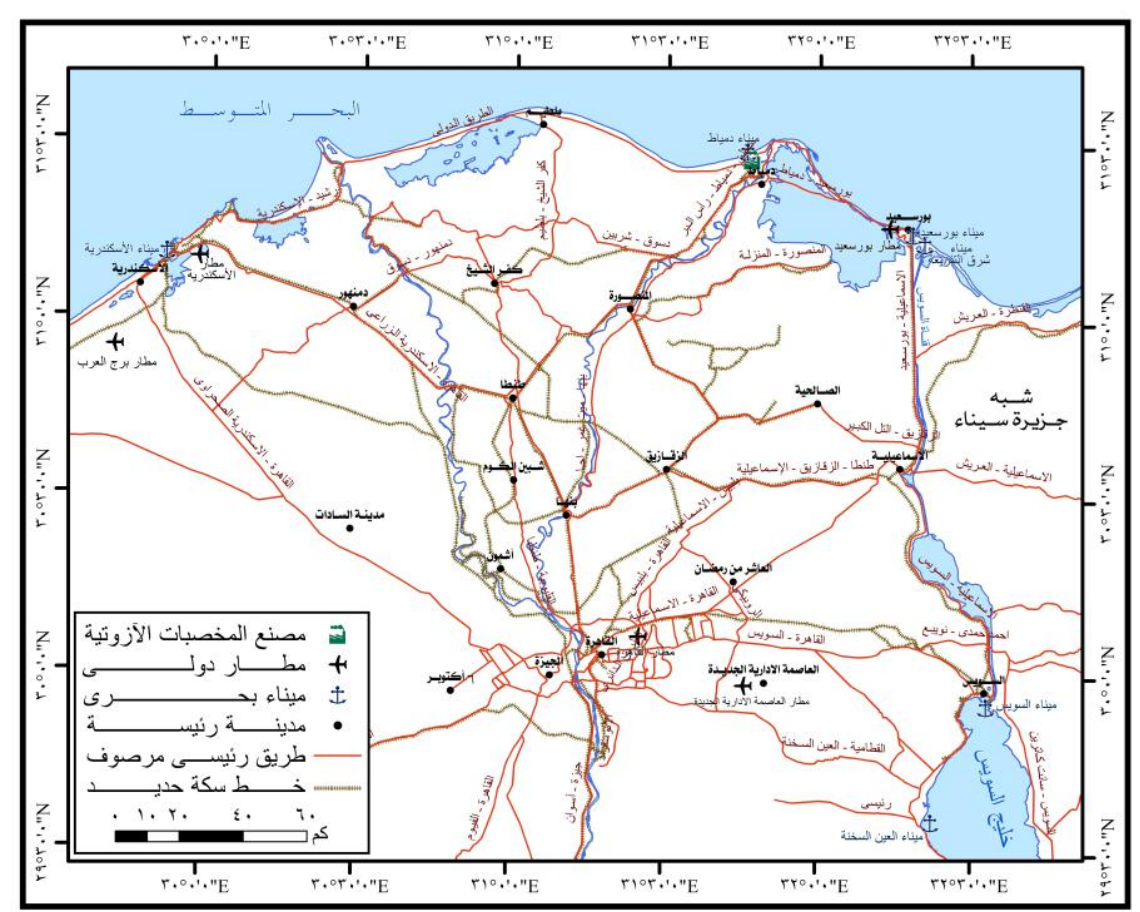

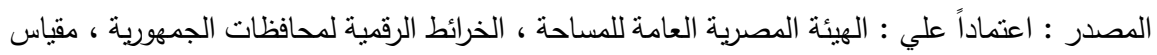
$r \cdot 1 \Lambda_{6} 0 \ldots:$ : I

شكل( \& 1) موقع مصنع دمياط لإنتاج المخصبات الآزوتية بالنسبة لوسائل النقل المختلفة.

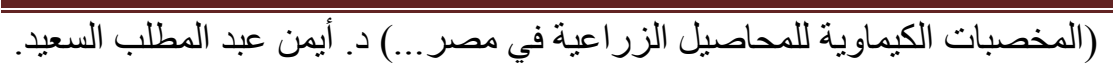


צ- المياه : تُعد المياه عاملاً أساسياً في اختبار موقع عدداً من الصناعات

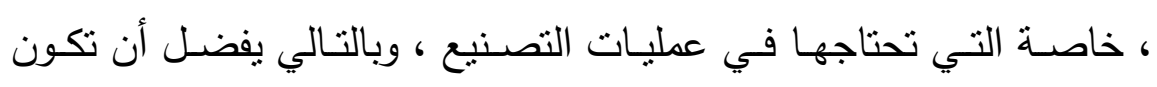

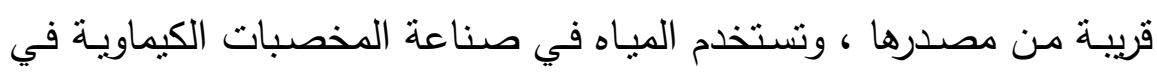

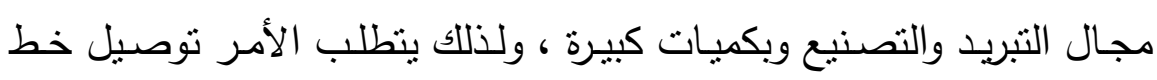

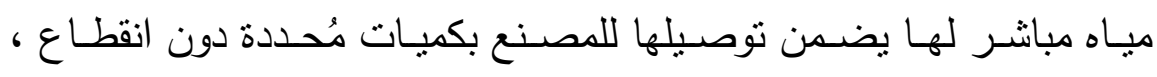

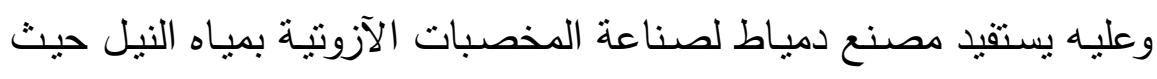
تصل إليه عن طريق خط مياه بطول ع اكم وقُطر بَ بوصة لتوصيل 10

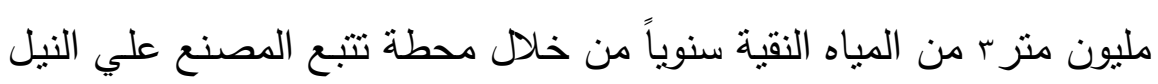

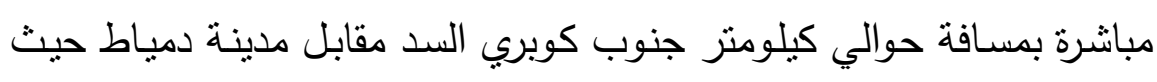

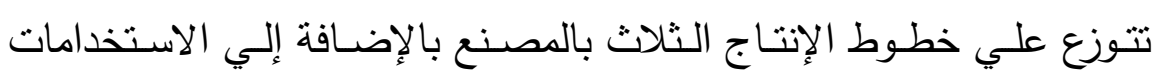

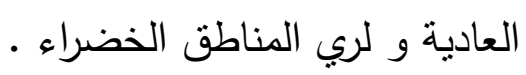

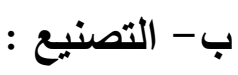
تعتمد المخصبات الآزوتية علي تصنيع الأمونيا التي تُعد المادة الخام

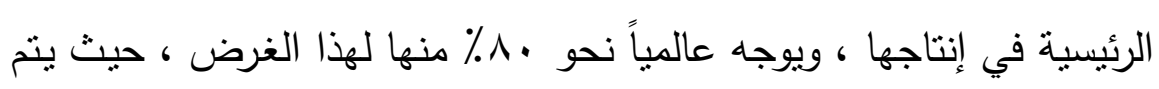

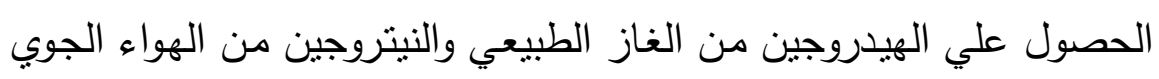

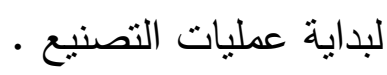

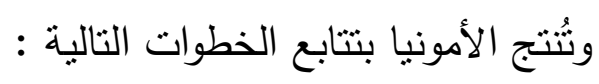

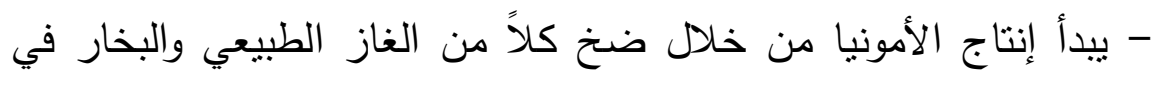

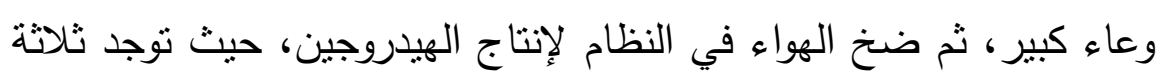

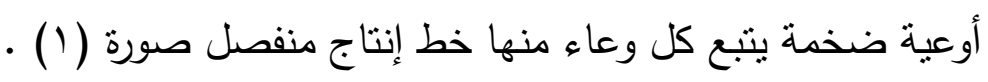

(المخصبات الكيماوية للمحاصيل الزراعية في مصر...) د. أيمن عبد المطلب السعيد.

$$
\text { ᄉ. } 1
$$


- - تتقية خليط الهيدروجين والنيتروجين بإزالة الماء والغازات من أكاسيد الكربون المصاحبة والأوكسجين فيتبقى الهيدروجين والنيتروجين. - تحويل الخليط من الهيدروجين والنيتروجين إلى الأمونيا بعد إدخال التيار الكهربي لله ومع استخدام مُحفزات منل المجنتيت يتم توفير ظروف تفاعل مناسبة

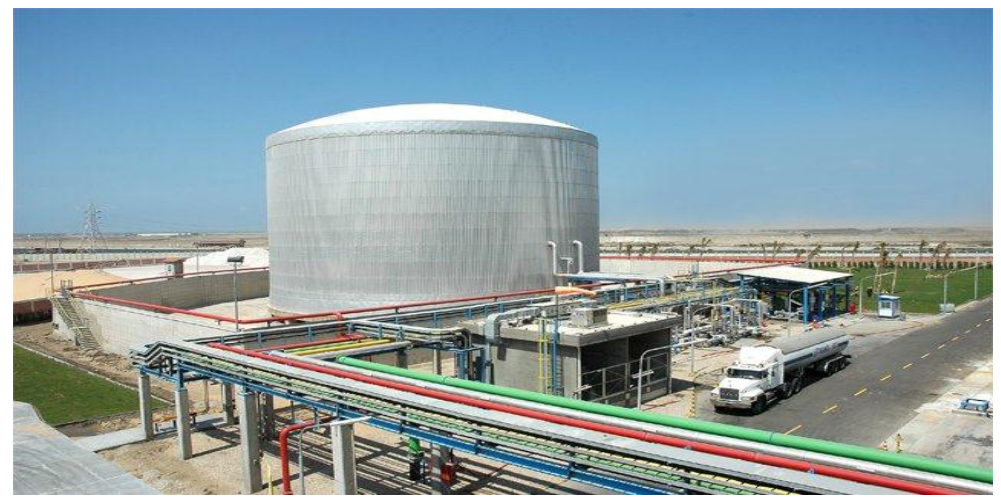

المصدر : شركة مصر لإنتاج الأسمدة الكيماوية ، يناير .r.r.

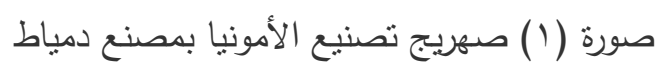

ويتم إنتاج الأمونيا في صورة غازية ويتم تحويلها إلي سائلة من خلال تبريدها تدريجياً لتصل إلي سم درجة تحت الصفر لتخزن بعدها في صهريج مجهز بوحدة تبريد، وبستخدم نحو 9 \% من الأمونيا التي تم إنتاجها بالمصنع في تصنيع اليوريا وتسوق الكميات المنتقية إلي مصانع المخصبات الأخرى، وتبلغ نسبة وزن الأمونيا السائلة المنتجة من المصنع ^و.9. و r. . ٪ من الماء وأقل من خمسة أجزاء في المليون من الزيت. ويتم إنتاج اليوريا بعد تصنيع الأمونيا في مرحلة لاحقة، وهي مركب ينتج بتقاعل الأمونيا مع ثاني أكسيد الكربون تحت ضغط مرتفع

(المخصبات الكيماوية للمحاصيل الزراعية في مصر...) د. أيمن عبد المطلب السعيد.

$$
\Lambda \cdot r
$$


" • اكجم/سم ب"، فيتكون مركب كاربامات الأمونيوم حيث يتحلل لنُتجج اليوريا في صورتها السائلة، ويتعرض محلول اليوريا لزيادة التركيز تدريجياً بوحدات الإنتاج من خلال الفصل والتدوير للمتفاعلات غير المتحولة مع تبخير المياه حتي يصل تركيز المحلول إلى 97 ٪ ليوجه بعدها إلي الوحدة الخاصة لإنتاج اليوريا ذات الشكل المحبب، صورة (r) •

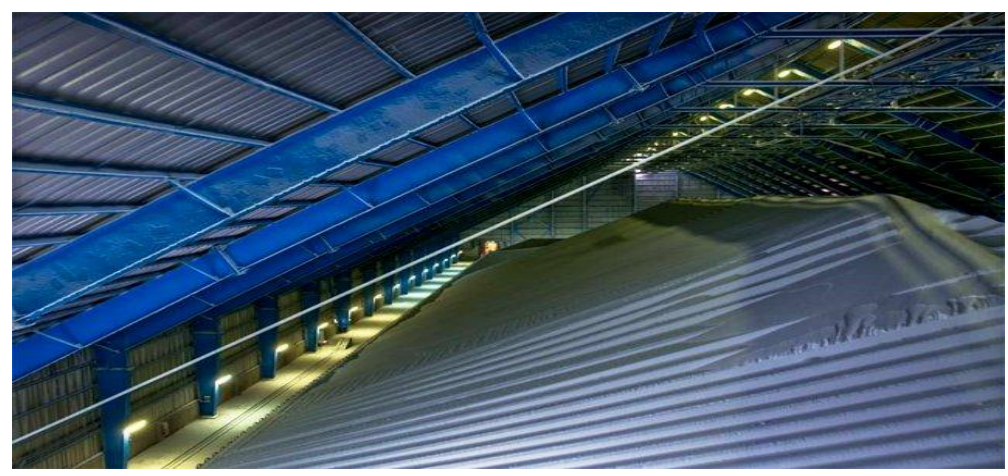

المصدر : شركة مصر لإنتاج الخضصبات الكيماوية ، يناير •r.r.

صورة (r) اليوريا السائبة بمصنع دمياط

ويتضح من الجدول (0 10) خصائص اليوريا المحبية التي يتم تعبئنها

في عبوات وزنها ـ مكجم للسوق المحلي بينما يتم نقلها سائبة في سيارات شحن كبيرة إلي رصيف التصدير بميناء دمياط مباشرة حيث يقع المصنع في محيطه ، ويتم إجراء اختبارات دورية للتأكد من أن المنتج ينسم بالمواصفات المطلوبة من خلال معرفة نسب المكونات وفقاً لمعايير محددة.

(المخصبات الكيماوية للمحاصيل الزراعية في مصر ...) د. أيمن عبد المطلب السعيد. 
جدول (10) خصائص اليوريا المحببة التي تتتجها شركة مصر للمخصبات الآزوتية

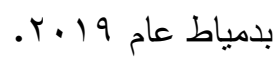

\begin{tabular}{|c|c|}
\hline الخصائص & العنصر \\
\hline 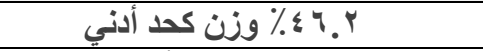 & نيتروجين كلي \\
\hline 1\% وزن كد أقصي & بيوريت \\
\hline r. • وزن كحد أقصي & الرطوبة. \\
\hline • • جزء في المليون كد أقصّي & الأمونيا الحرة \\
\hline 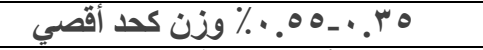 & القورمالدا هيا \\
\hline r كجم كد أدني لحبيبة بقطر 0 ا."مم & المقاومة للتقتيت \\
\hline 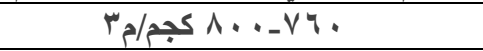 & الكثافة \\
\hline • مدرجة مئوية كد أقصي & درجة الحرارة \\
\hline 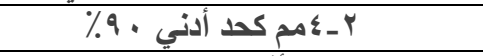 & 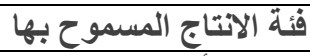 \\
\hline كد أقصي 1\% وزن & وزن أكبر من 1 مم \\
\hline
\end{tabular}

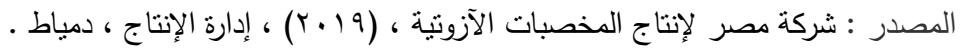

ويقوم النيتروجين "المكون الأساسي في اليوربا" بتكوين البروتينات والهردونات والأحماض النوويّة، حيث يضاف للنباتات حينما تعاني من انخفاضٌ في النمو مع اصفرار أوراقها، ويوضح الثكل (0) خطوات تصنيع المخصبات الآزوتية في شركة مصر بدمياط.

(المخصبات الكيماوية للمحاصبل الزراعية في مصر ...) د. أيمن عبد المطلب السعيد. 


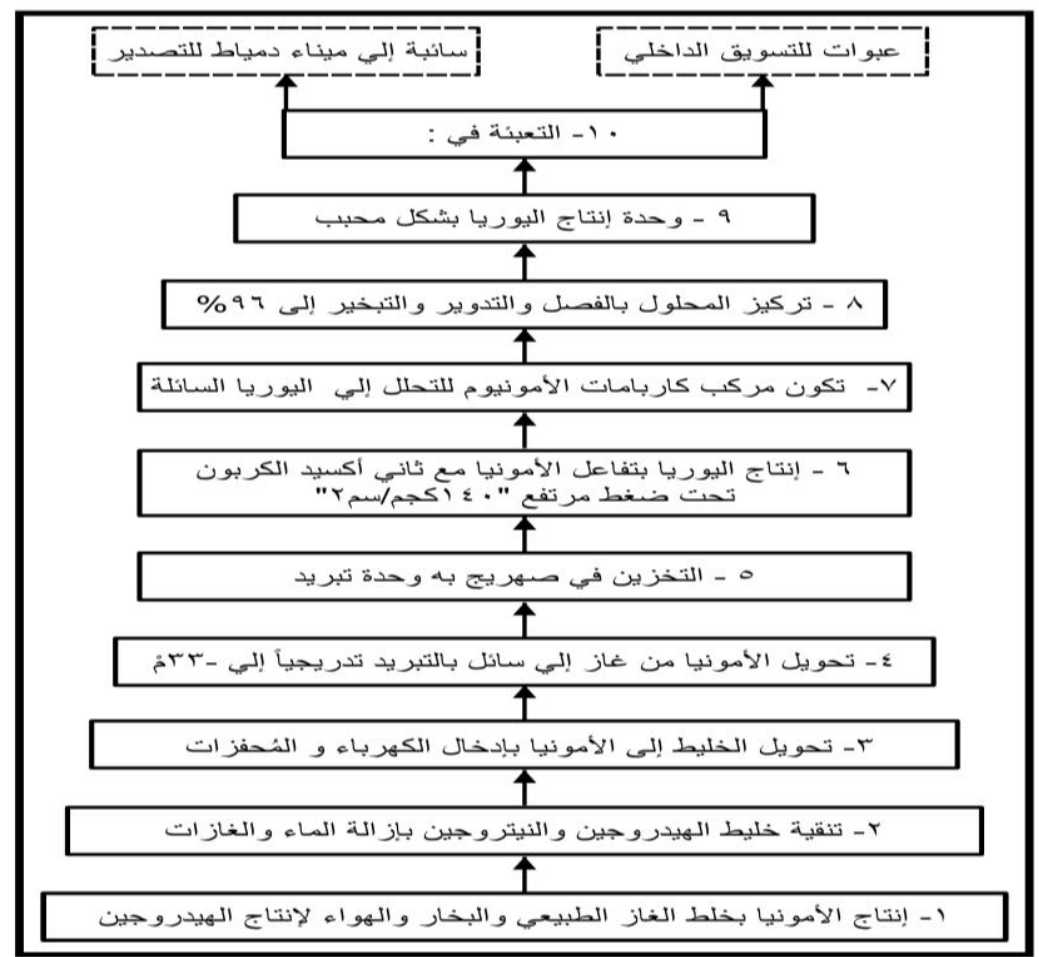

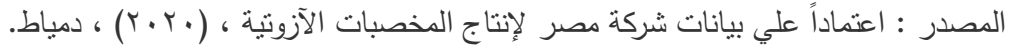

شكل (0) خطوات تصنيع المخصبات الآزوتية في شركة مصر بدمياط عام 9 1 . . .

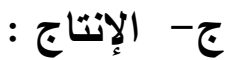

يمكن من خلال دراسة إنتاج شركة مصر لصناعة المخصبات الآزوتية

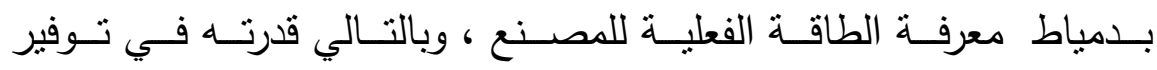
الاحتياجـات المحليـة منهـا وامكانـات التصـدير للفـائض مـع إبـراز التغيـر السنوي في الانتاج ، حيث شهد إنتاج المصنع تطوراً كبيراً خلال فترة إنتاجه منذ عام 991 حتي الآن بسبب عمليات التوسـع المستمرة استجابة للطلب الداخلي والخـارجي علي المخصبات الآزوتبـة للمحافظة علي كمبات الغذاء المنتجـة مـع التوسـع في المسـاحات المزروعـة ، وبحتوي المصنع علي ثلاثة (المخصبات الكيماوية للمحاصيل الزراعية في مصر ...) د. أيمن عبد المطلب السعيد. 
خطوط للإنتاج يوجد بكل خط منها وحدة إنتاج بطاقة . . 7 ألف طن سنوياً

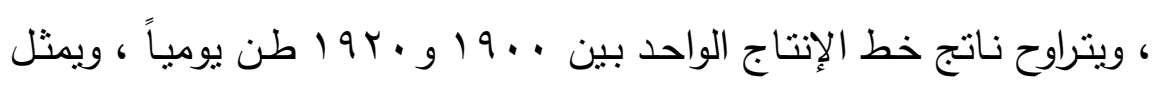

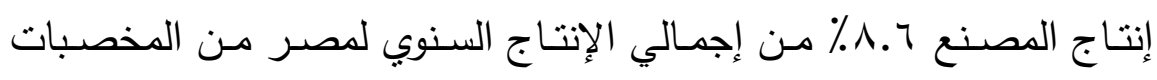

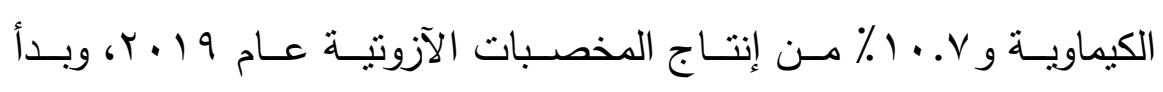
المصنع يعمل بوحدة إنتاج فقط في منتصف عام 1991 19، حيث أنتجب نصف طاقتها السنوية لكنها تضـاعفت في العام الذي يليه ، ويتضح من بن الجدول (7 (1) والثنكل (7 (1) النطور السنوي لإنتاج الدخصبات الآزوتية في

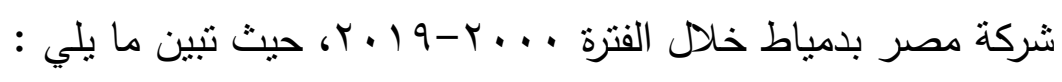

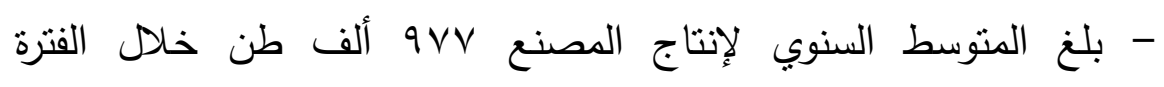

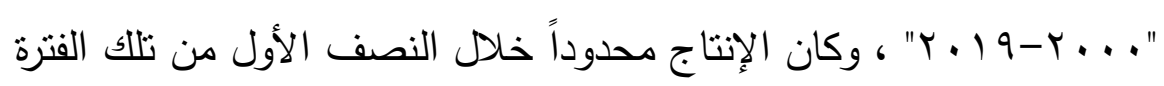

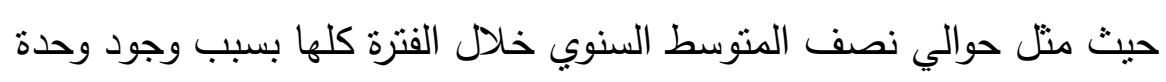
تصنيع واحدة فقط.

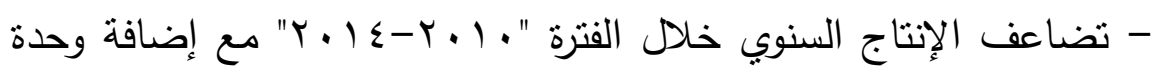

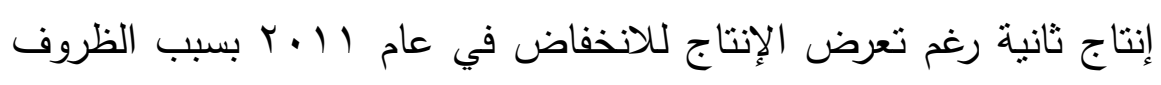
التي مرت بها مصر وتعليق الإنتاج لمدة تسعة أشهر ، كما انخفض الإنتاج

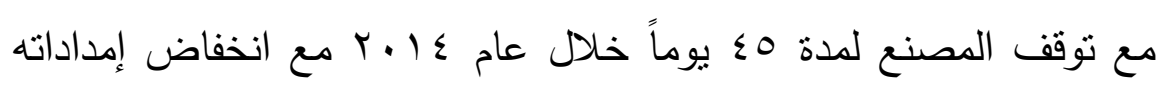
بالغاز الطبيعي لحوالي النصف بسبب توجيه كمياته إلي محطات إنتاج الكهرباء.

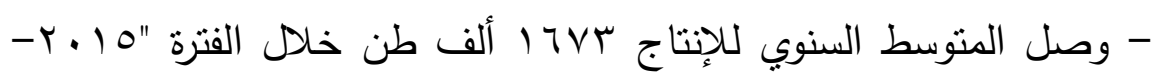

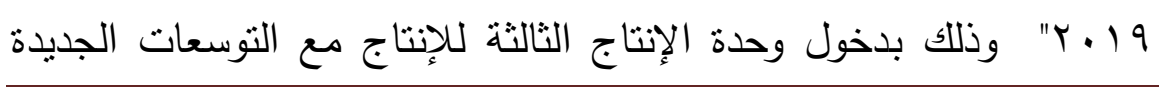
(المخصبات الكيماوية للمحاصيل الزراعية في مصر ....) د. أيمن عبد المطلب السعيد. 
التي قامت بها الثركة عام 1 ا ـ ب والتي نفذت إنشاءاتها شركة بتروجيت ، حيث يهدف المصنع إلى رفع إجمالي الطاقة الإنتاجية إلى مليوني طن من مخصبات اليوريا و • r ألف طن سنوباً من الأمونيا الفائضة من تصنيع اليوربا لتسهم في تغذية مصانع أخرى لإنتاج المخصبات الآزوتية ، ويصل متوسط أيام الصيانة نحو 00 يوم/ سنوياً موزعة علي شهور العام حيث تتوقف وحدات الإنتاج عن العمل فيها بشكل كامل . جدول(7 (1) متوسط الإنتاج السنوي في شركة مصر لإنتاج المخصبات الآزوتية بدمياط .

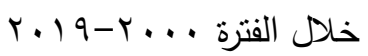

\begin{tabular}{|c|c|c|}
\hline معدل التغيير \% & الكمية (ألف طن) & عــــام \\
\hline - & OV $\varepsilon$ & $r \ldots \varepsilon_{-} r \ldots$ \\
\hline Y.r & $\bullet \wedge V$ & $r \ldots q_{-} r \ldots o$ \\
\hline$\Lambda r$ & $1 \cdot V \varepsilon$ & $r \cdot 1 \varepsilon_{-} r \cdot 1$. \\
\hline 07.5 & ITVT & $r .19-Y \cdot 10$ \\
\hline- & qVV & المتوسط السنوي \\
\hline
\end{tabular}

المصدر : اعتماداً علي بيانات شركة مصر لإنتاج للمخصبات الآزوتية ، (·. • (Y) ، دمياط.

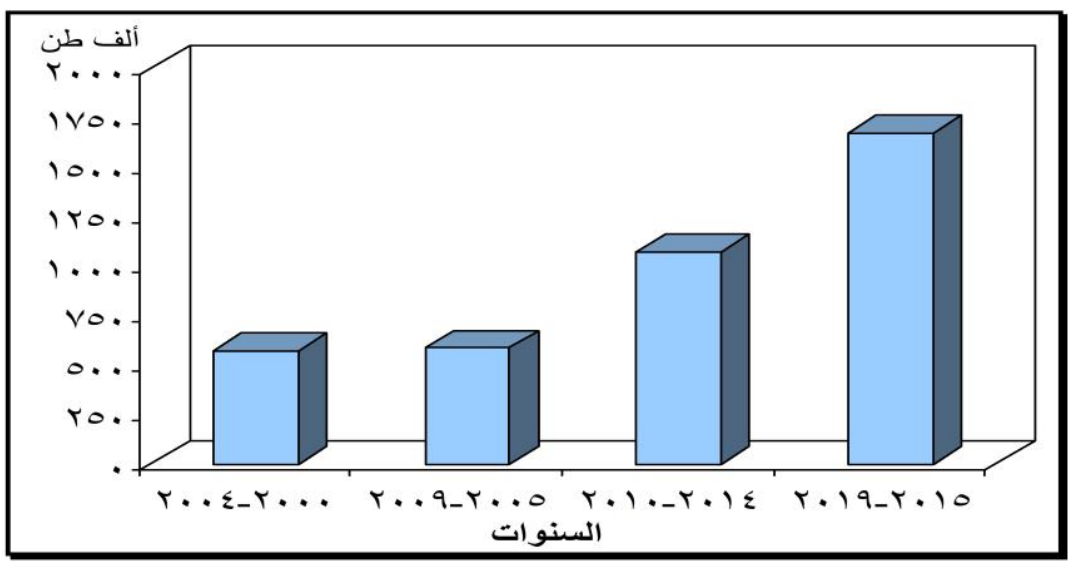

المصدر: اعتماداً علي بيانات الجدول (T ()) .

شكل(T ( ) منوسط الإنتاج السنوي في شركة مصر لإنتاج المخصبات الآزوتية بدمياط

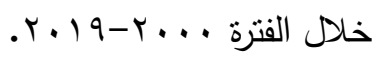

(المخصبات الكيماوية للمحاصيل الزراعية في مصر ...) د. أيمن عبد المطلب السعيد. 
د - التسويق : تهدف صناعة المخصبات الآزوتية في مصر إلي توفير احتياجات السوق المحلي منها وتصدير المتبقي ، وقد استهلكت مصر منها

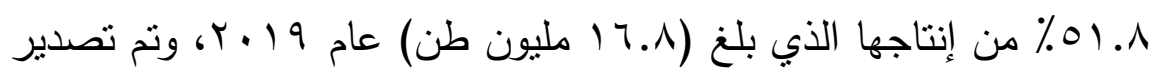
الفائض ، وبساهم مصنع دمياط في هذه المنظومة منذ نشأته حتي الآن، حيث يسوق جزءاً من إنتاجه إلي السوق المحلي ليتم تداوله من خلال وزارة الزراعة بأسعار تحددها لمواجهة الاحتياجات المتزايدة منها للأراضي الزراعية القديمة والمستصلحة، وتقدر بنحو ه0 \% من إجمالي إنتاجها السنوي، ويوضح الجدول (IV) والثكل(IV) الكميات التي يساهم بها مصنع دمياط لإنتاج المخصبات الآزوتية في الاستهلاك المحلي في أعوام هـ ..

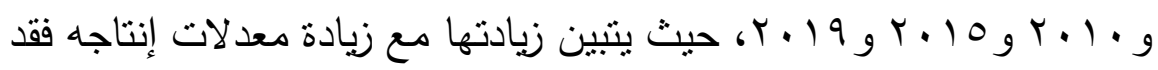

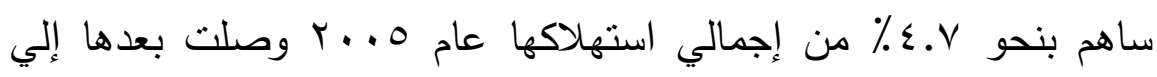

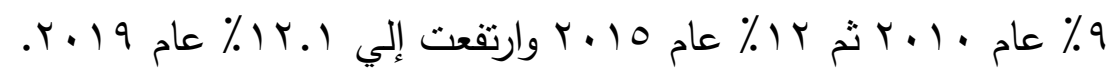
جدول(Y ) مساهمة مصنع دمياط لإنتاج المخصبات الآزوتية في نوفير الاستهلاك

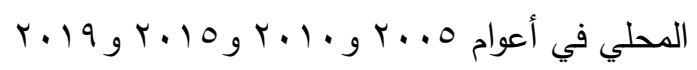

\begin{tabular}{|c|c|c|c|}
\hline \multicolumn{2}{|c|}{ مساهمة مصنع دمياط } & إجمالي & كان \\
\hline$\%$ & (ألف طن) & (مليون طن) & \\
\hline$\varepsilon . V$ & rrr & 7.9 & $r . .0$ \\
\hline 9 & 091 & 7.7 & $r \cdot 1$. \\
\hline Ir & QY। & V.V & $r .10$ \\
\hline $1 Y .1$ & $1.0 \%$ & ^. $\vee$ & 7.19 \\
\hline
\end{tabular}

المصدر : اعتماداً علي الجدول (0) و (1) )

(المخصبات الكيماوية للمحاصيل الزراعية في مصر ...) د. أيمن عبد المطلب السعيد.

$$
\Lambda \cdot \Lambda
$$




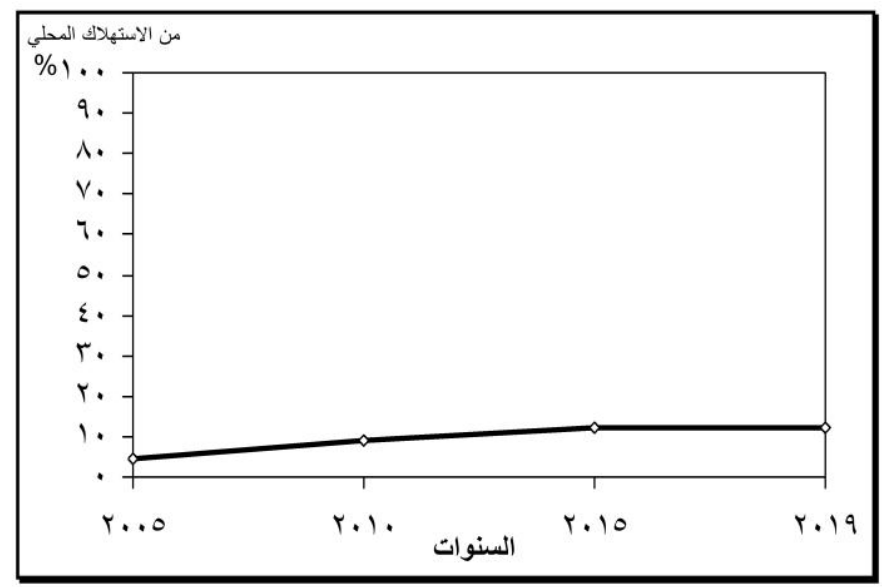

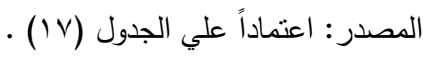

شكل(IV) مساهمة مصنع دمياط لإنتاج المخصبات الآزونية في توفير الاستهلاك

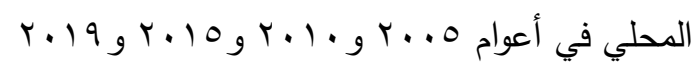

وتأخذ شركة مصـر لإنتاج المخصبات الآزوتيـة مكاناً لهـا في مجال

التجـارة الدوليـة للمخصـبات الكيماوبـة ، وذلـك مـن خـلال التزامهـا بشـروط التعاقد مـع الدول المستوردة ، وتقديم مُنتج جيد ، ومتابعـة عمليات الثـحن بالموانئ حفاظاً علي جودته ، وتقدر الكميات المصدرة سنوياً بنحو 0 ؛ ٪ من

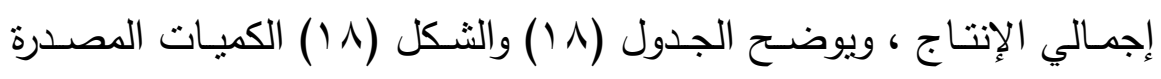
من المخصبات الآزونيـة من مصنع دمياط عام 9 ا . ب ، حيث تم تصديره إلي بr دولة أهمها ا دول وهي بالترتيب حسب كميـة وارداتها : البرازبل و والمكسـيك وكنـدا واسـتراليا ونيجيريـا وفرنسـا وروسـيا وتركسـتان والصـين • ومدغشقر

(المخصبات الكيماوية للمحاصيل الزراعية في مصر ...) د. أيمن عبد المطلب السعيد.

$$
\text { ᄉ. } 9
$$




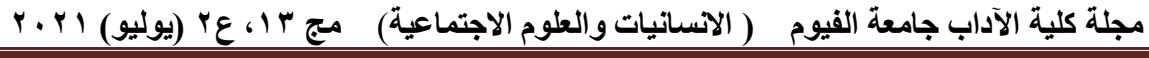

جدول(1 1 ) التوزيع الجغرافي لصادرات مصنع دمياط من المخصبات الآزوتية عام 9 ا ـ

الكمية (ألف طن)

\begin{tabular}{|c|c|c|c|c|c|c|c|c|c|c|c|c|}
\hline إجمالي & أخري & مدغشُقر & الصين & تركستان & روسيا & فُرْنسا & نيجيريا & استر اليا & كندا & المكسبيك & البر ازيل & الاولية \\
\hline$\Lambda \leqslant V$ & \& & $r r$ & VI & $V \psi$ & Vq & $\Lambda 1$ & 10 & $\Lambda V$ & 90 & 91 & $1 . \varepsilon$ & الكمية \\
\hline $1 \ldots$ & $\varepsilon . \wedge$ & r.9 & $\Lambda . \xi$ & 1.7 & $9 . r$ & 9.7 & 1. & $1 \cdot . r$ & $11 . r$ & 11.9 & IY.r & $\%$ \\
\hline
\end{tabular}

المصدر : اعتماداً علي بيانات شركة مصر لإنتاج المخصبات الكيماوية ، (·. • (Y) ، دمياط.

شكل (1 1 ) التوزيع الجغرافي لصادرات مصنع دمياط من المخصبات الآزوتية عام 9 1 ـ r.

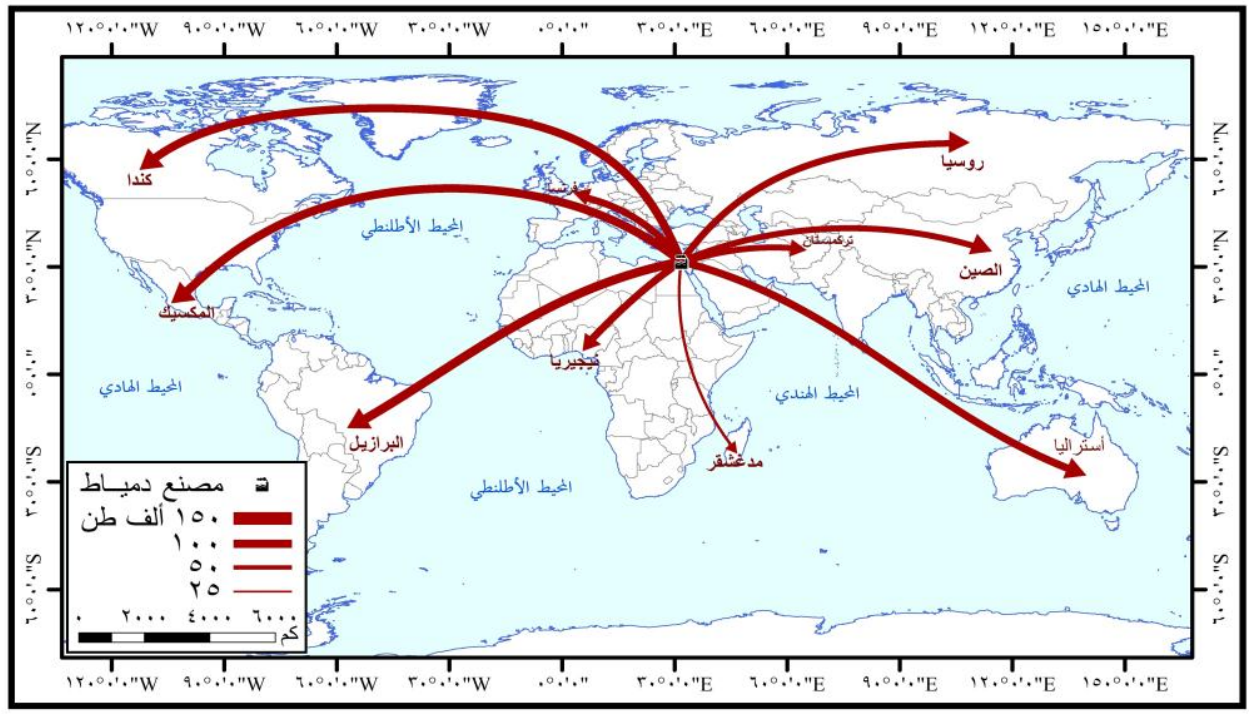

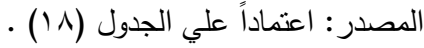

هـ - الآثار الناتجة عن صناعة المخصبات الآزوتية:

تهدف التتمية بشكل عام إلي الاهتمام بحياة الإنسان من خلال النواحي

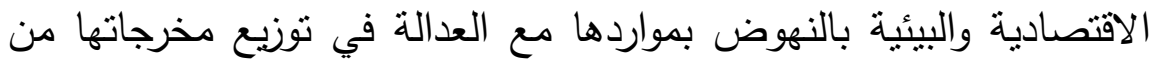

خلال حسن إدارة الموارد، وتتتوع الآتار الناتجة عن مصنع دمياط لإنتاج

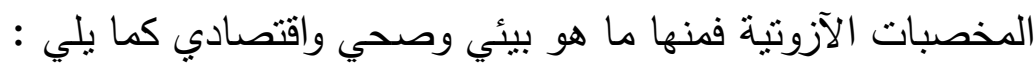

1- الآتار البيئية والصحية : يتأثر الإنسان والحيوان والنبات والهواء والتربة

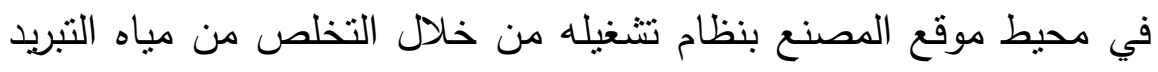

ومخلفات مياه الصناعة ومياه الصرف الصحي والتي يتم تجميعها في محطة لئا

(المخصبات الكيماوية للمحاصيل الزراعية في مصر ...) د. أيمن عبد المطلب السعيد. 
الصرف لتصرف بعدها في المجاري المائية القريبة ، وهذه المحطة تقع داخل الأراضي الزراعية مما يؤثر علي تلوث المحاصيل وجودة التربة

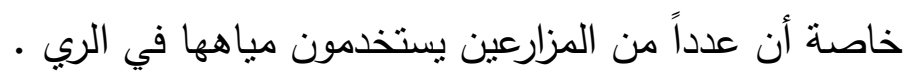
وتحتوي مياه الصرف التي يلقيها المصنع علي نسب عالية من الأمونيا والنيتروجين والزئبق ومركبات الكربون الهيدروجينية ، وتؤُثر مياه التبريد في

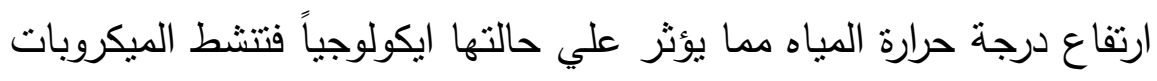
اللاهوائية مما ينتج روائح كريهة وغازات ضارة ، وتدهورت خصائص المياه بالمناطق القريبة من منطقة المصنع حيث التلوث البيولوجي وتغيير في رهاي تركيبها الفيزيائي والكيمائي في رواسب القاع كما حدث انخفاض كبير في يرقات الأسماك واختفاء لبعض أنواعها كالسردين ، كما تأثرت مياه شواطئ رأس البر ويؤثز هذا الوضع البيئي علي صحة الإنسان فيسبب انخفاضاً في مستوي الذكاء والتأثير علي الكبد والكلي والتسبب في الثلل الرعاش والسرطان (اللجنة العلمية لتقييم تأثير مصنع دمياط لإنتاج المخصبات

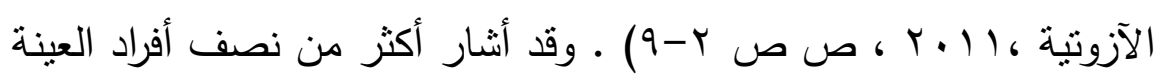
بقليل أن هناك تلوث بدرجات منوسطة إلي محدودة في منطقة المصنع

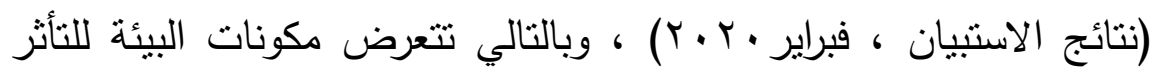

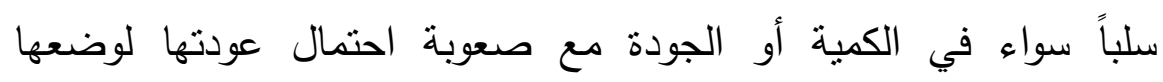
الطبيعي في ظل استمرار هذه الظروف (Murphy J., 2010) (

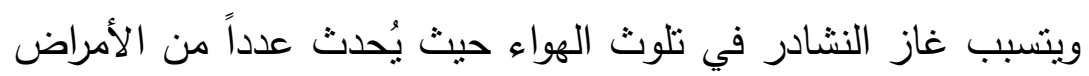
، منل تهيج الجلد والأنف والعين وتتابع الإغماء مع وجود الأمراض الصدرية كالسعال والربو وأزمات التنفس ، كما قد يحرق أوراق المحاصيل ، وكثيراً من الأضرار الصحية التي تصيب الإنسان والحيوان ترجع إلي جسيمات دقيقة

(المخصبات الكيماوية للمحاصيل الزراعية في مصر...) د. أيمن عبد المطلب السعيد. 
مثل الرماد ومركبات الكربون والرصاص تتسرب إلي الرئة ، وترجع إلي الاحتراق غير التام لكن وجود فلتزة لاخان مصنع دمياط يقلل من تلك الأضرار (جهاز الدولة لنشئون البيئة، دليل التفتيش عن صناعة المخصبات، $\cdot(r \cdot .0$

r- الآثار الاقتصادية: وتتقسم إلى نوعين وهما: - الآثار الإيجابية : أصبحت صناعة المخصبات الكيماوية أحد الصناعات الاستراتيجية المُهمة لأهميتها في زيادة الإنتاج الزراعي حيث توفر احتياجات السوق المحلي فضلاً عن التصدير ، وبذلك تُسهم في الدخل القومي ، رغم لإنت أن القطاع الاستثاري يذهب الجزء الأكبر من عائده إلي أصحاب شركاته لكنه يُدخل عملات أجنبية للدولة ، كما ثُسهر هذه الصناعة في علاج مشكلة البطالة بسبب فرص العمل التي توفرها . ويتضح من الجدول (9 (1) أرباح شركة مصر لإنتاج المخصبات

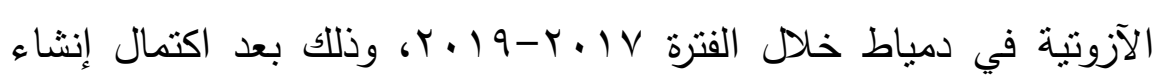
خطوط الإنتاج الثلاثة عام 1 ا ـ r، حيث يتبين منه زيادة أرباح الثركة حتي وصلت حوالي 9 ـ 1 مليار عام 9 ــ وذللك بسبب ارتفاع الكميات المصدرة بعد اتجاهها نحو فتح أسواق خارجية جديدة فضلاً عن زيادة أسعار المخصبات الآزوتية عالمياً. جدول(9 (1) أرباح شركة مصر لإنتاج المخصبات الآزوتية في دمياط خلال الفترة $r \cdot 19-r \cdot 1 V$

\begin{tabular}{|c|c|c|}
\hline معدل التغيير \% & الأرباح (مليون جنيه) & عام \\
\hline- & TKAT.Y & $T . I V$ \\
\hline 7.1 & $1+71.7$ & $r \cdot 1 \wedge$ \\
\hline rv.V & $1 \wedge \vee 0 . \varepsilon$ & $r .19$ \\
\hline
\end{tabular}

المصدر : اعتماداً علي بيانات شركة مصر لإنتاج المخصبات الآزوتية ، (·r.r. (Y) ، دمياط (المخصبات الكيماوية للمحاصيل الزر اعية في مصر ...) د. أيمن عبد المطلب السعيد. 
- الآثار السلبية : يصاب العمال بعدد من الأمراض المزمنة والتي تتطلب إنفاق الكثير من الدخل للعلاج ، إضافة إلي ضعفهم وبالتالي نراجع المجهود الذي يبذل في العمل ، مما يؤثر علي كمية الإنتاج ووجود عبئًا مادياً علي

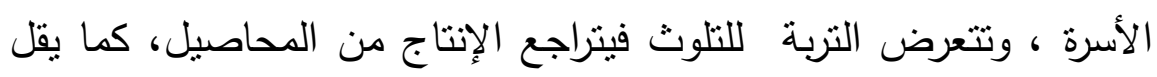
العائد الاقتصادي من الإنتاج الحيواني لتعرض غذاء الحيوانات لللتوث . ويراعي حماية الموارد من التلوث حيث يكون ذللك أقل في التكلفة وأكثر كفاءة من محاولة إعادتها إلي طبيعتها النقية مرة أخري، ويكون أحياناً من الصعب إجراء تقدير مالي للآثار السلبية التي تتشأ عن التلوث وخاصة فيما يختص بصحة بالإنسان محور التتمية مما يتطلب وضع خطة لحماية الموارد، حيث تستخدم المخصبات الكيماوية بالقدر المناسب حتي لا تتسبب

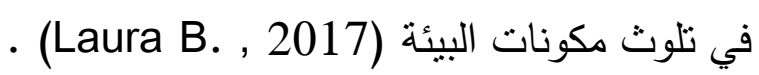

(المخصبات الكيماوية للمحاصيل الزراعية في مصر ...) د. أيمن عبد المطلب السعيد. 


\section{الخـاتمة :}

بدراسة المخصبات الكيماوية في مصر مع التطبيق علي شركة مصر لإنتاج المخصـبات الآزوتيـة فـي دميـاط كدراسـة فـي الجغرافيـة الاقتصـادية، توصـلت الدراسة إلي النتائج والتوصيات التالية:

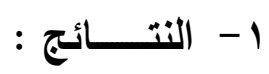

- تستخدم مصر المخصبات الكيماويـة منذ بدايـة القرن · ب ودخلت في صـناعتها

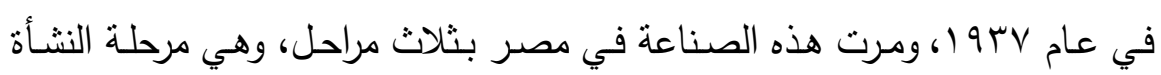

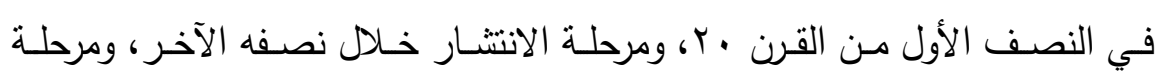

$$
\text { التوسعات بعدها حني الآن. }
$$

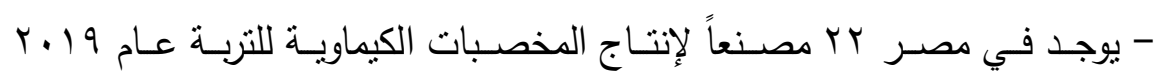
وتتوزع في أقاليم متفرقة علي عشر محافظات في المعمور المصري قريباً من المواد الخام والسوق الداخلي والموانئ البحرية حيث السوق الخارجي.

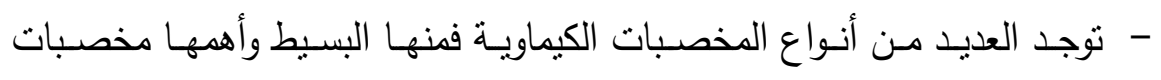
الآزوت، والفوسفات، والبوتاسيوم، والمركب الذي يحتوي على أكثر من عنصر .

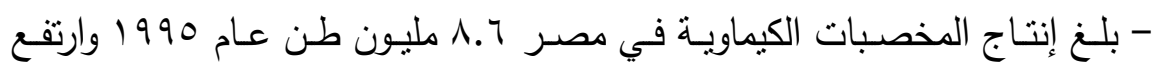

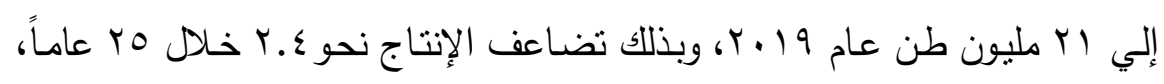
بسبب اتجـاه الاستثمارات المحلية والأجنبية لها، ويُنتج القطاع الخاص منها حوالي التُلثين. وقد تصدرت المخصبات الآزوتية الإنتاج لأهميتها للتربة المصرية ففي عام

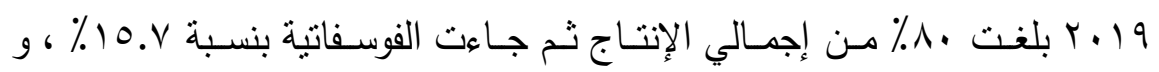

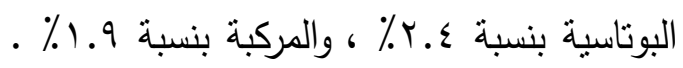
- وتزيـــ باسـتمرار الكميـات المستهلكة مـن المخصـبات الكيماويـة في مصـر حيث منلات ع. المليون طن عام 19 ــ حيث تتجهـ إلي الزراعة غير العضوية وأهمها الأرز والقمح والذرة والقطن وكانت عاملاً أساسياً في زيادة إنتاج الفدان.

(المخصبات الكيماوية للمحاصيل الزراعية في مصر...) د. أيمن عبد المطلب السعيد. 
- تتسم الكمبات الصـادرة من المخصبات الكيماويـة والمستوردة منها بالتذبذب لكنها

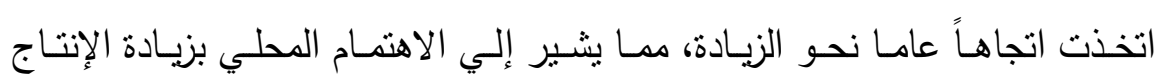

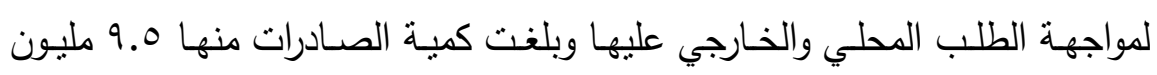

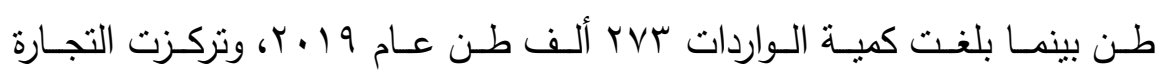
الخارجية لها مع دول أوروبا.

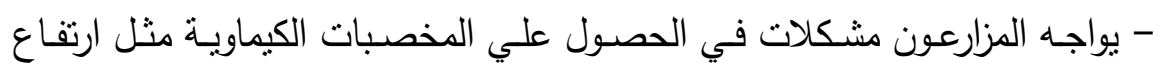
الأسعار ونقص في الكميات المتاحة وبعض أنواعها، وعدم البيع بالأجل من قبل فيل

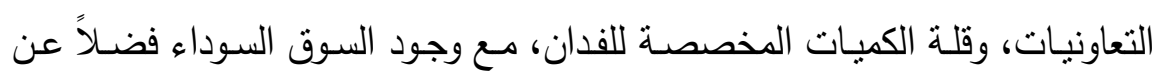
تراجع دور الإرشاد الزراعي واستمرارية الأزمة.

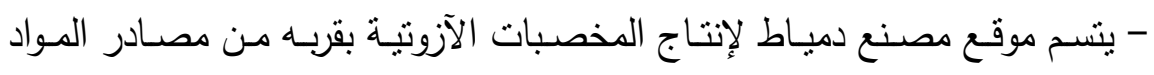

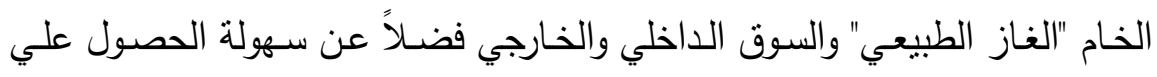
المياه والكهرباء والعمالة.

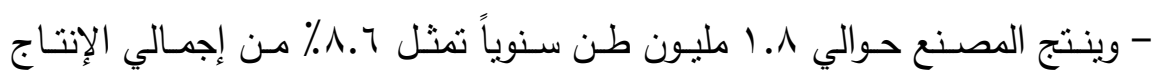

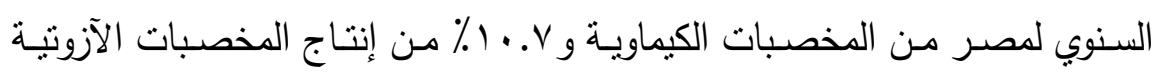

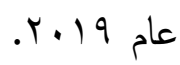

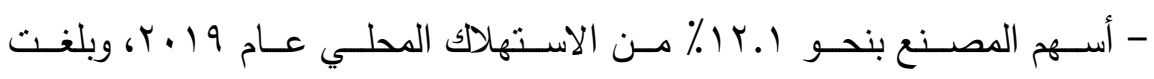

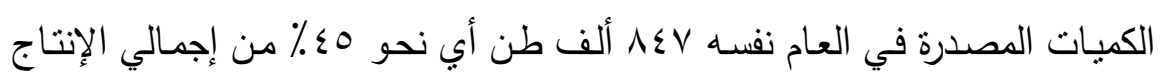
إلي دول في قارات العالم المختلفة. - تتعرض مكونات البيئة بمنطقة المصنع للنلوث بدرجات من متوسطة إلي محدودة

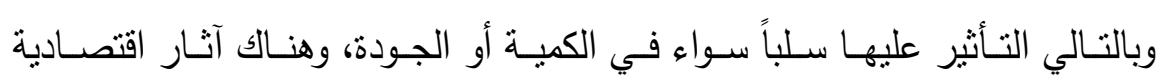
للمصنع منها ما هو ايجابي وآخر سلبي.

(المخصبات الكيماوية للمحاصيل الزراعية في مصر ...) د. أيمن عبد المطلب السعيد. 


\section{r}

- تشـجيع الاسـتشمار في صـناعة المخصـبات الكيماويـة لـوفره خاماتـهـ مـع إمكانية تسويقه داخلياً وخارجياً. - تخفيض الجمـارك على مـدخلاتها المسـتوردة، ونتـغيل المصـانع بكامـل فهل طاقتهـا، والتوسـع في إنتـاج المخصـبات البوتاسـية لتوفيره محليـاً، والمركبـة لمواجهة الطلب المتتامي عليها.

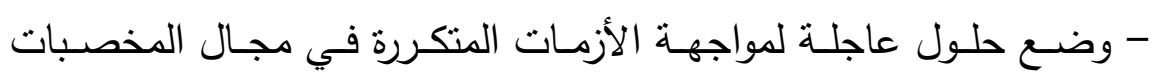
الكيماويـة مـن خـلال مراقبـة شـركات الإنتاج بتوفير الحصـة المقررة عليهـا للسـوق المحلي، وحصـر التوزبـع في الجمعيات الزراعيـة فقط مـع المتابعـة،

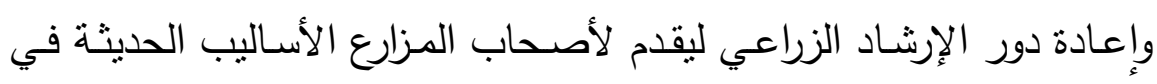

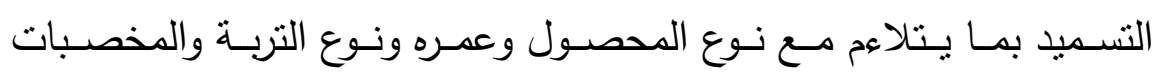
المناسـبة، واسـتبعاد الأراضــي الزراعيـة التـي تـم البـــاء عليهـا، وتشـليم

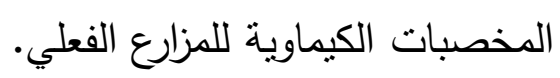
- التأكيد على أهميـة التقليل من التلوث لمكونـات البيئة بقدر الإمكان من خلال تحديث خطوط الإنتاج بالمصانع. - إنشاء المصـانع التي توجد قريباً من البحرين المتوسط والأحمر بما فيها

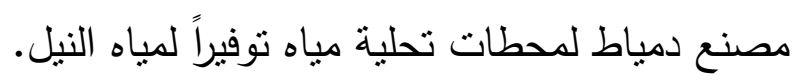

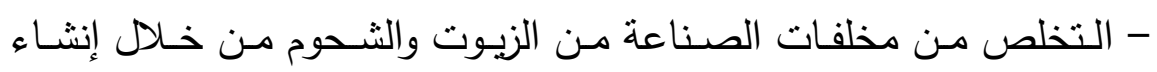

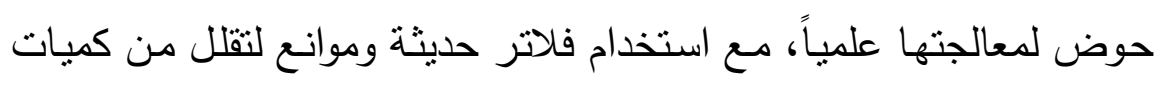
بخار الماء وغاز النشادر التي تخرج للهواء مباشرة.

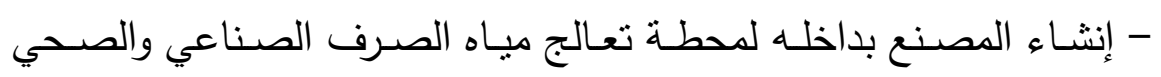
لإعادة استخدامها في الصناعة أو في ري المساحات الخضراء.

(المخصبات الكيماوية للمحاصيل الزراعية في مصر ...) د. أيمن عبد المطلب السعيد. 


\title{
نموذج استبيان
}

\author{
جامعة العريش \\ كلية الآداب ـ قسم الجغر افيا

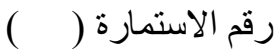

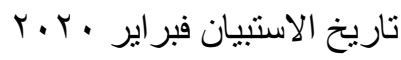

بيانات هذه الاستمارة سرية ولائ لان تستخدم إلا في البحث العلمي

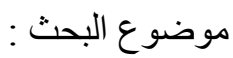

\section{المخصبات الكيماوية للمحاصيل الزراعية في مصر - حالة مصنع دمياط}

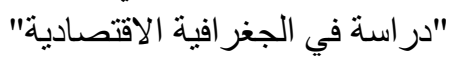

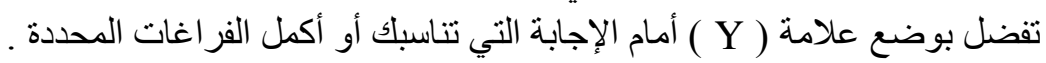

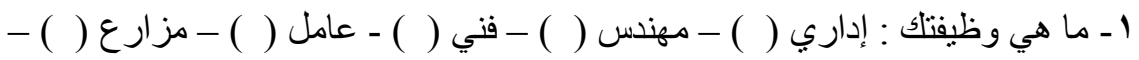

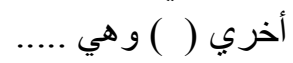

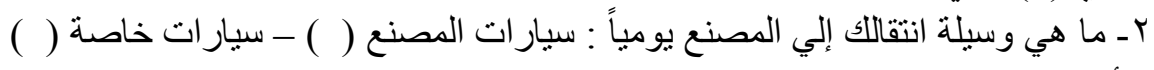

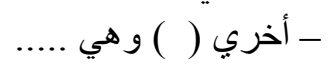

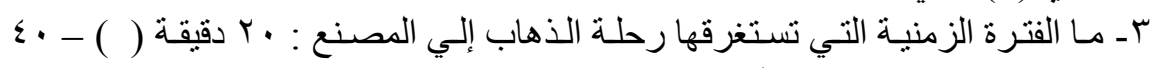

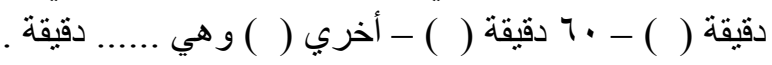

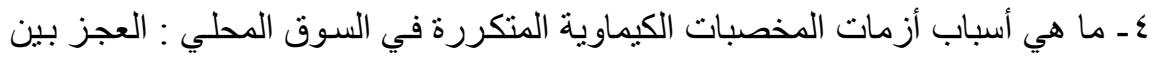

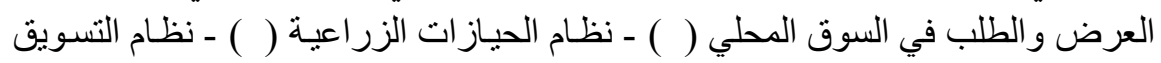

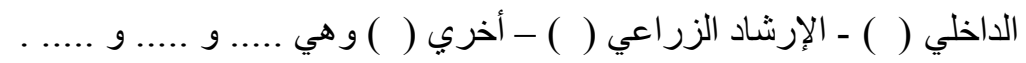

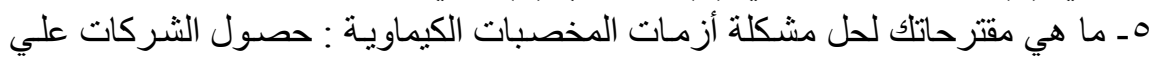

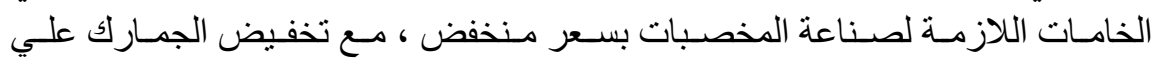

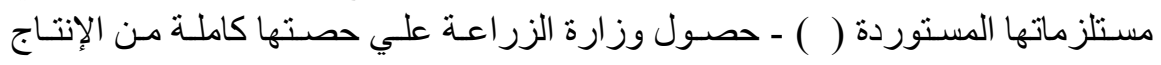

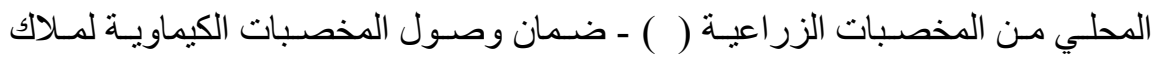

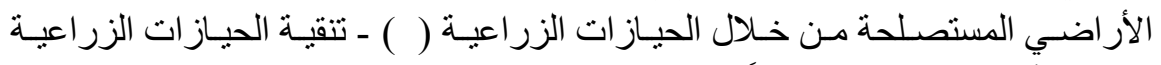

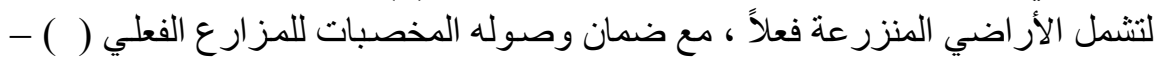

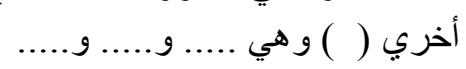

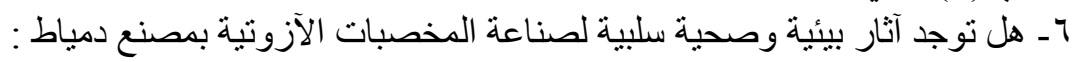

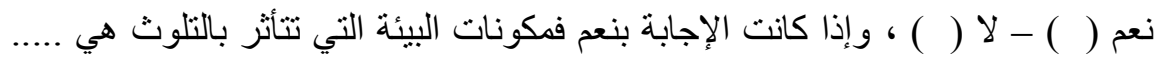

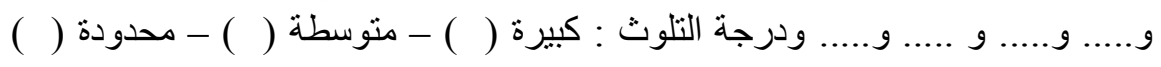

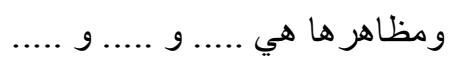
لـ الآثار الاقتصادية الإيجابية لصناعة المخصبات الكيماوية هي : ..... و .... و ......

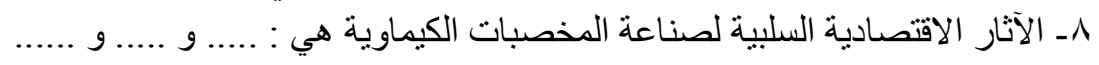
نشكركم على حسن تعاونكم

(المخصبات الكيماوية للمحاصيل الزراعية في مصر ...) د. أيمن عبد المطلب السعيد. 


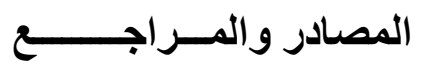

أولا : المراجع العربية : أماد المانية

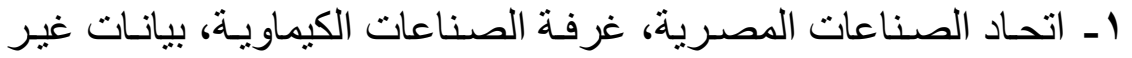

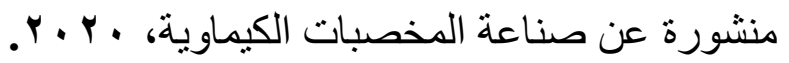

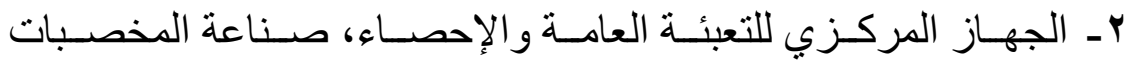

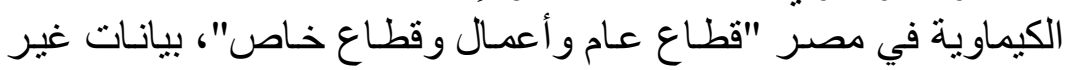

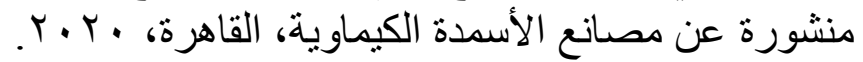

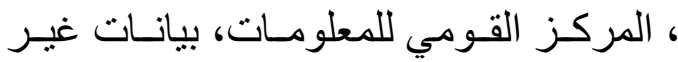

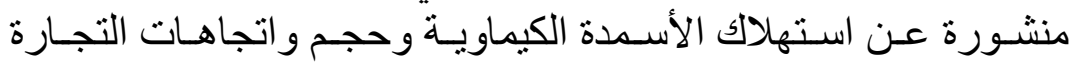

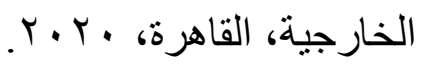

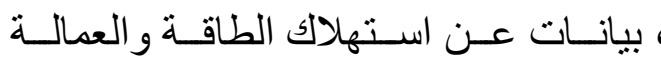
- $\varepsilon$

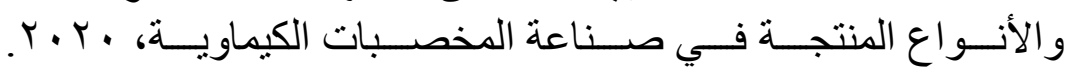
https://www.capmas.gov.eg

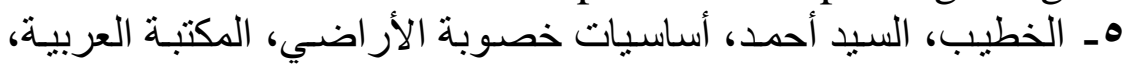

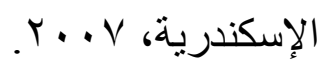

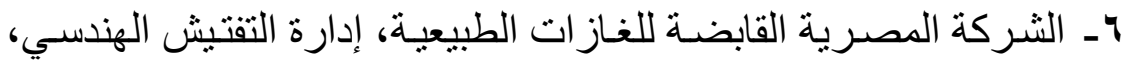

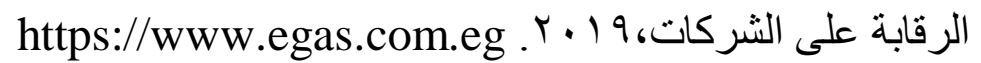
V- اللجنة العلمية لتقييم تأثنير مصنع دمياط لإنتاج الأسمدة الآزوتيـة، تقرير

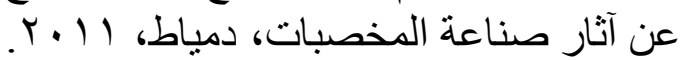

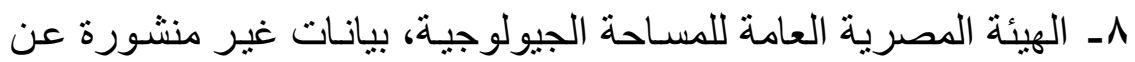

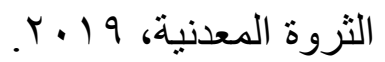

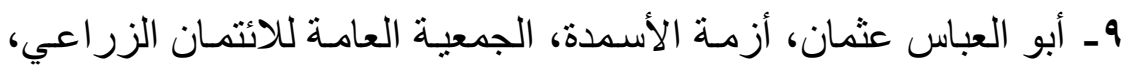

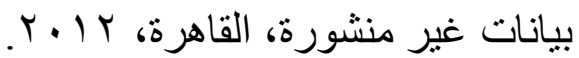

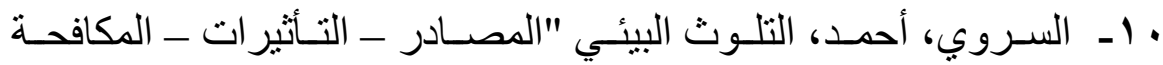

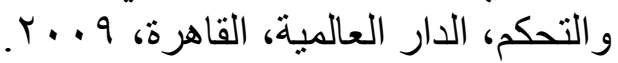

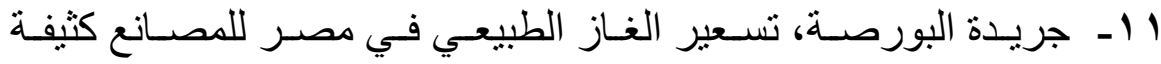

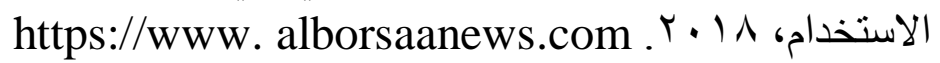

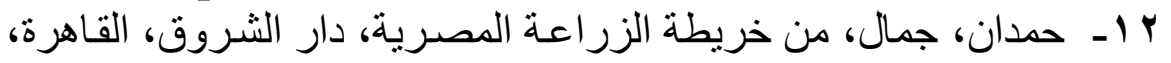
19 ع

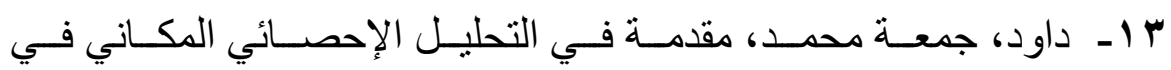

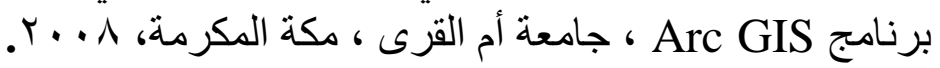

(المخصبات الكيماوية للمحاصيل الزر اعية في مصر ...) د. أيمن عبد المطلب السعيد. 
؛ ا - داود، جمعة محمد، أسس التحليل المكاني في إطسار نظم المعلومـات

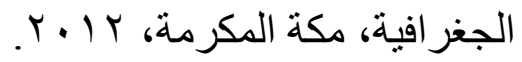

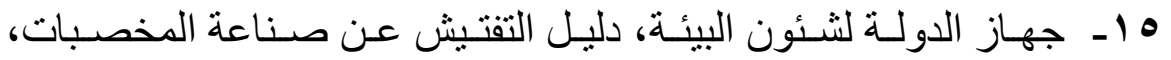

$$
\text { r... }
$$

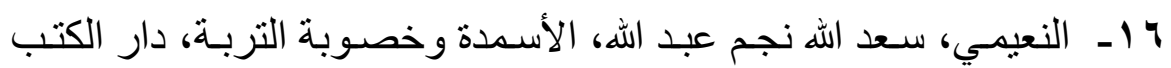

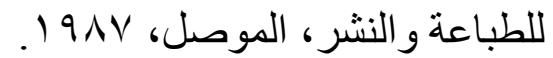
IV

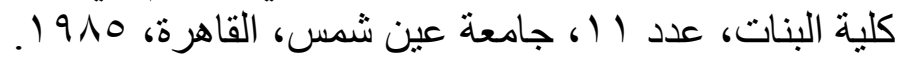

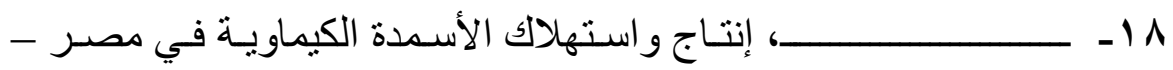

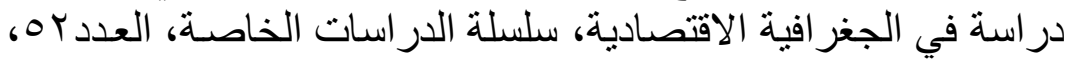

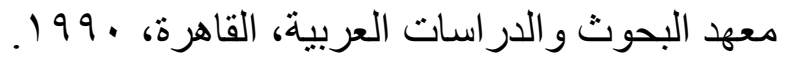

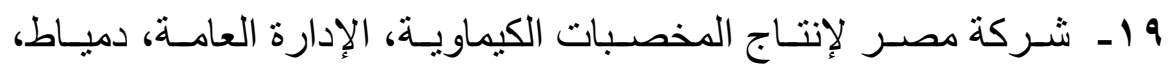
https://WWW.mopco-eg.com .r.r.

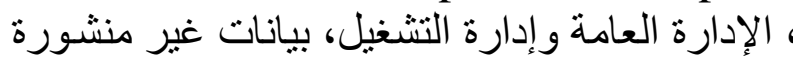

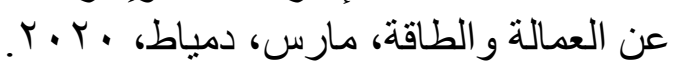

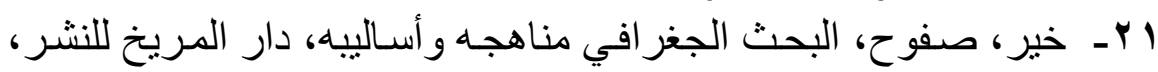

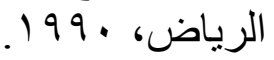

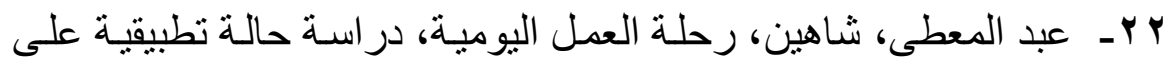

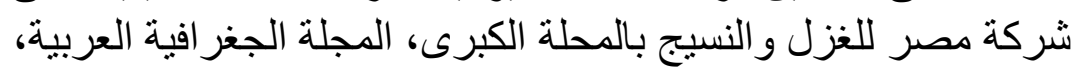

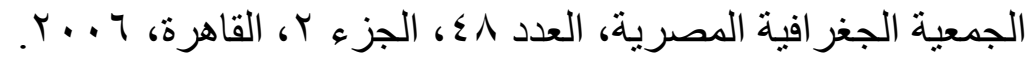

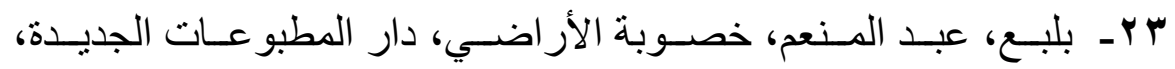

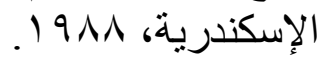

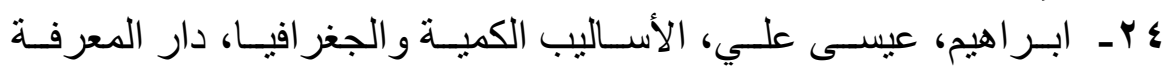

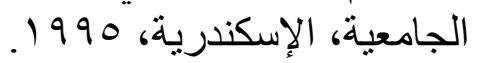

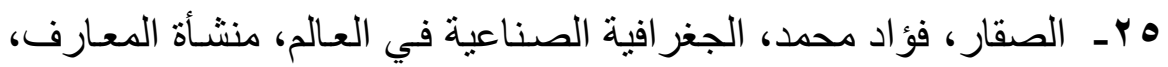

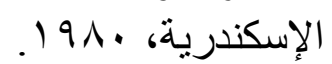

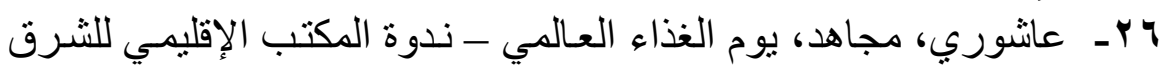

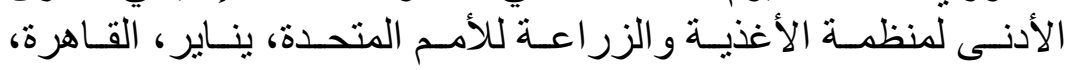

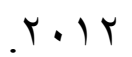

(المخصبات الكيماوية للمحاصيل الزراعية في مصر ...) د. أيمن عبد المطلب السعيد. 


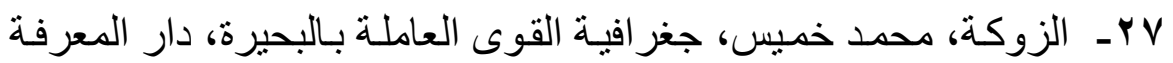

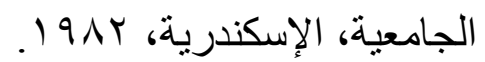

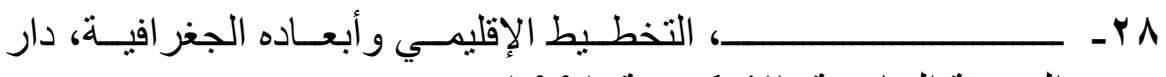
المعرفة الجامعية، الإسكندرية، الهة 99 1.

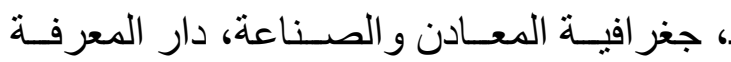
$-r q$

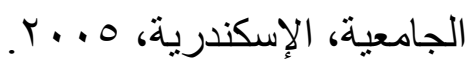

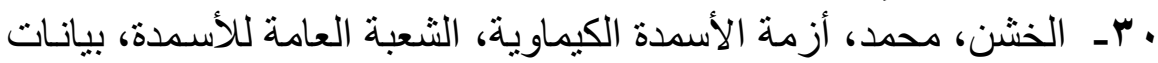

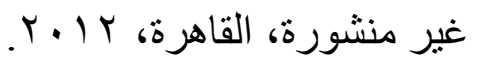

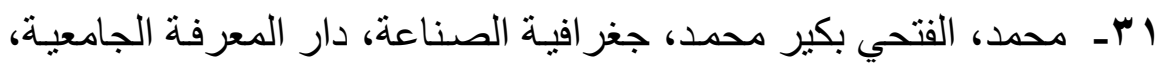

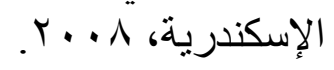

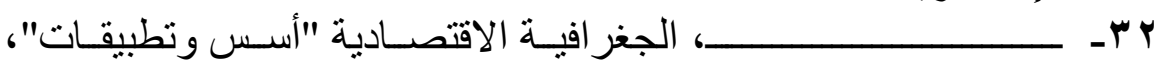

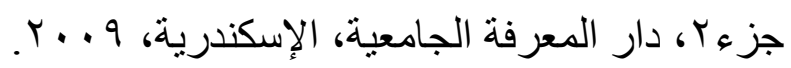

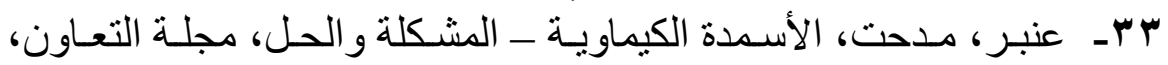

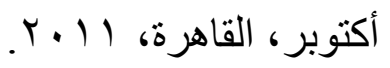

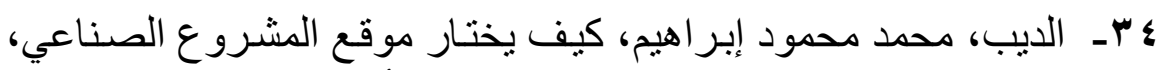

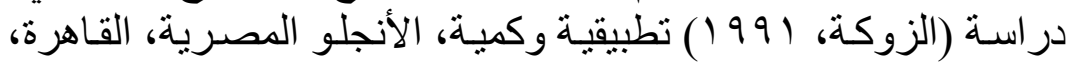
$.19 \vee 9$ ، الجغر افيــة الاقتصــادية، الأنجلــو المصـرية، $-r o$

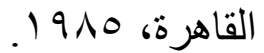

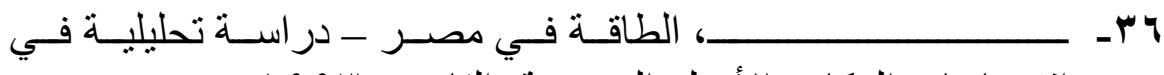

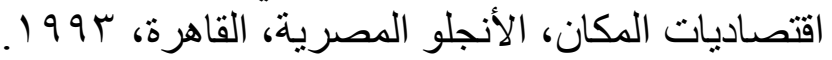

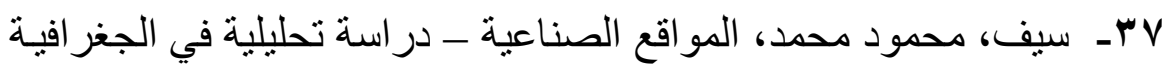

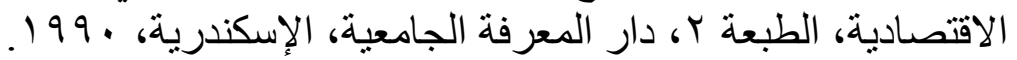

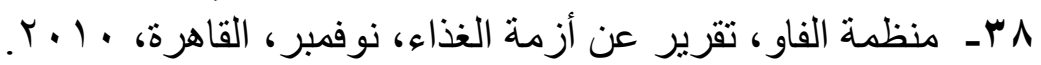

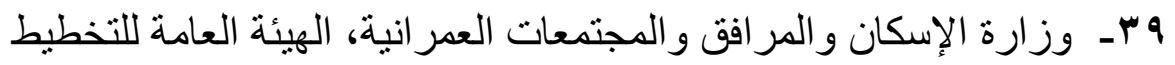

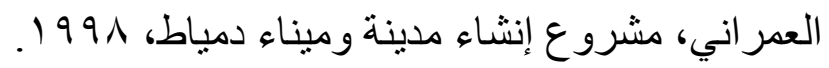

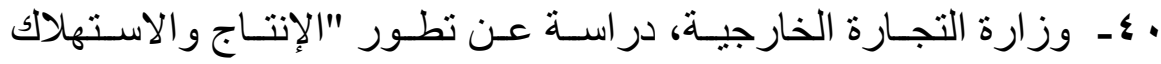

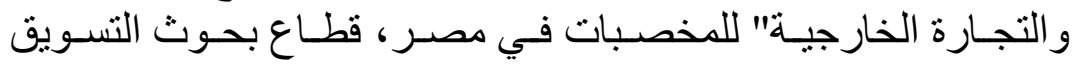

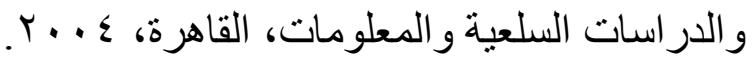

(المخصبات الكيماوية للمحاصيل الزراعية في مصر...) د. أيمن عبد المطلب السعيد. 


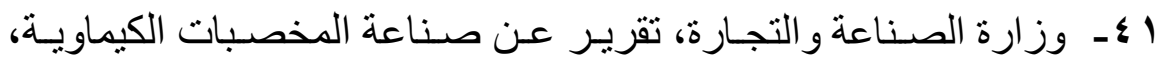

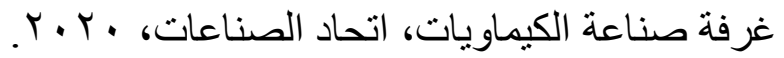

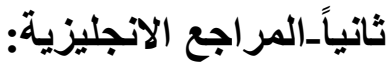

1- Alexander J. and Gibson L., Economic Geography, Prentice Hall, New Jersey, 1979.

2- Charlotte H., Report on the production of chemical fertilizers, International Fertilizer Industry Association, 2019, Paris, France, 2020.

3- How Fertilizer is made?, https://www.brenntag.com. Oct. 2020.

4- Laura B., The Hidden dangers of chemical fertilizers , Environmental Protection , Dec. 2017 , https://eponline.com, Oct. 2020

5- Leinter Helga, the Political economy of international labour migration. In Shepard, E. \& Barnes, T. J (Eds) A companion to economic geography, Blackwell Publishers Itd, Oxford, 2020.

6- Murphy J., Sustainable Development, 2010. http://www.un.org, Sep. 2019.

7- Robinson R. Jocksin I., "People on Earth: Human Geography" Longman, Harlow. Essex, England, 1984.

8- The Importance of using chemical fertilizers, Agricultural Supplies, April 2019. https://fruitgrowers.com, Oct 2020.

9- Travis P., History of chemical fertilizers, volume 15, Fertilizer Manual, 1985. https://link.springer.com

10-United Nation, Statistical yearbook 1978, New York, 1979.

11-Wheeler J. el. al., Economic Geography, 3 Rd Ed, John Wiley \& Sons, Inc., New York, 1998.

(المخصبات الكيماوية للمحاصيل الزر اعية في مصر ...) د. أيمن عبد المطلب السعيد. 


\section{Chemical Fertilizers for Agricultural Crops in Egypt -}

\section{The Case of Damietta Factory}

\section{"A Study in Economic Geography"}

\section{Abstract}

Chemical fertilizers of soil in Egypt affect the quantity and quality of agricultural production, and the number of their factories that produced 21 million tons of Various Kinds has reached 22. They are Located in the Valley, the Delta and the Suez Canal Region, where the Factors of their Establishment are available. They provide 9.6 million tons for Local Consumption while exporting 11.4 million tons but they suffer from crises regarding the quantities and types that are distributed to farmers.

Damietta factory's shares of nitrogenous fertilizers amounted to $8.6 \%$ of the total annual production of Egypt in 2019, goes to local consumption and exportation. There are negative effects on the environmental components in the factory's area but not to a great extent. They also result positive and negative economic effects. This industry can be promoted through good management and avoiding its negative effects.

Key words: Fertilizers, Damietta, The environment

(المخصبات الكيماوية للمحاصبل الزراعية في مصر ...) د. أيمن عبد المطلب السعيد. 